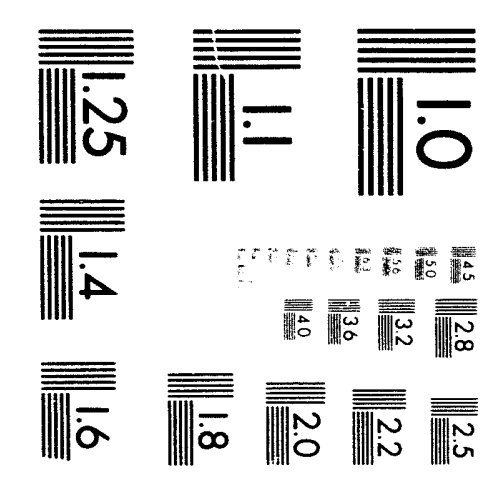



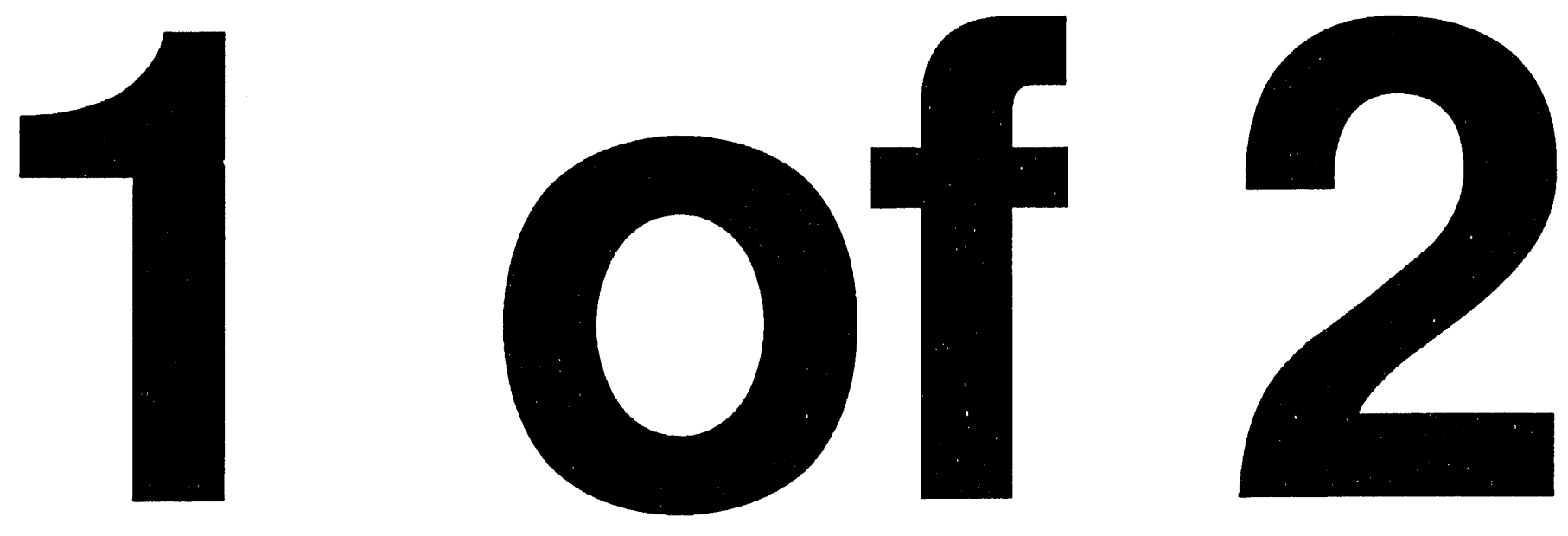
DOE/RL-93-70

Revision 1

UC-630, 721

\section{Waste Analysis Plan for Confirmation or Completion of Tank Farms Backlog Waste Designation}

Date Published

October 1993

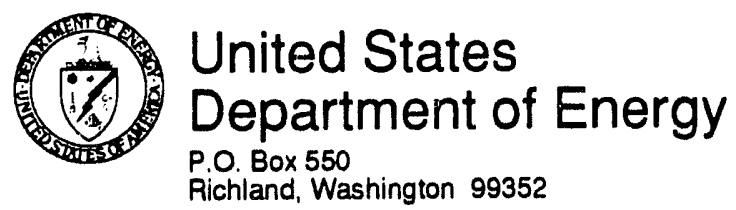

Approved for Public Release

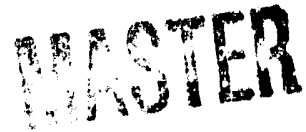




\section{LEGAL DISCLAIMER}

This report was prepared as an account of work sponsored by an agency of the United States Government. Neither the United States Govarnment nor any agency thereof, nor any of their employees, nor any of their contractors, subcontractors or their employees, makes any warranty, express or implied, or assumes any legal liability or responsibility for the accuracy, completeness, or any third party's use or the results of such us $\theta$ of any information, apparatus, product, or process disclosed, or represents that its use would not infringe privately owned rights. Reference herein to any specific commercial product, process, or service by trade name, trademark, manufacturer, or otherwise, does not necessarily constitute or imply its endorsement, recommendation, or favoring by the United States Government or any agency thereof or its contractors or subcontractors. The views and opinions of authors expressed herein do not necessarily state or reflect those of the United States Government or any agency thereof.

This report has been reproduced from the best available copy Available in paper copy and microfiche.

Available to the U.S. Department of Energy

and its contractors from

Office of Scientific and Technical Information

P.O. Box 62

Oak Ridgo, TN 37831

(615) $576-8401$

Available to the public from the U.S. Department of Commerce National Technical Information Service

5285 Port Royal Road

Springfield, VA 22161

(703) 487.4650

Printed in the Uniled Stales of America

DISCLM-1.CHP $(1.91)$ 


\section{CONTENTS}

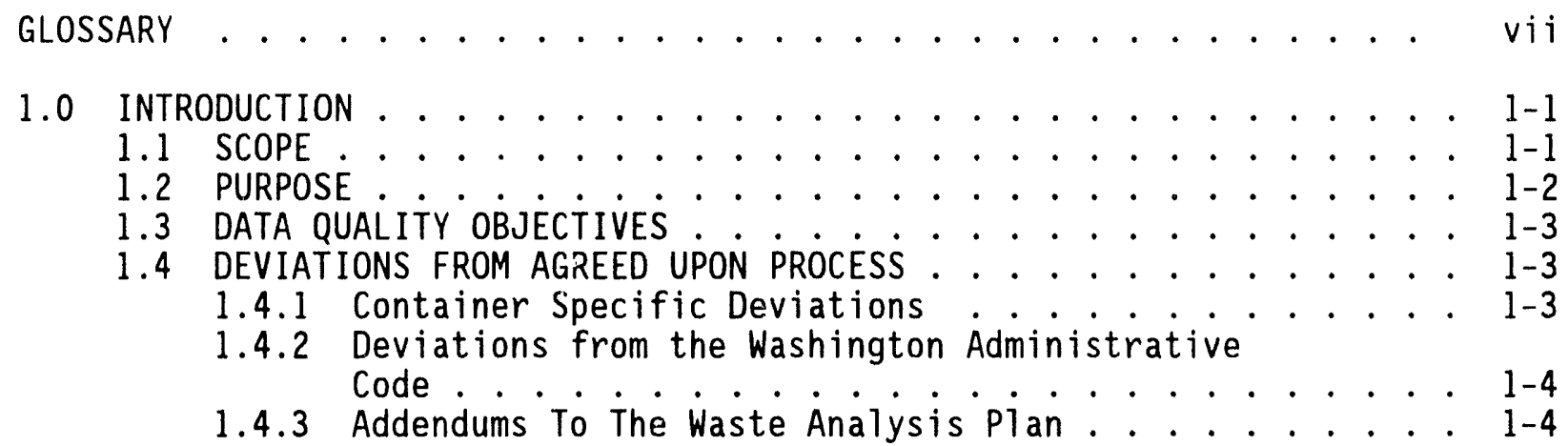

2.0 WASTE MANAGEMENT ORGANIZATIONAL RESPONSIBILITIES . . . . . . . . . . 2-1

2.1 TANK FARMS . . . . . . . . . . . . . . . . . . . . . . . 2-1

2.2 SOLID WASTE DISPOSAL ORGANIZATION . . . . . . . . . . . . . 2-2

2.3 HANFORD ANALYTICAL SERVICES MANAGEMENT ORGANIZATION . . . . . . 2-2

2.4 SAMPLE AND MOBILE LABORATORY . . . . . . . . . . . . . . . . 2-3

2.5 REPACKAGING ORGANIZATION RESPONSIBILITIES . . . . . . . . . 2-3

2.6 TRANSPORTATION AND PACKAGING ORGANIZATION . . . . . . . . 2-3

3.0 WASTE MANAGEMENT CRITERIA AND TRAINING . . . . . . . . . . . . . 3-1

3.1 WASTE MANAGEMENT CRITERIA . . . . . . . . . . . . . . . . . . . 3-1

3.2 WASTE MANAGEMENT TRAINING . . . . . . . . . . . . . . . 3-2

3.3 CATEGORY 1 TRAINING - ALL EMPLOYEES . . . . . . . . . . . . . 3-2

3.4 CATEGORY 2 TRAINING - GENERAL WORKER . . . . . . . . . . . . . 3-2

3.4.1 Personnel Who Work With Dangerous Wastes... . . . . . 3-2

3.4.2 General Workers Who Work Within a TSD Unit. . . . . . . 3-3

3.5 CATEGORY 3 TRAINING - GENERAL MANAGER ........... . . . 3-3

3.5.1 Decision-making Authorities in Emergencies

Involving Dangerous Waste .. . . . . . . . . 3-3

3.5.2 First-1ine Management in Dangerous Waste

Management Facilities .............. . 3-3

3.6 CATEGORY 4 TRAINING - GENERAL SHIPPERS . . . . . . . . . . . 3-3

3.7 ADDITIONAL TRAINING REQUIREMENTS . . . . . . . . . . . . . . 3-4

3.7.1 Personnel Responsible for Designating Waste and

Determining the Waste Meets Minimum Requirements

for Storage ............... . . 3-4

3.7.2 Personnel Responsible for Making Decisions on

Flagging Containers for Further Analys is and

Making the Decision that a Container or Waste

Stream has Sufficient Information for

Characterization for Storage . . . . . . . . . . . 3-4

46

3.7.3 Personnel Who Perform Waste Sampling or Who Clean and Certify Sampling Equipment . . . . . . 3-4 
4.0 WASTE STREAM DESCRIPTION ..................... 4-1

4.1 DESCRIPTION OF WASTE GENERATING PROCESSES . . . . . . . . . . . 4-1

4.1.1 Waste Generating Activities . . . . . . . . . . . . . 4-1

4.1.2 Waste Description . . . . . . . . . . . . . 4-3

4.2 WASTE MANAGEMENT PRACTICES . . . . . . . . . . . . . . . . . . 4-3

4.3 WASTE IDENTIFICATION ....................... . . . . . . . . . 4

4.3.1 Tank Farms Complexes ................. . 4-5

4.3.2 Potential Waste Designation . . . . . . . . . . . 4-5

5.0 PROCESS FOR CONFIRMATION OR COMPLETION OF DESIGNATION . . . . . . $5-1$

5.1 SPECIAL HANDLING OF CONTAINERS . . . . . . . . . . . . . . . . 5-1

5.2 DOCUMENTING FLAGGED CONTAINERS . . . . . . . . . . . . . . . 5-2

5.3 DETERMINATION OF ADEQUATE KNOWLEDGE FOR STORAGE . . . . . . . . 5-3

5.4 PRELIMINARY WASTE SORTING . . . . . . . . . . . . . . . . . 5-4

5.5 DOCUMENTATION ASSESSMENT . . . . . . . . . . . . . . . . . 5-4

5.5.1 Waste Stream Segregation . . . . . . . . . . . . 5-4

5.5.2 Characterization Information Criteria . . . . . . . 5-5

5.5.2.1 Interviews . . . . . . . . . . . . 5-6

5.5.2.2 Logbooks .................. . 5-6

5.5.2.3 Procurement Records . . . . . . . . . . 5-6

5.5.2.4 Analytical Results . . . . . . . . . . . 5-6

5.5.2.5 Qualified Analytical Data . . . . . . . . 5-6

5.5.2.6 Radiation Work Packages . . . . . . . . . 5-6

5.5.2.7 Procedures and/or Methods . . . . . . . . . 5-6

5.5.2.8 Process Flow Charts ............ 5-6

5.5.2.9 Inventory Sheets . . . . . . . . . . . 5-7

5.5.2.10 Vendor Information .. . . . . . . . . . 5-7

5.5.3 Identification of Containers Requiring

Special Handling. . . . . . . . . . . . . . . 5-7

5.6 PHYSICAL CONFIRMATION OR COMPLETION OF DESIGNATION . . . . . . 5-7

5.6.1 Physical Screening................ . 5-7

5.6.1.1 Physical Measurements . . . . . . . . . . . 5-8

5.6.1.2 Nondestructive Examination . . . . . . . . . 5-8

5.6.2 Visual Inspection of Container Contents . . . . . . . 5-9

5.6.2.1 Visual Inspection Criteria . . . . . . . . . . 5-9

5.6.2.2 Limitations on Visual Inspection . . . . . . 5-9

5.6.3 Quality Control of Physical Analysis . . . . . . . . . . 5-10

5.7 CHEMICAL CONFIRMATION OR COMPLETION OF DESIGNATION $. . . \quad . \quad . \quad 5-10$

5.7.1 Selection of Sample Set . . . . . . . . . . . . . 5-11

5.7.2 Screening and Segregation ............ . 5-13

5.7.3 Characterization Information Determination . . . . . 5-13

5.7.4 Laboratory and Field Analytical Criteria. . . . . . . . 5-13

5.7.5 Limitations on Chemical Sampling . . . . . . . . . . 5-14

5.7.6 Quality Control of Chemical Analysis......... . 5-14 


\section{CONTENTS (cont)}

6.0 WASTE TYPE SPECIFIC PROTOCOL . . . . . . . . . . . 6-1

6.1 DEBRIS .................... 6- . . . . .

6.1.1 Physical Analysis Protocol . . . . . . . . . . . 6-1

6.1.2 Chemical Analysis Protocol . . . . . . . . . . 6-6 6-3

6.1.3 Management Protocol . . . . . . . . . . . . . . 6-4

6.2 SOILS . . . . . . . . . . . 6-5

6.2.1 Physical Analysis Protocol . . . . . . . . . 6-5

6.2 .2 Chemical Analysis Protocol . . . . . . . . . 6-8

6.2.3 Management Protocol . . . . . . . . . . . . 6-8

6.3 Low-Level Waste . . . . . . . . . . . . . 6-9

6.3.1 Physical Analysis Protocol . . . . . . . . . . 6- 6-9

6.3.2 Chemical Analysis Protocol . . . . . . . . . . . 6-12

6.3.3 Management Protocol . . . . . . . . . . . . 6-12

6.4 LIQUIDS . . . . . . . . . . . . . . . . . . . . 6-13

6.4.1 Uncontainerized Free Liquids . . . . . . . . . . 6-13

6.4 .2 Containerized Liquids . . . . . . . . . . . 6-14

6.4.3 Management Protocol . . . . . . . . . . 6-15

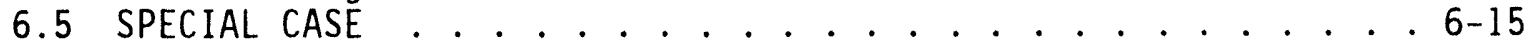

7.0 LABORATORY ANALYSIS METHODS ............... . . 7-1

7.1 DANGEROUS CONSTITUENT SAMPLING . . . . . . . . . . . 7-1

7.2 CRITERIA FOR WASTE TYPE SAMPLING ............ . . $7-1$

7.3 WASTE SAMPLING TECHNIQUES . . . . . . . . . . . . 7-1

7.3.1 Sample Handling . . . . . . . . . . . . . 7-1

7.3.1.1 Chain of Custody .......... 7-2

7.3.1.2 Sample Containers .......... 7-5

7.3 .1 .3 Reagents ............ 7-5

7.3.1.4 Equipment . . . . . . . . . . . 7-5

7.3.2 Sample Collection . . . . . . . . . . . 7-6

7.3.3 Sample Disposition . . . . . . . . . . . . . . 7-6

7.3.4 Container Sampling Procedures . . . . . . . . . . 7-6

7.4 QUALITY ASSURANCE AND QUALITY CONTROL PROTOCOL . . . . . . . 7-7

7.4.1 Blank Samples . . . . . . . . . . . 7-8

7.4.2 Equipment Blanks . . . . . . . . . . 7-8

7.4 .3 Trip Blanks ............... 7-8

7.4.4 Duplicate Samples . . . . . . . . . . . . . 7-8

7.5 ANALYTICAL TECHNIQUE REQUIREMENTS . . . . . . . . . . . . 7-8

7.5.1 Liquid Matrix Analytical Methods ... . . . . . . . . 7-9

7.5.2 Solid Waste Matrix Analytical Methods . . . . . . . . 7-9

7.5.3 Deviations from SW-846 Protocol . . . . . . . . 7-9

7.5.3.1 Inorganic Analysis ........ . 7-10

7.5.3.2 Volatile and Semivolatile Organics .... . 7-10

7.5.3.3 Toxicity Characteristics Leaching

Procedure .......... . . 7-10

8.0 RECORDKEEPING . . . . . . . . . . . . . . . . . . 8-1

9.0 REFERENCES . . . . . . . . . . . . . . . . . . 9-1 


\title{
APPENDICES
}

\author{
A BACKLOG WASTE DESIGNATION GUIDANCE \\ B DOCUMENTATION ASSESSMENT \\ C BACKLOG WASTE REAL-TIME RADIOGRAPHY GUIDANCE \\ D CHAIN OF CUSTODY/SAMPLE ANALYSIS REQUEST GUIDANCE
}

\section{FIGURES}

5-1. Confirmation or Completion of Designation Process . . . . . . . F5-1 6-1. Physical and Chemical Analysis Process for Drums and Boxes (Option 1) Containing Debris . . . . . . . . . . . . Ff-1.1

6-1. Physical and Chemical Analysis Process for Boxes (Option 2) Containing Debris . . . . . . . . . . . . . . F6-1.2

6-2. Physical and Chemical Analysis Process for Soils Option 1. . . . F6-2.1

6-2. Physical and Chemical Analysis Process for Soils Option 2. . . . F6-2.2 6-3. Physical and Chemical Analysis Process for Drums and Boxes (Option 1) of Low-Level Waste . . . . . . . . . . . . . . F6-3.1

6-3. Physical and Chemical Analysis Process for Boxes (Option 2) of Low-Level Waste . . . . . . . . . . . . . F6-3.2

6-4. Physical and Chemical Analysis Process for Liquids . . . . . . . FG-4

\section{TABLES}

4.1. Tank Farms Waste Generating Activities and Waste Materials . . . T4-1

4.2. Waste Material Descriptions . . . . . . . . . . . . . . T4-2

4.3. Tank Farms Complexes . . . . . . . . . . . . . . . . . . . . T4-3

4.4. Tank Farms Dangerous Waste Identification . . . . . . . . . . . T4-4

5.1. Analytical Testing for Completion of Designation . . . . . . . . T5-1

6.1. Analytical Methods for Debris .. . . ............. . T6-1

6.2. Analytical Methods for Soil . . . . . . . . . . . . . . . . T6-2

6.3. Analytical Methods for Low-Level Waste . . . . . . . . . . . . . . T6-3

6.4. Analytical Methods for Liquids . . . . . . . . . . . . . . . . . . T6-4

7.1. Sample and Analysis Protocol .. . . . . . . . . . . . . T7-1 


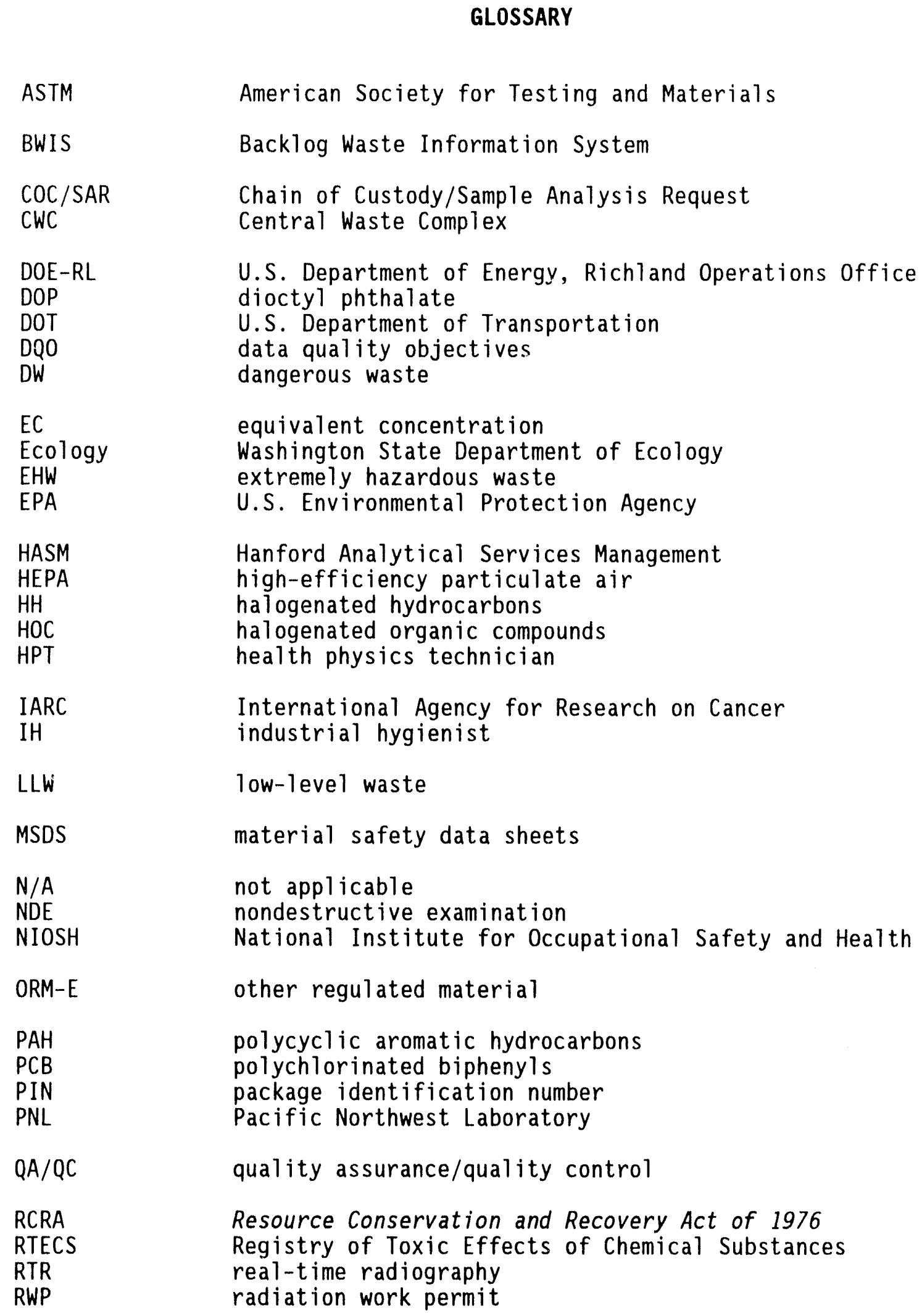


WAC WSDR

\section{GLOSSARY (cont)}

Society of Automotive Engineers storage disposal approval record semivolatile organic analysis Solid Waste Acceptance Services sample and mobile laboratory solid waste disposal

Solid Waste Information and Tracking System

toxicity characteristic

toxicity characteristics leaching procedure total organic halogen

Toxic Substances Control Act of 1976

treatment, storage, and/or disposal

unusual occurrence

volatile organic analysis

Westinghouse

Washington Administrative Code

Hanford (WHC) Westinghouse Hanford Company

waste storage/disposal request

less than

greater than

less than or equal to

percent

weight percent

parts per million

negative concentration logarithm of the hydroç?n-ion concentration 
DOE/RL-93-70, Rev. 1 $10 / 27 / 93$

\subsection{INTRODUCTIŪN}

On January 23, 1992, waste management problems in the Tank Farms were acknowledged through an Unusual Occurrence (UO) Report \# RL-WHC-TANKFARM-19920007 (DOE-RL 1992).

On March 10, 1993, the Washington State Department of Ecology (Ecology) issued Order 93NM-201 (Order) to the U.S. Department of Energy, Richland Operations Office (DOE-RL) and the Westinghouse Hanford Company (Westinghouse Hanford) asserting that "DOE-RL and Westinghouse Hanford have failed to designate approximately 2,000 containers of solid waste in violation of WAC 173-303$170(1)(a)$ and the procedures of WAC 173-303-070" (Ecology 1993).

On June 30, 1993, a Settlement Agreement and Order Thereon (Settlement Agreement) among Ecology, DOE-RL, and Westinghouse Hanford was approved by the Pollution Control Hearings Board (PCHB). Item 3 of the Settlement Agreement requires that DOE-RL and Westinghouse Hanford submit a waste analys is plan (WAP) for the waste subject to the Order by September 1, 1993 (PCHB 1993). This revision of the WAP is being written in accordance with Item $H$ of Stipulation to Revise Settlement Agreement and Order Thereon (Stipulation) dated September 15, 1993 (PCHB 1993). The parties will submit the approved WAP as proof of settlement to the PCHB on November 1, 1993 or will raise the remaining issues as appropriate.

\subsection{SCOPE}

This WAP satisfies the requirements of Item 3 of the Order as amended per the Settlement Agreement. Item 3 states: "Within forty (40) calendar days of receipt of this Order, DOE-RL and WHC provide Ecology with a waste analysis plan for review and approval detailing the established criteria and procedures for waste inspection, segregation, sampling, designation, and repackaging of all containers reported in item \#1. The report shall include sampling plan criteria for different contaminated media, i.e., soils, compactable waste, high-efficiency particular air (HEPA) filters, etc., and a schedule for completing the work within the time allowed under this Order."

Item 3 was amended per the Settlement Agreement as follows: "In addition to the waste inspection plans for the "unknowns" previously provided and currently being supplemented, DOE-RL and WHC shall provide a draft waste analysis plan for the containers reported in Item 1 of the Order to Ecology by July 12, 1993. A final, DOE-RL approved waste analysis plan shall be submitted to Ecology by September 1, 1993, for Ecology's written approval by September 15, 1993." 
1 The scope of the waste subject to this WAP was agreed upon by the Management 2 Team $^{1}$ on October 7, 1993 as:

- Waste identified under the Order and Tank Farm waste identified by DOE-RL/Westinghouse Hanford in the 90-day response dated June 10, 1993, less any exceptions noted below.

- The scope of this WAP covers only that waste generated under Tank Farms management.

- All Tank Farms "Unknown" containers processed through T-Plant are not covered under this WAP.

For purposes of this WAP only, the scope of the waste covered under the WAP will be referred to as backlog waste ${ }^{2}$.

\subsection{PURPOSE}

This WAP describes the procedures that will be undertaken to confirm or to complete designation of the solid waste identified in the order.

The backlog waste has a two step acceptance process. The first step is called interim acceptance. It requires a minimum level of information needed for short term staging. But before waste can be formally accepted for treatment, storage, or disposal (second step), it must be properly certified, documented, and packaged in accordance with the Hanford Site Solid Waste Acceptance Criteria (WHC 1991). This WAP addresses the second step of the process.

Ecology alleged failure to designate solid waste containers in violation of WAC 173-303-170(1)(a) and the procedures of WAC 173-303-070 in Order 93NM-201. Pursuant to Item 3 of this Order as it is modified by the Settlement Agreement and Order Thereon (PCHB No. 93-64), DOE-RL and Westinghouse Hanford were required to provide a WAP for al1 containers in the agreed upon scope of the waste program. This WAP is intended to fulfill this requirement and provide a means for confirming or completing the solid waste designation of all containers within its scope. For the purposes of this WAP, to confirm designation means to be able to demonstrate with sufficient documented information that the waste is characterized to the extent necessary for compliant storage.

1

The Management Team is also referred to as the Policy Review Team. This team consisted of two staff members each from Ecology, DOE-RL, and Westinghouse Hanford. This team was established to resolve issues deemed by the Working Level Team to have ramifications outside of the scope of this WAP or where resolution of issues could not be reached by the Working Level Team. The Working Level Team consisted of two line staff members each from both Ecology and Westinghouse Hanford. Their task was to develop an acceptable and implementable WAP in accordance with Item $H$ of Stipulation to Revise Settlement Agreement and Order Thereon (PCHB 93-64).

2 A clear definition of the backlog waste program was not agreed upon by either the Working Level

$49-2$ A clear definition
50 Group or the Management Team. 


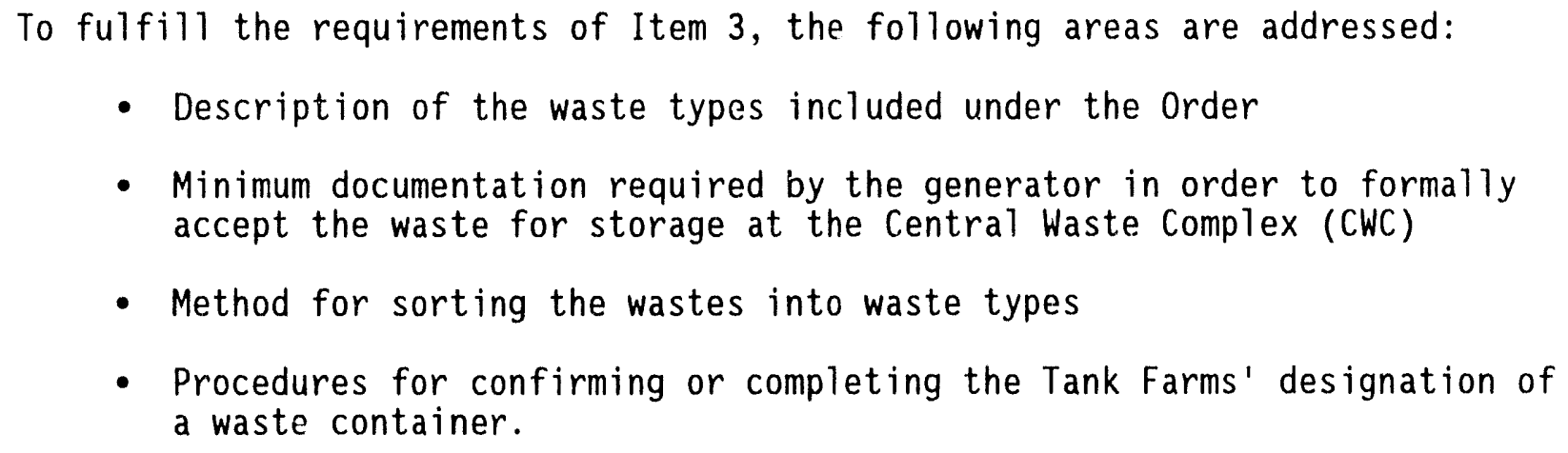

To fulfill the requirements of Item 3, the following areas are addressed:

- Description of the waste types included under the order

- Minimum documentation required by the generator in order to formally accept the waste for storage at the Central Waste Complex (CWC)

- Method for sorting the wastes into waste types

- Procedures for confirming or completing the Tank Farms' designation of a waste container.

\subsection{DATA QUALITY OBJECTIVES}

The data quality objectives (DQO) planning process recommended by the U.S. Environmental Protection Agency (EPA) (EPA 1987) has been used as guidance for developing this WAP.

The question established during the DQO process is: "How does one demonstrate that the waste (in the containers) has been properly designated in accordance with the Order and Settlement Agreement?"

The data obtained to answer this question are specifically intended to ensure the following:

- The Tank Farms' designation has been confirmed or completed

- The designated waste class of the waste is correct (i.e., dangerous waste or extremely hazardous waste)

- The waste is designated in accordance with WAC 173-303-070

- Sufficient characterization information is obtained so the waste can be properly managed during storage.

The DQOS developed for the process are specifically addressed as criteria throughout this document.

\subsection{DEVIATIONS FROM AGREED UPON PROCESS}

It may be necessary to deviate from the agreed upon procedures out 1 ined in this WAP.

\subsubsection{Container Specific Deviations}

All deviations that are not required to be approved by Ecology in accordance with the WAC will be container specific and will not be applicable to the overall process. Prior to the deviation, a justification memo will be written. This memo must identify the container(s) covered under the deviation 
and must clearly state the reason for the deviation. The justification will be sent via facsimile to the Ecology Lead for the Order and the Ecology Lead for the Implementation of the WAP. If, after two (2) working days, Ecology has not responded, it will be deemed as acceptance of the deviation for the container(s) specified.

\subsubsection{Deviations from the Washington Administrative Code}

All deviations from the requirements of the WAC (such as deviations from WAC 170-303-110) will be submitted to Ecology for their review and approval.

\subsubsection{Addendums To The Waste Analys is Plan}

All changes to the process described in this WAP will be approved by DOE-RL and Ecology. The DOE-RL/Westinghouse Hanford may implement any proposed change once Ecology is notified of the proposed change. However, if the change is eventually disapproved, DOE-RL/Westinghouse Hanford will be responsible for fulfilling any requirements that were not met because of implementation of the change.

The process to be followed is as follows:

- DOE-RL/Westinghouse Hanford will submit the proposed change to the Ecology Lead for the Order and the Ecology Lead for the Implementation of the WAP by means of a letter. The proposed changes will be in the form of an addendum to this WAP where the specific changes and reasons for the changes are identified.

- Ecology will respond to the proposed change in a letter. The letter will state if the change is approved or disapproved and, if disapproved, the reason(s) for the disapproval. This response will be given no later than ten (10) working days after receipt of the request.

- DOE-RL/Westinghouse Hanford may resubmit a modified proposed addendum in which case Ecology has 10 working days to respond. Alternately, DOE-RL/Westinghouse Hanford may choose to elevate the proposed addendum to a management level team. The management team would consist of members from DOE-RL, Westinghouse Hanford, and Ecology. The members of the management team will not be identified until such time that it becomes necessary to establish the team. The DOE-RL and Westinghouse Hanford will be responsible for naming the appropriate people from their respective organizations to the team.

- If the proposed addendum is appealed to the management team, the management team will have five (5) working days to approve or disapprove the request. 
DOE/RL-93-70, Rev. 1

$10 / 27 / 93$

\subsection{WASTE MANAGEMENT ORGANIZATIONAL RESPONSIBILITIES}

Waste management organizational responsibilities are discussed in the following sections.

\subsection{TANK FARMS}

Tank Farms will be responsible for processing the backlog waste included in the order in accordance with this WAP.

Tank Farms, as a generating unit, will maintain responsibility for the waste included under the Order until the waste is formally accepted by the CWC. This responsibility includes waste designation, laboratory analys is, formal acceptance certifications, compaction/void filling (if required), repackaging, appropriate documentation, container manar ment (including labeling), and other regulatory requirements applied to onsite generating units.

Tank Farms will be responsible for ensuring that the waste included under the order has accurate documentation required for designation. This documentation includes, but is not limited to, sampling results; inventory sheets; documented process knowledge; and certification plans, studies, and tank characterization analyses.

Tank Farms also will be responsible for the following.

- Determining the final sorting of the containers into waste streams for confirmation or completion of waste designation.

- Requesting storage/disposal approval records (SDARs) that would allow for the waste to be formally accepted by the CWC. These requests will be made in accordance with Hanford Site Solid Waste Acceptance Criteria (WHC 1991) and will be for open SDARs for waste streams or for specific SDARs for individual containers.

- Signing a certification statement for each waste container (WHC 1991).

- Reporting, through the occurrence reporting system, all significant discrepancies found during confirmation or completion of the waste designation.

NOTE: Significant discrepancies in waste designation are defined as discrepancies that, if uncorrected, would cause mismanagement of the container(s) at a storage unit. (Conservative designation of the waste is not considered a significant discrepancy.) Significant discrepancies include the following.

- The waste is determined to have a characteristic that was not previously listed. 
- The discrepancy, if uncorrected, would result in the storing of incompatible wastes together.

- Waste was accepted that is prohibited as defined in Section 3.1.

\subsection{SOLID WASTE DISPOSAL ORGANIZATION}

The Solid Waste Disposal (SWD) organization will provide the following:

- Technical assistance on characterization issues

- Perform technical assistance for all field analysis for confirmation or completion of designation, as required by this WAP

- Issue SDARs for the waste

- Ensure that all containers, once approved for final acceptance at CWC, are stored in accor Jance with WAC 173-303 interim status TSD requirements

- Inspect all waste containers included under the Order to confirm container integrity (A list of those intainers needing repackaging/overpacking will be proviaed to Tank Farms.)

- Retrieve the containers in a sequence requested by Tank Farms for shipping the backlog containers for processing

- Receive and store and/or dispose of containers approved in accordance with acceptance criteria (WHC 1991) and this WAP. Only those containers previously identified as LLW can be disposed of under this WAP

- Perform physical confirmation such as nondestructive examination (NDE) via X-ray and nondestructive assay of the containers, as necessary, as described by this WAP

- Coordinate all changes necessary for the solid waste information tracking system (SWITS) to track all containers throughout the process

- Track the waste containers through SWITS (this will include data input and report output as necessary)

- Perform surveillances, as required, if Tank Farms are not an approved generating unit in accordance with the acceptance criteria (WHC 1991).

\subsection{HANFORD ANALYTICAL SERVICES MANAGEMENT ORGANIZATION}

The Hanford Analytical Services Management (HASM) organization will coordinate sampling efforts between the laboratory and the CWC or the T Plant Complex sampling unit. 
1

\subsection{SAMPLE AND MOBILE LABORATORY}

The Sample and Mobile Laboratory (S\&ML) will provide the following:

- Collecting samples for laboratory analysis in support of backlog waste confirmation or completion of designation

- Initiating aid maintaining chain of custody on collected samples

- Shipping collected samples to offsite laboratories

- Documenting sampling activities in a controlled field logbook.

\subsection{REPACKAGING ORGANIZATION RESPONSIBILITIES}

The Repackaging Organization will make appropriate preparations for the following:

- Accepting waste for confirmation

- Accepting waste that fails confirmation

- Performing completion of designation as necessary

- Performing repackaging as necessary.

The Repackaging Organization will be responsible for obtaining permits (as applicable), writing procedures, and ensuring all necessary supplies are available.

\subsection{TRANSPORTATION AND PACKAGING ORGANIZATION}

The Transportation and Packaging organization will provide support for shipment of samples and containers. 
DOE/RL-93-70, Rev. 1

$10 / 27 / 93$

This page intentionally left blank. 
$\mathrm{DOE} / \mathrm{RL}-93-70$, Rev. 1

$10 / 27 / 93$

\subsection{WASTE MANAGEMENT CRITERIA AND TRAINING}

Waste management criteria and personnel training are discussed in the following sections.

\subsection{WASTE MANAGEMENT CRITERIA}

Before final acceptance by the CWC, waste will be designated in accordance with WAC 173-303-070. The requirements of the Central Waste Complex Final Safety Analysis Report (WHC 1992) must be followed at all times. The CWC will not accept unidentified or uncharacterized waste not identified in the Hanford Central Waste Complex Part A Permit Application (DOE/RL-88-21). In addition, the CWC will not accept the following prohibited items:

- Etiologic agents (49 CFR 173.386)

- Chemically incompatible materials in any waste container (40 CFR 265.313)

- Explosives (10 CFR 61.56)

- Pyrophorics (10 CFR 61.56)

- Gas cylinders not permanently vented.

Containers must be in good condition with no visible cracks, holes, dents, bulges, corrosion, or other damage that affects the integrity of the container (WHC 1991).

The radioactive limits for the CWC cannot be exceeded without documentation from the SWD organization allowing a deviation from the limits as follows.

- The maximum surface-radiation dose rate will not exceed 100 millirems per hour at any point. If the dose rate exceeds the limit, the package will be shielded down to the acceptable limit.

- Removable contamination on the exterior surfaces of all waste packages will not exceed the following limits:

- 220 disintegration per minute per 100 square centimeters for alpha contamination

- 1,000 disintegration per minute per 100 square centimeters for betagamma contamination.

- The total fissile content of any container will not exceed 15 grams. 
DOE/RL-93-70, Rev. 1 $10 / 27 / 93$

\subsection{WASTE MANAGEMENT TRAINING}

Al1 training will be performed to meet the requirements of WAC 173-303-330.

Each TSD unit involved in the processing of backlog waste is responsible for their own personnel training. The TSD units have specific training plans that contain the detailed iraining needed at that TSD unit. The training might exceed the training required under this WAP. Other organizations who do not have a training plan and are performing work under this WAP are responsible for meeting the minimuin training requirements outlined in this section.

Although formal training is not required on the specific processes described in this WAP, workshops will be given to present this WAP along with the methodology, and to discuss in detail the various processes embodied by this WAP.

All employees involved with the backlog program will be placed into one of the following four categories based on their job titles, positions, and

responsibilities:

- Category 1 - Al1 Employees

- Category 2 - General Worker

- Category 3 - General Manager

- Category 4 - General Shipper.

Training courses for each category are described in the following sections. Specific training course numbers and course descriptions are available on request.

\subsection{CATEGORY I TRAINING - ALL EMPLOYEES}

Required training courses are as follows:

1. "Hazardous Communication and Waste Orientation"

2. "Asbestos General Employee Training"

3. "Facility Specific Orientation" (for the facility or facilities where the employee will perform their job duties).

\subsection{CATEGORY 2 TRAINING - GENERAL WORKER}

\subsubsection{Personnel Who Work With Dangerous Wastes}

Personnel who handle or transport wastes including repackaging and movement of containers are included in this category.

Required training courses are as follows:

1. "Category 1 Training Requirements"

2. "Generator Hazards Safety Training" (every 2 years) 
3. "Facility Specific Training" using the Facility Emergency and Hazard Information Checklist (annually)

4. "Job Specific Training" (as determined by the facility management)

5. "Hazardous Waste Operations Training," either 24-hour or 40-hour initial training (8-hour retraining annually).

\subsubsection{General Workers Who Work Within a TSD Unit}

Personnel who provide written direction on handling dangerous waste in the form of work plans, work packages, and operating procedures are included in this category.

Required training courses are as follows:

1. "Category 1 Training Requirements"

2. "Generator Hazards Safety Training" (every 2 years)

3. "Facility Specific Training" using the Facility Emergency and Hazard Information Checklist (annually)

4. "Job Specific Training" (as determined by the facility management)

5. "Hazardous Waste Operations Training," either 24-hour or 40-hour initial training (8-hour retraining annually).

\subsection{CATEGORY 3 TRAINING - GENERAL MANAGER}

\subsubsection{Decision-making Authorities in Emergencies Involving Dangerous Waste}

Required training courses are as follows:

1. "Category 1 Training Requirements"

2. "Generator Hazards Safety Training" (every 2 years)

3. "Building Emergency Director Training" or "Building Warden Training" (annually)

4. "Review of Building Emergency Plan" (annually).

\subsubsection{First-line Management in Dangerous Waste Management Facilities}

1. "Generator Hazards Safety Training" (every 2 years)

2. "Hazard Evaluation Workshop".

\subsection{CATEGORY 4 TRAINING - GENERAL SHIPPERS}

Required training courses for dangerous and mixed waste shippers are as follows:

1. "Category 1 Training Requirements"

2. "Generator Hazards Safety Training" (every 2 years)

3. "Hazardous Waste Shipment Certification Training" (annually) 
4. "Facility Specific Training" using the Facility Emergency and Hazard Information Checklist

5. "Hazardous Waste Operations Training," either 24-hour or 40-hour initial training (8-hour retraining annually)

6. "Waste Designation Support" (annua11y).

\subsection{ADDITIONAL TRAINING REQUIREMENTS}

The following sections discuss training requirements that are in addition to any training discussed previously.

\subsubsection{Personnel Responsible for Designating Waste and Determining the Waste Meets Minimum Requirements for Storage}

The required training course for these personnel is as follows.

1. "Waste Designation Certification Training" (annually).

\subsubsection{Personnel Responsible for Making Decisions on Flagging Containers for Further Analysis and Making the Decision that a Container or Waste Stream has Sufficient Information for Characterization for Storage}

The required training course for these personnel is as follows.

1. "Waste Designation Support" (annually).

\subsubsection{Personnel Who Perform Waste Sampling or Who Clean and Certify Sampling Equipment}

Required training courses for these personnel include the following:

1. "Generator Hazards Safety Training" (every 2 years)

2. "Hazardous Waste Operations Training," either 24-hour or 40-hour initial training (8-hour retraining annually)

3. "Facility Waste Sampling and Analysis"

4. "Job Specific Training". 


\subsection{WASTE STREAM DESCRIPTION}

Although Tank Farms primary mission is the receipt and long-term storage of highly radioactive liquid wastes in large underground tanks, some containerized solid waste is generated. The generation of containerized wastes is limited to activities such as surveillance, monitoring, maintenance of electrical and mechanical equipment, and the removal of radiologically contaminated soil. In order to maintain exposures as low as reasonably achievable (ALARA), very little work in Tank Farms involves direct contact with the tank wastes. The generation of mixed waste primarily results from other activities occurring in the Tank Farms.

\subsection{DESCRIPTION OF WASTE GENERATING PROCESSES}

To adequately describe the waste generating processes for containerized waste in Tank Farms a description of the waste generating activities and the subsequent waste descriptions are found in the following sections. A matrix illustrating the waste that results from each activity is found in Table 4.1. Each waste material is described in Table 4.2.

\subsubsection{Waste Generating Activities}

The are 11 primary waste generating activities that take place in Tank Farms:

- gasket replacements

- gauge/manual liquid level tape repairs

- sampling

- tank pumping

- in-tank photography

- vent and balance

- surveillance

- maintenance and repairs

- contamination control

- spills

- construction.

The following describes these waste generating activities.

Gasket replacement entails the dismantling of tank riser covers, the removal and replacement of asbestos gaskets, and the reinstallation of the riser covers.

Tank Farms generates waste using two liquid level indication devices in the various tanks: a Food Instrument Corporation ${ }^{m}$ (FIC) gauge and a manual tape. Repairs on these devices generates waste meeting a variety of descriptions.

Sampling in the Tank Farms involves several different activities. The sampling activities that generate the most waste are tank core and bore hole drilling. 
1

As part of Tank Farms' primary mission of managing highly radioactive liquid waste, a certain amount of pumping of the liquid waste is required. SingleShell Tank stabilization, waste receiving, removing liquids from tanks that are suspected of leaking, and some tank-to-tank transfers involve tank pumping. Some amount of waste that directly contacts the tank waste is generated from these activities as well as a volume of non-contact waste.

In-tank photography generates waste that results primarily from the placement and removal of the photographic equipment from inside of a tank.

Vent and balance activities involve only the calibration and testing of ventilation, exhaust, and filtration equipment.

Surveillances represent the most frequent activity that occurs in the Tank Farms. As a result, it is expected that the largest volume of backlog waste resulted from this activity. A surveillance involves the donning of personal protective equipment, entering a Tank Farm Complex, performing a surveillance, leaving the complex, and removing the personal protective equipment.

Personnel conducting surveillances read instruments, perform visual inspections, and perform oversight activities, but do not normally come into direct contact with the tank wastes.

The category of maintenance and repairs involves a wide range of waste generating activities that occur in Tank Farms. These activities include preventive maintenance of equipment, housekeeping, replacement of failed equipment, and repair of broken equipment. This category excludes in-tank equipment. The repair, maintenance, and disposal of in-tank equipment generates wastes that are handled in the WAP as special case waste.

The control of radioactive contamination is an important and required activity conducted in Tank Farms. Radioactive contamination has been inadvertently deposited on the soils within the Tank Farms during years of routine operations. Much of this contamination is fixed and does not spread. Some of the contamination is not fixed, or non-fixed contamination is uncovered during activities such as excavation. As a result it is imperative that Tank Farms reduce the potential for spreading contamination by containerizing the soil that contains the radioactive contamination.

Tank Farms does not intentionally spill either dangerous or nondangerous materials. Spills, however, might occur despite the most stringent

precautions. The most common spill that could occur in the Tank Farms results from the use of diesel fuel. Various equirment in the Tank Farms is powered with diesel fuel. This equipment sometime; develops leaks that result in spills or the diesel fuel is spilled during refueling. On rare occasions, tank waste also is spilled to the soil.

Construction activities in the Tank Farms vary greatly in scope. The wastes that result from construction activities are difficult to categorize in terms of description, volume, or characteristics. Most construction is small scale, such as the pouring of new concrete, but some like the 242-A Evaporator upgrades are major construction efforts. Most of the waste volume results 
DOE/RL-93-70, Rev. 1

$10 / 27 / 93$

from demolition actions that produce rubble and debris. The more prevalent wastes include rags, hand tools, plastic, paint, metal parts, and lumber.

\subsubsection{Waste Description}

Table 4.2 provides a brief description of the waste materials that are typically generated during Tank Farms activities. Table 4.2 also provides additional clarification to the waste generating matrix found in Table 4.1 .

\subsection{WASTE MANAGEMENT PRACTICES}

The vast majority of the wastes that are to be addressed by this WAP are currently being stored at the CWC and are designated as dangerous waste (DW) with only the waste codes F001, F002, F003, and F005 ident ified on the Backlog Waste Information Sheet (BWIS) and on the containers. Both federal and state regulations state that a mixture of a solid waste with any listed waste also will be designated as a listed waste. Tank Farms' management has historically not segregated waste streanis. Consequently, Tank Farms were unable to substantiate the waste designations and were not allowed to ship the waste as low-level waste.

By employing the Backlog Waste Program, Tank Farms used their existing characterization information (Tank Farms lacked the information to demonstrate that the wastes were properly segregated and had not been in direct contact with the tank waste), and applied the waste codes F001, F002, F003, and F005. The Backlog Waste Information Sheet (BWIS) was used as the tool for documenting the existing characterization information as determined by Tank Farms.

In early 1993, new process knowledge based on the use of decontamination chemicals at $T$ Plant became available. The knowledge resulted in the application of the F004 waste code to tank waste. As a result, all waste covered under this WAP and either currently designated as F001, F002, F003, and F005 or suspected of having contacted tank waste, also will be designated with the F004 waste code. Both the container labels and the container documentation will be updated accordingly.

\subsection{WASTE IDENTIFICATION}

All of the Tank Farms' backlog waste can be grouped into one of the following waste types:

- Debris

- Soil

- Containerized Liquids

- Non-Containerized Liquids

- LLW

- Speciar Case. 
Mrre than one activity can generate the same type of waste. Conversely, more than one waste type can be generated during the same activity. Waste streams can be defined for the backlog waste based on the process knowledge and characterization information of the waste and the location where the waste was generated. The waste types can be divided into the following waste stream classes:

- Contamination control soil

- Diesel contaminated soil

- Other contaminated soil

- Low-level waste debris (dangerous and nondangerous)

- F-listed debris

- Other radioactive mixed waste debris

- Containerized liquids

- Uncontainerized liquids

- Speciar case waste.

Debris will be defined according to 40 CFR 268 as solid material exceeding 60-millimeter particle size that is intended for disposal and that is a manufactured product, plant or animal matter, or natural geologic material. A mixture of debris and other materials is considered debris if the mixture is primarily debris, by volume, based on visual inspection. Intact containers of dangerous waste that are not ruptured and that retain $75 \%$ of their original volume are not considered debris. These intact, inner containers, such as an aerosol can containing lubricant, will be handled as containerized liquids.

Contamination control soil was generated solely from contamination control activities. The contamination is assumed to be the result of either direct or indirect contact with tank wastes.

Diesel contaminated soil is the result of a diesel spill cleanup. The soil might or might not be radioactively contaminated.

Other contaminated soil could have been generated from any spill or other activity other than incidental contact with the tank wastes or diesel fuel. Three of these incidents have already been documented: a lead-acid battery spil1, 241-SY-101 airlance rinsate spill, and 241-T-106 borehole drill cuttings.

Low-level waste debris is debris that has no measurable levels of radioactive contamination above background, nor any visible contamination of any kind. The use of the term ' $L L W$ ' is not intended to connote the actual designation of the waste stream class.

Debris that is considered $\mathrm{F}-\mathrm{listed}$ contains measurable levels of radioactivity above background or has been designated as F-listed on the corresponding BWIS. No other visible contamination other than that which would be attributed to contact with the tank waste can be present. A determination as to the applicability of the other waste codes that have been assigned to tank waste will be made via representative sampling of debris waste streams as described in Section 6.1. The F-listed debris also is suspected of containing lead as 52 described in Section 4.3.2. 
typically assigned the D008 waste code. Recently, DOE-RL and Westinghouse Hanford determined that all electronic components containing lead solder exceed the Toxicity Characteristics Leaching Procedure (TCLP) level for lead of $5 \mathrm{ppm}$. Consequently, the designation for waste streams with lead solder containing items might have to change.

7

8 The waste designation and the assignment of all applicable waste codes will be 9 conducted according to Appendix A. 
Other mixed waste debris might be designated as F-listed on the BWIS but also exhibits visible contamination other than would be attributed to contact with the tank waste. This debris also is suspected of containing lead as described in Section 4.3.2.

Containerized liquids include all containers found in the backlog waste drums that are not empty as defined in WAC 173-303-160(2)(a) and (b). Empty containers will be considered debris.

Uncontainerized liquids include all free liquids in the backlog waste drums that are not contained in an internal container. It is expected that the primary uncontainerized 1 iquid will be water, which is the result of condensation or that was used to wet asbestos. Small drops and unpooled condensation are addressed in accordance with Section 6.4.

Special Case waste is any waste that is not described by any of the previous descriptions. All special case waste will be handled on a case-by-case basis.

\subsubsection{Tank Farms Complexes}

The Tank Farms Complexes and the buildings and/or structures included within each complex are listed in Table 4.3. The waste stream classes of soil and debris will be divided into waste streams by these complexes. The existing container documentation or additional documentation gained during this process will indicate the generating location. The information in Table 4.3 will allow that container to be assigned to a Tank Farms Complex to assist in establishing the waste stream.

\subsubsection{Potential Waste Designation}

Table 4.4 summarizes the waste generating activities that contributed to each of the previously identified waste streams. The potential waste codes that would apply to these waste streams and the rationale for this designation also are reflected in Table 4.4 .

Potential waste codes refers to waste codes that may apply if certain types of dangerous wastes are contained within a waste stream, or the concentration of a dangerous waste constituent is high enough for the waste stream to exhibit a dangerous waste characteristic. If additional waste codes are identified as a result of the process described in this WAP, Table 4.4 will be updated accordingly.

The following are several examples of waste codes:

- The containerized liquid waste stream may contain aerosol cans with enough, remaining flammable product to cause the waste stream to be designated as D001,

- The F-listed debris waste stream may contain electronic circuit boards from maintenance and repair activities. This waste stream is not 
Table 4.1. Tank Farms Waste Generating Activities and Waste Materials.

\begin{tabular}{|c|c|c|c|c|c|c|c|c|c|c|c|}
\hline \multirow{2}{*}{ Waste Materials ${ }^{\star \star}$} & \multicolumn{11}{|c|}{ Waste Generating Activities* } \\
\hline & \begin{tabular}{|l|} 
Gasket \\
Replacements
\end{tabular} & $\begin{array}{l}\text { FIC/Manual } \\
\text { Tape Repairs }\end{array}$ & Sampl ing & \begin{tabular}{|l|} 
Tank \\
Pumping
\end{tabular} & $\begin{array}{l}\text { In-Tank } \\
\text { Photography }\end{array}$ & \begin{tabular}{|l|} 
Vent \& \\
Balance
\end{tabular} & Surveillance & \begin{tabular}{|l|} 
Maintenance \\
$\&$ Repairs
\end{tabular} & \begin{tabular}{|l|}
$\begin{array}{l}\text { Contamination } \\
\text { Control }\end{array}$ \\
\end{tabular} & Spills & Construction \\
\hline Soil (diesel spills) & & & & & & & & $x$ & & $x$ & $x$ \\
\hline Soil (cont. control) & & & & & & & & & $x$ & $x$ & $\bar{x}$ \\
\hline Soil (other cont.) & & & & & & & & & & $x$ & \\
\hline Rags & & $x$ & & $x$ & & $x$ & & $x$ & & & $x$ \\
\hline Vacuum Pump & & & & & & & & $x$ & & & \\
\hline CAM Parts & & & & & & & & $x$ & & & \\
\hline Electric Motors & & $\underline{x}$ & & & & & & $x$ & & & \\
\hline Belts & & & & & & & & $\bar{x}$ & & & \\
\hline Tools & $\underline{x}$ & $x$ & $\underline{x}$ & $\underline{x}$ & $\underline{x}$ & $\underline{x}$ & & $\underline{x}$ & & $x$ & $x$ \\
\hline Plastic Sheeting & $\underline{x}$ & $x$ & $\mathbf{x}$ & $x$ & $\mathrm{x}$ & $x$ & & $x$ & $x$ & $x$ & $x$ \\
\hline PPE & $x$ & $x$ & $x$ & $x$ & $\underline{x}$ & $\underline{x}$ & $x$ & $x$ & $x$ & $x$ & $x$ \\
\hline $\begin{array}{l}\text { Misc. Step-off Pad } \\
\text { Haste }\end{array}$ & $x$ & $x$ & $\mathrm{x}$ & $\mathrm{x}$ & $x$ & $x$ & $x$ & $x$ & $x$ & $x$ & $x$ \\
\hline Nuts \& Bolts & $\mathrm{x}$ & $\underline{x}$ & & & $x$ & & & $x$ & & & $x$ \\
\hline Wire & & $x$ & & & & & & $x$ & & & $x$ \\
\hline Lumber & & & $x$ & $x$ & $x$ & & & $x$ & & & $x$ \\
\hline $\begin{array}{l}\text { Tape Housing \& Misc. } \\
\text { Equip. }\end{array}$ & & $x$ & & & & & & & & & \\
\hline Drill Rod & & & $x$ & & & & & & & & \\
\hline Drill Bits & & & $x$ & & & & & & & & \\
\hline In-tank Equipment & & $x$ & & $x$ & & & & $\underline{x}$ & & & $x$ \\
\hline Liquid Level Tapes & & $x$ & & & & & & & & & \\
\hline Lead Shielding & & $x$ & $x$ & & & & & & & & $x$ \\
\hline $\begin{array}{l}\text { Exhauster Housing \& } \\
\text { Parts }\end{array}$ & & & & & & & & $x$ & & & \\
\hline HEPA Filters & & & & & & $x$ & & & & & \\
\hline $\begin{array}{l}\text { Items } \\
\text { w/lead solder }\end{array}$ & & $x$ & & & & & & $x$ & & & \\
\hline oils & & & & & & & & $x$ & & & \\
\hline Hydraulic Fluid & & & & & & & & $x$ & & & \\
\hline Paints & & & & & & & & $x$ & & & $\bar{x}$ \\
\hline Misc. Aerosol Cans & & & & & & & & $x$ & & & $x$ \\
\hline $\begin{array}{l}\text { Asbestos Gaskets \& } \\
\text { Water }\end{array}$ & $x$ & & & & & & & & & & \\
\hline $\begin{array}{l}\text { Asbestos (other) \& } \\
\text { Water }\end{array}$ & & & & & & & & & & & $x$ \\
\hline
\end{tabular}


Table 4.2. Waste Material Descriptions.

\begin{tabular}{|c|c|}
\hline Waste Materials & Description \\
\hline Soil (diesel spills) & Soil contaminated with diesel fuel packaged typically in a plastic bag. \\
\hline Soil (rad. cont.) & Soil with some measurable level of radioactivity above background. \\
\hline Soil (other cont.) & $\begin{array}{l}\text { Soil contaminated from several sources: lead acid battery spills, sY-101 } \\
\text { Airlance rinsing, T-106 drill cuttings, and other miscellaneous spills. }\end{array}$ \\
\hline Rags & $\begin{array}{l}\text { Rags contaminated with tank wastes, oils, paint, or other miscellaneous } \\
\text { chemicals. }\end{array}$ \\
\hline Vacuum Pump & Spent equipment \\
\hline CAM Parts & Spent equipment \\
\hline Electric Motors & Spent equipment \\
\hline Belts & Rubber based "fan belts". \\
\hline Tools & Hand tools and power tools. \\
\hline Plastic Sheeting & Plastic from greenhouses, contamination control and waste packaging. \\
\hline PPE & SWPs (whites), gloves, boots, masks, and mask filters \\
\hline Misc. Step-off Pad Waste & Tape, plastic, and rags \\
\hline Nuts \& Bolts & Spent equipment \\
\hline Wire & Spent equipment \\
\hline Lumber & Treated and untreated wood \\
\hline $\begin{array}{l}\text { Tape Housing \& Misc. } \\
\text { Equip. }\end{array}$ & Spent equipment that may or may not have contacted tank waste. \\
\hline Drill Rod & Spent equipment that contacted tank waste. \\
\hline Drill Bits & Spent equipment that contacted tank waste. \\
\hline In-tank Equipment & Spent equipment that contacted tank waste. \\
\hline $\begin{array}{l}\text { Liquid Level Tapes } \\
\text { Lead Shielding }\end{array}$ & Spent equipment that contacted tank waste. \\
\hline Exhauster Housing \& Parts & Spent equipment that may or may not have contacted tank waste. \\
\hline HEPA Filters & Filter media and housing. \\
\hline Items w/ lead solder & $\begin{array}{l}\text { circuit boards, light bulbs, and other electrical equipment containing } \\
\text { significant amounts of lead solder. }\end{array}$ \\
\hline oils & Compressor oil, hydraulic fluid, motor oil \\
\hline Other liquids & Cleaning products \\
\hline Paints & $\begin{array}{l}\text { Empty paint containers, dangerous waste paints and residue, non- } \\
\text { dangerous paints and residue. }\end{array}$ \\
\hline Misc. Aerosol Cans & Cleaning products, paint cans, lubricants, and solvents \\
\hline Asbestos Gaskets \& Water & Asbestos packaged with water as a wetting agent. \\
\hline Asbestos (other) \& Water & Asbestos packaged with water as a wetting agent. \\
\hline
\end{tabular}

CAM = continuous air monitor.

PPE = personal protective equipment.

SWP = special work permit. 
Table 4.3. Tank Farms Complexes. (sheet 1 of 3 )

PUREX A-Farm Complex

241-A Tank Farm

6 SSTs (241-A-101 to 106)

241-A-271 Control Room

241-A-401 Condenser Building

241-A-701 Compressor Building

241-A-702 Ventilation Building

241-A-4,000 CFM Backup Exhauster

241-AX Tank Farm

4 SSTs (241-AX-101 to 104)

241-AX-801 Water Service Building

241-AX-2707 Changeroom

241-AY Tank Farm

2 DSTs (241-AY-101 \& 102)

241-AY-801 Instrument Building

241-AZ Tank Farm

2 DSTs (241-AZ-101 \& 102)

241-AZ-801 Instrument Building

Miscellaneous subgrade ancillary equipment (i.e., diversion boxes, valve pits, catch tanks, and vaults).

\section{AP/AW Tank Farm Complex}

241-AW Tank Farm and support buildings

6 DSTs (241-AW-101 to 106)

241-AW-271 Control Building

241-AW-273 Compressor Building

241-AW Water Service Building

241-AN Tank Farm and support buildings

7 DSTs (241-AN-101 to 107)

241-AN-271 Control Building

241-AN Water Service Building

241-AN-273 Compressor Building

241-AP Tank Farm and support buildings

8 DSTs (241-AP-101 to 108)

241-AP-271 Control Building

241-AP Water Service Building

241-AP-701 Compressor Building

204-AR Railcar Unloading Facility

244-AR Vault.

244-AR-701 Generator Building

244-AR-715 Closed-Loop Cooling System Building

291-AR Filter Building and Stack

292-AR Vessel Vent Stack

207-A Retention Basins

244-A Lift Station

Miscellaneous subgrade ancillary equipment (i.e., diversion boxes, valve pits, catch tanks, and vaults). 
Table 4.3. Tank Farms Complexes. (sheet 2 of 3 )

242-A Evaporator

\title{
242-A Evaporator
}

242-A-81 Water Service Building

242-A-702 Evaporator Ventilation Building

\author{
B-Farm Complex
}

241-B Tank Farm

16 SSTs (241-B-101 to 112 \& 241-B-201 to 204)

241-B-701 Compressor Building

241-BX Tank Farm

12 SSTs (241-BX-101 to 1i2)

244-BX Double-Contained Receiver Tank

2724-BX Check-Out Station

241-BY Tank Farm

12 SSTs (241-BY-101 to 112)

$241-B Y-254$ ITS 2 Building

241-BY-301 ITS 1 Building

241-BY-302 Compressor Building

2724-BY Check-Out Station

M0-114 Changeroom (BY Farm)

Miscellaneous subgrade ancillary equipment (i.e., diversion boxes, valve pits, catch tanks, and vaults).

$$
\text { C-Farm Complex }
$$

241-C Tank Farm

16 SSTs (241-C-101 to $112 \& 241-C-201$ to 204)

241-CR-271 Control Room

2724-C Check-Out Station

2724-CA Check-Out Station 244-CR Vault

Miscellaneous subgrade ancillary equipment (i.e., diversion boxes, valve pits, catch tanks, and vaults).

$$
\text { T-Farm Complex }
$$

\section{1-T Tank Farm}

16 SSTs (241-T-101 to 112 \& 241-T-201 to 204)

Miscellaneous subgrade ancillary equipment (i.e., diversion boxes, valve pits, catch tanks, and vaults). 
Table 4.3. Tank Farms Complexes. (sheet 3 of 3 )

TX/TY-Farm Complex

241-TX Tank Farm

18 SSTs (241-TX-101 to 118)

241-TY Tank Farm

6 SSTs (241-TY-101 to 106)

242-T Evaporator

244-TX Double-Contained Receiver Tank

Miscellaneous subgrade ancillary equipment (i.e., diversion boxes, valve pits, catch tanks, and vaults).

\section{U-Farm Complex}

\section{1-U Tank Farm}

16 SSTs (241-U-101 to 112 \& $241-U-201$ to 204))

244-U Double-Contained Receiver Tank

Miscellaneous subgrade ancillary equipment (i.e., diversion boxes, valve pits, catch tanks, and vaults).

\section{S-Farm Complex}

241-S Tank Farm

12 SSTs (241-S-101 to 112)

241-SX Tank Farm

15 SSTs (241-SX-101 to 115)

241-SY Tank Farm

3 DSTs (242-SY-101 to 103)

242-S Evaporator-Crystallizer

244-S Double-Contained Receiver Tank

Miscellaneous subgrade ancillary equipment (i.e., diversion boxes, valve pits, catch tanks, and vaults).

\section{Buildings/Structures not Part of any Complex}

Grout Treatment Facility

Liquid Effluent Retention Facility (LERF)

151 ER Diversion Box

152 ER Diversion Box

153 ER Diversion Box

154 UX Diversion Box

CFM = cubic feet per minute.

DST = double-shell tank .

ITS = in-tank solidification.

SST = single-shell tank . 
Table 4.4. Tank Farms Dangerous Waste Identification.

\begin{tabular}{|c|c|c|c|c|}
\hline ACTIVITY & WASTE STREAM CLASS* & POTENTIAL WASTE CODES & RATIONALE & DW/EHW \\
\hline Gasket Replacements & LLW - Debris & N/A & Contact with tank wastes did not occur. & \\
\hline \multirow{2}{*}{$\begin{array}{l}\text { FIC/Manual Tape } \\
\text { Repairs }\end{array}$} & LLW - Debris & N/A & Contact with tank wastes did not occur. & \\
\hline & Derived from RMH - Debris & $\begin{array}{l}\text { F001, F002, F003, F004, } \\
\text { F005, D008 }\end{array}$ & $\begin{array}{l}\text { Incidental contact with listed wastes and } \\
\text { quantities of lead solder. }\end{array}$ & DW \\
\hline \multirow[t]{2}{*}{ Sampl ing } & LLH - Debris & N/A & Contact with tank wastes did not occur. & \\
\hline & Derived from RMW - Debris & $\mathrm{FOO1}, \mathrm{FOO2}, \mathrm{FCO3}, \mathrm{FOO4}, \mathrm{FOOS}$ & Incidental contact with listed wastes. & DW \\
\hline \multirow[t]{2}{*}{ Tank Pumping } & LLH - Debris & N/A & Contact with tank wastes did not occur. & \\
\hline & Derived from RMW - Debris & $\mathrm{FOO1}, \mathrm{F} 002, \mathrm{FOO3}, \mathrm{FOO4}, \mathrm{F} 005$ & Incidental contact with listed wastes. & DW \\
\hline \multirow[t]{2}{*}{ In-Tank Photography } & LLH - Debris & N/A & Contact with tank wastes did not occur. & \\
\hline & Derived from RMW - Debris & $\mathrm{FOO1}, \mathrm{FOO2}, \mathrm{FOO3}, \mathrm{FOO4}, \mathrm{FOOS}$ & Incidental contact with listed wastes. & DW \\
\hline Vent \& Balance & LLW - Debris & N/A & Contact with tank wastes did not occur. & \\
\hline Surveillance & LLW - Debris & N/A & Contact with tank wastes did not occur. & \\
\hline \multirow{4}{*}{$\begin{array}{l}\text { Maintenance \& } \\
\text { Repairs }\end{array}$} & LLW - Debris & N/A & Contact with tank wastes did not occur. & \\
\hline & Derived from RMH - Debris & $\begin{array}{l}\text { FOO1, FOO2, FO03, F004, } \\
\text { FOO5, DO08 }\end{array}$ & $\begin{array}{l}\text { Incidental contact with listed wastes and } \\
\text { quantities of lead solder. }\end{array}$ & DW \\
\hline & Other RMH - Debris & W001, D006, D007, D008, D009 & PCB and heavy metal residues in used oils. & DW \\
\hline & Containerized liquids & $\begin{array}{l}\text { Determined according to Sec. } \\
6.4\end{array}$ & & DW \\
\hline $\begin{array}{l}\text { Contamination } \\
\text { Control }\end{array}$ & Rad. contaminated soil & $\mathrm{F} 001, \mathrm{FO02}, \mathrm{FOO3,F004,F005}$ & Incidental contact with listed wastes. & DW \\
\hline \multirow[t]{2}{*}{ Spills } & Diesel contaminated soil & $\begin{array}{l}\text { F001, F002, F003, F004, } \\
\text { F005, D018, WCO2 }\end{array}$ & $\begin{array}{l}\text { Incidental contact with listed wastes and the } \\
\text { concentration of benzene in diesel fuel. }\end{array}$ & DH \\
\hline & Other contaminated Soil & $\begin{array}{l}\mathrm{F001}, \mathrm{F002}, \mathrm{F003}, \mathrm{F004} \\
\mathrm{F005}, \mathrm{D002}, \mathrm{D0??}\end{array}$ & Direct contact with listed wastes from the tanks. & DW \\
\hline \multirow[t]{5}{*}{ Construction } & Rad. contaminated soil & $\mathrm{FO01}, \mathrm{FOO2}, \mathrm{FOO3}, \mathrm{FOO4}, \mathrm{FOOS}$ & Incidental contact with listed wastes. & DW \\
\hline & LLW - Debris & N/A & Contact with tank wastes did not occur. & \\
\hline & Derived from RMW - Debris & $\begin{array}{l}\text { F001, F002, F003, F004, } \\
\text { F005, D008 }\end{array}$ & $\begin{array}{l}\text { Incidental contact with } l \text { isted wastes and } \\
\text { quantities of lead solder. }\end{array}$ & DW \\
\hline & Containerized liquids & $\begin{array}{l}\text { Determined according to Sec. } \\
6.4\end{array}$ & & DW \\
\hline & Uncontainerized liquids & N/A & & DW \\
\hline
\end{tabular}

* The Waste Stream Classes described in this Table for soil and debris will be divided into specific waste streams according to the Tank Farm Complex where the waste was generated. See Section 4.3 .1 .

** ?? means a contaminant may be present which would cause the waste to be regulated for one of the TCLP contaminants. 
DOE/RL-93-70, Rev. 1

$10 / 27 / 93$

\subsection{PROCESS FOR CONFIRMATION OR COMPLETION OF DESIGNATION}

2

3

4

This section describes the general approach that will be used for confirmation or completion of the backlog waste designation. The purpose of the process is to demonstrate that the defined waste streams meet the criteria of a waste stream and to obtain characterization information for confirmation or completion of designation sufficient for proper management of the waste during storage. The process is designed to prevent false negative results in the designation of a container.

The steps in the process are shown in Figure 5-1. The basic steps to be followed are as follows:

- Sorting

- Documentation Assessment

- Physical Analysis

- Field Analysis

- Laboratory Analysis.

Each container will be evaluated and the confirmation and completion of designation performed on an individual basis. However, each container does not have to go through all of the steps. Information obtained from analyses on containers within a waste stream could be applied to other containers within the same waste stream.

Section 6.0 of this WAP outlines the basic protocol to be followed for each waste stream. All containers will be processed through the sorting and documentation assessment. The number of containers in each waste stream to be processed through the remaining steps, along with the specific physical, field, and/or laboratory analysis to be performed are described in Section 6.0 .

At any point in the process, when Tank Farms determines that sufficient information is available for proper storage of a container or waste stream, Sol id Waste Acceptance Services (SWAS) can be requested to issue a SDAR for the container or waste stream. The process to be used for this request is outlined in Section 5.3.

\subsection{SPECIAL HANDLING OF CONTAINERS}

At any step in the process, information can be obtained for a container that would cause the evaluator to question the validity of the available documentation. The container documentation will be flagged so that additional steps can be taken to ensure that sufficient characterization information is obtained so that the designation is completed or confirmed.

Examples of when flagging of a container is required include the following.

- The documentation assessment uncovers questionable documentation on a container. 
- Physical or chemical analysis raises questions concerning the documentation on a container.

- An object or material is found in a waste container that is not substantiated by the documentation assessment.

- An indication of a mixture of waste streams is found that has not been previously identified.

Whenever a container is flagged as a result of the documentation assessment, physical analysis, or chemical analysis, the evaluator must determine if the other containers in the waste stream potentially could be impacted. The evaluator must determine the appropriate course of action based on the waste stream documentation. Possible courses of action include subjecting other containers in the waste stream to further analyses, applying the results obtained from the flagged container to other containers in the waste stream, or redefining a waste stream and subsequently resorting some waste containers.

Whenever a container has a waste code(s) added as a result of analysis, the same waste code(s) could be added to the remaining containers in the same waste stream in lieu of performing additional analysis on those containers. However, it must be demonstrated that all of the containers still belong in the same waste stream.

At any step in the process, a significant discrepancy in waste designation could be revealed. A significant discrepancy in waste designation is defined as a discrepancy that, if uncorrected, would cause mismanagement of the container or the waste stream storage unit. (Conservative designation of the waste is not considered a significant discrepancy.) Significant discrepancies include the following.

- The waste is determined to have a characteristic that was not previously listed.

- The discrepancy, if uncorrected, would result in the storing of incompatible wastes together.

- Waste was accepted that is prohibited as defined in Section 3.1.

\subsection{DOCUMENTING FLAGGED CONTAINERS}

When flagging of a container results in the need for additional actions to be taken on the container or other containers in the waste stream, the actions taken must be documented in the operating record. A statement of the actions taken and the reason(s) for the action will be kept in the container file. The statement will be signed and dated by the evaluator. 


\subsection{DETERMINATION OF ADEQUATE KNOWLEDGE FOR STORAGE}

On completion of any step after the documentation assessment, Tank Farms could request SWAS to issue a SDAR for any waste container or waste stream that is believed to have adequate documentation to demonstrate that the waste has been designated according to WAC 173-303-070 and that the waste meets the acceptance criteria requirements (WHC 1991).

The SDAR specifies the waste type, the hazardous constituents in the waste (if any), and the designation of the waste according to WAC 173-303-070 (if the waste is designatable). The SDAR will be applicable to either a specific container or a complete waste type. In the first case, the SDAR is called a 'specific' SDAR. The package identification number(s) (PIN) for the container(s) are specified on the specific SDAR. In the second case, the SDAR is called an 'open' SDAR. It can be used for any container that meets the criteria on the SDAR.

The following steps will be followed to make and evaluate a request.

- Step 1. A waste storage/disposal request (WSDR) will be completed for the container(s). Tank Farms waste characterization data will be referenced or placed in each container field file belonging to the waste stream.

- Step 2. The WSDR and Tank Farms field file(s), as well as supporting documentation referenced in the field file, will be transmitted to SWAS for evaluation.

- Step 3. SWAS will answer the question, "Does adequate knowledge exist for designation according to this WAP?", by comparing the documentation to WAC 173-303-070 and waste acceptance requirements (WHC 1991). The designation criteria for meeting WAC 173-303-070 are provided in Appendix A. Table 5.1 contains the analytical testing used in the designation process.

If the answer to the question is 'YES', SWAS will issue a notice of adequate documentation to Tank Farms (and other organizations as applicable). The appropriate SDAR to be used for the container or waste stream and the specific container PINs allowed will be specified. If an SDAR is not currently written for the waste, an SDAR will be written.

If the answer to the question is 'NO', the waste has not been characterized sufficiently for storage, and a notice of rejection will be issued. The notice of rejection must be accompanied with a list of the criteria that has not been met and the required actions needed to meet the criteria.

- Step 4. On receiving the notice of adequate documentation, Tank Farms will prepare the waste for shipment as specified in the SDAR.

Preparations could include packaging and labeling. If the container is al ready located at the CWC, shipment will not be necessary. In the 
case of a rejection, the required activities to meet the acceptance criteria will be performed and the request will be resubmitted.

\subsection{PRELIMINARY WASTE SORTING}

Tank Farms will perform a preliminary paperwork sort of the containers based on the backlog waste documentation. The waste container files will be sorted into waste types.

Preliminary sorting wi11 be performed using information provided in SWITS and the BWIS. During preliminary sorting, containers will be placed in one of the following five waste types based on the description of each waste type in Section 4.3:

- Debris

- Soil

- Containerized Liquids

- Non-Containerized Liquids

- LLW

- Special Case

Containers with a mixture of waste types will be flagged to ensure that confirmation or completion of designation is performed on all waste types in the container.

\subsection{DOCUMENTATION ASSESSMENT}

The documentation assessment will review all process and characterization knowledge available on the backlog waste at the CWC.

To consistently and objectively assess all waste containers, a 'container waste documentation checklist' will be used (Appendix B). This checklist will assist Tank Farms in determining the following:

- The segregation of containers into waste streams

- If there is sufficient knowledge about the container for designation at this stage of the process

- Containers within a waste stream that require flagging for special management.

\subsubsection{Waste Stream Segregation}

During the documentation assessment, the information on the BWIS files (including the waste type) will be verified and the waste types will be divided into waste streams. 


\begin{abstract}
Segregation will occur using information contained in field files and various characterization documents (e.g., tank characterization analys is or process history documents). The waste stream criteria and Tank Farins Complexes used for the segregation are defined in Section 4.3. Segregation will iake place based on the following criteria:
\end{abstract}

- Debris will be divided into waste streams based on the Tank Farm Complex.

- Soil will be divided into waste streams based on the waste generating activity (diesel spill, contamination control, or special case). All soil that has been designated as F-Listed during the backlog process will be divided by Tank Farm Complex.

- Containerized Liquids will be divided into the following streams:

- Aerosols

- Paints

- Acids

- Dangerous liquids

- 0 ils

- LLW wi . . considered one waste stream.

- Special Case will be divided into streams based on the type of activity that generated the waste and the location where the waste was generated.

(Note that it is possible that a waste stream will consist of a single container.)

Further division of the previously defined waste streams might occur for logistical purposes (e.g., debris boxes could be segregated from debris drums because of different management protocol). Other waste streams could be identified as the confirmation or completion of the backlog waste designation process progresses. New waste streams will be identified according to physical and chemical characteristics.

Each waste stream will be identified by a 10-digit sorting number that will clearly identify the waste stream(s) in the container. After all containers have been assigned a sorting number, the sorting number will be entered into SWITS.

\title{
5.5.2 Characterization Information Criteria
}

During the documentation assessment, all available documentation will be reviewed to determine if a waste stream is characterized sufficiently to allow for storage of the container(s) at the CWC. If a determination is made that sufficient documentation for storage exists, a SDAR can be requested in accordance with the steps outlined in Section 5.3. 
1 Sources of information used during the documentation assessment include the 2 individual field (container) files and all other supporting documentation. 3 The field file contains the specific information on a file such as container 4 inventory sheets, MSDSs, and sampling and analysis results. Supporting 5 documentation is all of the information available for a waste stream including $6 \mathrm{log}$ books and procedures. The following sources represent typical sources of 7 characterization information.

5.5.2.1 Interviews. Interviews could be used to determine if chemicals known to be present were used, if procedures were used as written or if deviations were allowed, or to verify the events in a logbook.

5.5.2.2 Logbooks. Logbooks could contain the documentation of activities of an individual or could be kept to document the activities of a specific project. Logbooks could be reviewed to identify waste streams and gain information supporting waste designation.

5.5.2.3 Procurement Records. Procurement records could indicate a specific application of products at a given site and/or a given job. Use of procurement records is acceptable only for waste streams that were generated directly from the use of a product (e.g., solvents, absorbents, etc.).

5.5.2.4 Analytical Results. Analytical results could provide concentration of constituents present in samples. The usefulness of analytical results depends on the representativeness of a sample to the media it was sampled from, its correlation to a specific stream, and the constituents that were analyzed. If only one or two process control constituents were analyzed, the target analytes could be used to support other documentation. If the concentrations of the analyzed constituents match logbook or operating records, then credibility could be given to other logbook/operating record entries for containers within a waste stream.

5.5.2.5 Qualified Analytical Data. Qualified analytical data could be used for characterization. Reasons for qualifying data include having missing or incomplete chain of custody or sampling plans or exceeding holding times. Data must be identified with a specific container or waste stream. Without validated data, sampling and analys is might be required to be repeated.

5.5.2.6 Radiation Work Packages. Radiation work packages could contain information regarding waste generating activities at the Tank Farms.

5.5.2.7 Procedures and/or Methods. Procedures and/or methods could give specifics as to how an activity was or will be performed. This could allow for either a determination of the amount of waste generated or characterization of the waste. Documented evidence must exist indicating that the procedures and/or methods were followed. Documented evidence should be initialed and dated.

5.5.2.8 Process Flow Charts. Process flow charts could show chemical input and output of various streams. Process flow charts can be studied along with the reactions that occur during processing to determine constituents as well as constituent concentrations. Process flow charts must show a specific 
application at a specific site and/or for a given job to be acceptable as process knowledge.

5.5.2.9 Inventory Sheets. Inventory sheets listing the container contents could be produced as a container of waste is generated. These sheets could be signed and dated as a certification of the contents.

5.5.2.10 Vendor Information. Vendor information (i.e., MSDSs) could provide chemical data that could be used to characterize dangerous waste. The MSDSs must be identified with a specific application at a specific site and/or for a given job to be acceptable as process knowledge. If the MSDS does not give enough information to make this determination, the manufacturer of the product could be contacted and should be able to provide additional information on chemical constituents and concentrations.

\subsubsection{Identification of Containers Requiring Special Handling}

Those containers that do not have enough information to complete the documentation assessment or for which questions exist as to the validity of the characterization information will be flagged to ensure that further actions are taken to evaluate the container. These actions should be documented in accordance with Section 5.2.

All boxes must be flagged for visual inspection because real-time radiography (RTR) for these boxes might not be possible.

\subsection{PHYSICAL CONFIRMATION OR COMPLETION OF DESIGNATION}

The intent of physical analysis is to ensure the following.

- The waste is described accurately in the waste management documentation to ensure that the container has been assigned to the correct waste stream.

- The container does not contain any prohibited articles as described in Section 3.1 or any other items that are indicative of a different waste stream.

- All containers with containerized and noncontainerized liquids are identified.

If, after physical analysis, Tank Farms believes enough information exists to request a SDAR for the waste stream, SWAS can be consulted in accordance with Section 5.3. 


\subsubsection{Physical Screening}

Physical screening provides a mechanism for determining those containers that need to be opened for visual inspection. Screening methods used consist of physical measurements and nondestructive examination by RTR.

5.6.1.1 Physical Measurements. The CWC will validate the weight and dose rate noted in the backlog waste documentation.

A difference in measured weight greater than 10 percent of the documented weight will cause the container to be flagged for visual inspection. Weights can be expected to vary because initial measurements were obtained in the field.

The measured dose rate will be compared to the documented dose rate to find dose rate anomalies. A graduated approach will be used to determine if visual inspection needs to be done on the container. For containers with documented dose rates less than or equal to $5 \mathrm{mrem} / \mathrm{hr}$, if the measured dose rate varies by more than $100 \%$ of the documented dose rate, the container will be flagged for visual inspection. For containers with documented dose rates greater than $5 \mathrm{mrem} / \mathrm{hr}$, if the measured dose rate varies by more than $5 \mathrm{mrem} / \mathrm{hr}$ of the documented dose rate, the container will be flagged for visual inspection.

5.6.1.2 Nondestructive Examination. Using RTR equipment, the waste container will be viewed and the observed contents will be compared to available documentation. The NDE technician will record NDE results on a NDE checklist (Appendix C, Backlog Waste Real-Time Radiography Guidance). The NDE also will be used to obtain information that does not impact confirmation or completion of designation, but is applicable to long-term management of the waste (i.e., determination of the presence of a liner, percentage of void space, etc.). The checklist will be maintained in the container field file.

The RTR of the waste in a container will result in the following actions.

- No inconsistencies are found that conflict with the documentation for the waste stream. No further action is required for physical analysis of the container.

- Inconsistencies are identified between the RTR and the inventory sheets for the container but the waste codes for the container do not change and the other containers in the waste stream are not affected. The change will be made on the inventory sheet and on the low-level waste storage/disposal record. Visual inspection of the container is not required.

- Inconsistencies are identified that could affect the waste codes for the container or for the waste stream. Further characterization information could be gathered to substantiate the designation of the waste. If the information is not sufficient to make this determination, the container must be opened for visual inspection. 
- Inconsistencies are found that show an undocumented mixture of waste streams within the container. The inconsistency will be noted and a determination will be made as to the applicability to other containers in the waste stream.

- Undocumented free liquids are found in the container (also referred to as uncontaminated 1iquids). Characterization of the 1iquids will be performed based on the waste stream criteria in Section 6.0.

- The RTR could reveal containerized liquids. When containerized liquids are identified during RTR, the container will be flagged for resorting to remove and characterize the liquid. On removal of the containerized liquid, the container will continue through the process.

Other anomalies not identified here or in the specific protocol in Section 6 will be determined at the time of RTR by the evaluator. The reason for the action(s) taken will be documented in accordance with Section 5.2.

\subsubsection{Visual Inspection of Container Contents}

The criteria for performing visual inspections are explained. The actions to be taken when a container can not be opened also are described.

5.6.2.1 Visual Inspection Criteria. The container will be opened for a visual inspection of the waste and the contents will be compared to the documentation provided.

During the visual inspection for all waste streams except soils, the entire content of the container will be emptied and inspected. Visual inspection of soils will consist of a cursory inspection with an attempt to identify inconsistencies that might be under the surface by mixing or digging the soil.

Visual inspection of the waste in a container will result in the following actions.

- No inconsistencies are found that conflict with the documentation for the waste stream. No further action is required.

- Additional characterization information gathered after visual inspection of the waste could result in sufficient information to determine whether additional waste codes need to be added to the container.

- Visual inspection could identify waste that needs chemical analysis. The container will be flagged and the appropriate chemical analysis wi11 be performed.

5.6.2.2 Limitations on Visual Inspection. In keeping with the ALARA precept (DOE Order 5400.5), containers will not be opened for visual inspection if, by so doing, it could expose personnel to unacceptable risks of exposure to radionuclides and/or dangerous substances. 
As a rule of thumb, containers with external dose rates greater than

$10 \mathrm{mrem} / \mathrm{hr}$ will not be opened. Deviations from this rule can be made by the health physics technician (HPT) as allowed by the radiation work permit (RWP) for the job. The decision to deviate will be based on the waste type and the available information for the container. The deviation must be documented in the container field file and signed and dated by the HPT.

The industrial hygienist (IH) will make the decision that a container will not be opened because of a chemical hazard. The decision must be documented in the field file and signed and dated by the IH making the decision.

If a container cannot be opened for ALARA reasons, a worst-case designation will be performed based on the documentation available for the container as well as the waste stream. If this determination cannot be made, Ecology will be notified and an action plan for managing the container will be developed. This deviation will be made in accordance with Section 1.4.

\subsubsection{Quality Control of Physical Analysis}

Containers flagged for visual examination will be used to determine the effectiveness of the physical screening process. At 1 east $10 \%$ of the containers from the screening process must be verified through the visual examination process. If at 1east $10 \%$ of the containers are not flagged for visual inspections, additional containers will be chosen at random to make up the 10\%. (The only exception to this process is for soil containers, which will not undergo RTR. The quality control criteria for these soil containers is found in Section 6.2.1.)

During visual inspection, the container contents will be noted and compared to the inventory in the field file and the results of the screening process. If waste is found during the visual examination process that (1) was not identified by the physical screening and (2) would have caused the waste container or the waste stream to be erroneously designated, Tank Farms must determine an alternative process for identifying these inconsistencies and notify Ecology. The process of obtaining an addendum to this WAP described in Section 1.4 will be followed.

\subsection{CHEMICAL CONFIRMATION OR COMPLETION OF DESIGNATION}

The intent of chemical confirmation or completion of designation is to ensure the following:

- The waste stream is adequately characterized for current management of the container for storage at the CWC.

- The waste stream does not contain any prohibited contaminants or exhibit attributes that are prohibited for storage at the CWC. 
- Provide additional characterization information for confirmation or completion of designation and possible updating of Tank Farms' waste stream designation.

Chemical analysis will be accomplished using field testing equipment, nonobtrusive testing such as $x$-ray fluorescence, headspace gas analysis, or laboratory chemical analysis. Chemical analysis consists of field screening and segregation, field analysis, and laboratory analytical analysis.

Containers will be selected randomly from a waste stream. Containers that are already opened for other reasons could be used as the containers on which chemical analysis will be performed. However, at least $25 \%$ of the samples must be obtained from containers that were not flagged previously. The amount of containers selected from any single waste stream will be based on the criteria in Section 5.7.1.

\subsubsection{Selection of Sample Set}

The contents of the waste streams must be tested per Section 6.0 for the presence of dangerous constituents to confirm or complete the backlog waste designation. The backlog containers have been divided into several groups that represent different waste streams for which statistical inferences are desired.

The DOE-RL/Westinghouse Hanford will test whether $95 \%$ or more of the containers in a waste stream grouping do not contain significant discrepancies. This relates to a Type I decision error of $5 \%$ or less (this is the probability of falsely concluding that less than $95 \%$ of the containers contain significant discrepancies). Type II error rate of $20 \%$ or more will be used to test if the true proportion of containers that contain significant discrepancies is $70 \%$ or less. (A Type II error is the probability of falsely concluding that less than $95 \%$ of the containers do not have significant discrepancies.)

In statistical terminology, the DOE-RL/Westinghouse Hanford will test the nu11 hypothesis that $95 \%$ or more of the containers do not contain significant discrepancies against the alternative hypothesis that less than $95 \%$ of the containers do not contain significant discrepancies. The Type I error will be $5 \%$ or less with the power of the test being $80 \%$ or greater if the true proportion is $70 \%$ or less.

Mathematically this is stated as:

DOE-RL/Westinghouse Hanford will test the proportion of containers, $p$, such that under the null hypothesis, $H_{0}: p \geq .95$

and under the alternative hypothesis, $H_{A}: p<.95$.

The test is designed so that the Type I error, $\alpha$, will be .05 or less and the Type II error, $B$, will be .20 or less at $p=.8$ under the alternative hypothesis. 
This testing situation was resolved by designing a hypogeometric model that tracks the number of containers in a sample of observations that are tested and declared to be free of significant discrepancies. Let $X$ be the number of drums in a sample of size $n$ that are declared to be free of significant discrepancies. Then a test of the form

if $X \geq k$ fail to reject $H_{0}$ and if $X<k$ accept $H_{A}$

is most powerful for testing $H_{0}$ versus $H_{A}$ under the hypogeometric model. $k$ is the critical number of containers. It is the number of containers in a sample set that must not have any significant discrepancies in order to accept the nul1 hypothesis.

Based on the developed test, the appropriate sample size, $n$, is given as well as the critical value $k$ for each waste stream group by range as follows: ${ }^{3}$

- For waste streams $\geq 400 ;(n=13, k=11)$ or $(n=35, k=28)$.

- For waste streams $<400$ and $\geq 50 ;(n=13, k=11)$ or $(n=16$, $k=13)$.

- For waste streams $<50 ;(n=4, k=0)$ or $(n=4, k=1$ and $n=4$, $k=0$ ). (If the sampling shows no significant discrepancies, then we fail to reject $H_{0}$. If 1 container is found to have a significant discrepancy, then an additional four samples must be taken.)

In the first two cases, either sample size can be selected. However, should the waste stream not meet the specifications of the test, no statistical inferences can be made and the waste stream will be addressed on a container by container basis. If the specifications of the test are not met, the container will be flagged and the guidance found in Section 5.1 will be followed. All containers in the waste stream will be addressed to determine if a sorting error occurred. If a sorting error did not occur, either all other containers in the waste stream will be given the conservative designation based on the previous sample results or each container will be sampled.

If chemical analysis indicates that a waste stream requires additional waste code designation(s), the applicability of applying the waste code designation(s) to other containers with in the stream will be addressed. This activity would not qualify as a significant discrepancy. If no correlation can be determined among the chemical analysis results, waste codes, and generating activity, the containers either will be sampled to determine the applicability of additional waste codes or all containers within a stream will be conservatively designated.

'Due to the discrete distributions, the Type 1 and Type 11 numbers may not be exact, but will be calculated to be reasonably close. 
DOE/RL-93-70, Rev. 1 $10 / 27 / 93$

\subsubsection{Screening and Segregation}

All containers selected for chemical confirmation or completion of designation will be screened and the contents will be segregated into groups using radioactive characteristics, visual inspection for obvious contamination, $\mathrm{pH}$, and low-range (1-20 ppm) benzene analyzer tubes (used to easily detect the possibility of high concentrations of diesel contamination). The screening and segregation step provides a quick determination of the types of contaminants potentially present in the waste and allows the field personnel to make sampling decisions using the criteria set forth in Section 6.0.

\subsubsection{Characterization Information Determination}

After the waste in a container has been segregated using field screening techniques, Tank Farms must determine if enough characterization information exists to adequately designate the specific waste groups. The SWAS must be consulted if Tank Farms has decided not to sample a specific group of waste to ensure no further information is needed before placing the waste back into the container. Field testing could be used to confirm knowledge, but field testing methods cannot be the sole basis for determining that a waste is not designated dangerous waste.

A waste container might not require 'full' sampling for characterization. In most cases, sampling will be performed based on the predetermined fingerprint parameters for each waste type (Section 6.0). For example, on inspection of the contents of a container, a sludge weight is observed. Based on the Tank Farms initial characterization of the material and the fact that sludge weights could only be generated from one source on the Hanford Facility, the process is complete.

\subsubsection{Laboratory and Field Analytical Criteria}

Currently, HAZCAT ${ }^{4}$ kits and other EPA-approved field testing methods and equipment are used to confirm the identity of wastes. Field analysis may be used for the following:

- Confirming whether a waste is ignitable, corrosive, or reactive.

- Confirming the presence of organic or inorganic constituents.

Field analyses are not adequate to demonstrate that a waste does not have one of the above characteristics or constituents.

If additional capabilities for field analysis are acquired, an addendum to this WAP will be submitted in accordance with the requirements of Section 1.4. The submittal must include specific criteria and application of the technology to backlog waste. 
Laboratory testing criteria are specified in Section 7.0

The acceptable error tolerance for analytical analysis is \pm 20 percent of the spike. If a laboratory analys is falls into this area, the sample $Q A / Q C$ will be assessed to determine the acceptability of the analytical result. A decision of regulatory status will be based on this assessment and the relative difference between the analytical results and the regulatory limit.

\subsubsection{Limitations on Chemical Sampling}

In keeping with ALARA, containers will not be opened for sampling if, by so doing, opening the container could expose personnel to unacceptable risks of exposure to radionuclides and/or dangerous substances.

As a rule of thumb, containers with external dose rates greater than $10 \mathrm{mrem} / \mathrm{hr}$ will not be opened. Deviations from this rule can be made by the HPT as allowed by the RWP for the job. The decision to deviate will be based on the waste type and the available information for the container. The deviation must be documented in the container field file and signed and dated by the HPT.

The IH will make the decision that a container will not be opened because of a chemical hazard. The decision must be documented in the field file and signed and dated by the IH making the decision.

If a container is chosen for random sampling and it cannot be sampled for ALARA reasons, another container will be chosen in its place.

If a container cannot be opened for ALARA reasons, a worst-case designation will be performed based on the documentation available for the container as well as the waste stream. If this determination cannot be made, Ecology will be notified and an action plan will be developed for managing the container. This deviation will be made in accordance with Section 1.4.

\subsubsection{Quality Control of Chemical Analysis}

Field analysis results are confirmed by performing SW-846 protocol laboratory testing (EPA 1986) on 10 percent of the waste samples. Quality control on laboratory analytical sampling will be performed in accordance with Section 7.0 of this WAP. 


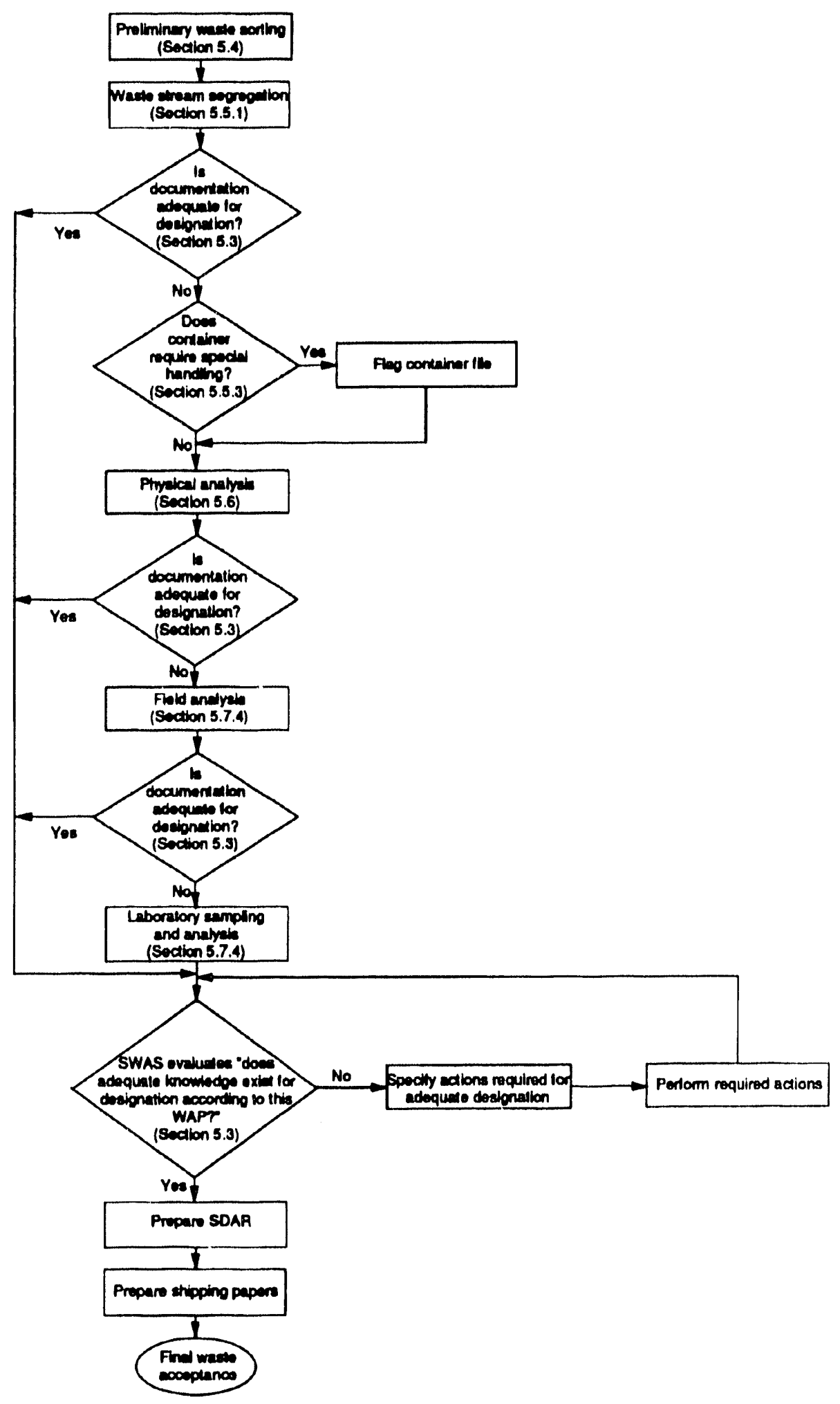

Figure 5-1. Confirmation or Completion of Designation Process. 
Table 5.1. Analytical Testing for Completion of Designation.

\begin{tabular}{|c|c|}
\hline Designation criteria & Analys is and information required \\
\hline Discarded chemical products & Process knowledge \\
\hline Dangerous waste sources & SVOA, VOA, and process knowledge \\
\hline Toxicity & $\begin{array}{l}\text { SVOA, VOA, ICP metals, anions, } \\
\text { process knowledge }\end{array}$ \\
\hline Carcinogenic & $\begin{array}{l}\text { SVOA, VOA, ICP metals, anions, } \\
\text { process knowledge }\end{array}$ \\
\hline Persistence & TOX \\
\hline Ignitability & $\begin{array}{l}\text { Flashpoint } \\
\text { Field flammability testing } \\
\text { Field oxidizer testing }\end{array}$ \\
\hline Corrosivity & $\mathrm{pH}$ \\
\hline Reactivity & $\begin{array}{l}\text { Analytical cyanide/sulfide } \\
\text { field reactivity testing }\end{array}$ \\
\hline TCLP & ICP metals, SVOA, VOA \\
\hline PCB & PCB; process knowledge \\
\hline
\end{tabular}

NOTE: TCLP will not necessarily be used as a basis for designation. A TCLP analysis could be taken on a percentage of the samples with the primary use of the results being for future treatment and disposal of the waste [i.e., to meet the Land Disposal Restriction Requirements (40 CFR 268 and WAC 173-303)].

SVOA = semivolatile organic analysis.

VOA = volatile organic analysis.

ICP = inductively coupled plasma.

TOX = total organic halogens.

$P C B=$ polychlorinated biphenyls.

TCLP = toxicity characteristics leaching procedure. 


\subsection{WASTE TYPE SPECIFIC PROTOCOL}

This section describes the specific physical/chemical protocol that will be followed for confirmation or completion of designation of each waste type.

Sampling of each waste type will be performed using the sampling procedure referenced in Section 7.0. Analytical methods will be performed in accordance with Section 7.0, Table 7.1, except in those cases in which a modified method must be used due to the radioactivity associated with the sample. Each waste type and associated streams are defined in Section 4.0.

\subsection{DEBRIS}

Debris will be processed through the physical/chemical analysis protocol by waste stream. Figure 6-1 shows the basic process in a flow diagram.

\subsubsection{Physical Analysis Protocol}

OBJECTIVE: The following is a list of objectives:

- Identify containers with a previously unidentified mixture of waste streams

- Identify containers with free liquids for proper management of the containers

- Identify containers with containerized liquids for removal and characterization of the internal container

- Identify containers with lead to document the lead in the field file and to add the D008 waste code

- Identify containers with undocumented waste for proper management of the container.

PROTOCOL: Two options are possible for these containers: $100 \%$ of the debris containers either will go through RTR (Option 1) or a combination of RTR(drummed wastes) and visual examination (boxes) (Option 2). The rational for analyzing $100 \%$ is that debris containers have the highest probability of containing waste stream mixtures that would affect the current designation and possible management of the container.

DRUMMED AND BOXED WASTE (OPTION 1): Physical screening of containerized wastes will consist of RTR. During the RTR process, Tank Farms will flag containers under the following conditions and perform the required actions. 
- Containers that contain lead or lead substances for addition of the D008 waste code (lead used as shielding is considered to be part of the container and will not be assigned the D008 code. The lead will be documented as being used as shielding.)

- Containers that contain free liquids for further characterization and management in accordance with Section 6.4 .

- Containers containing containerized liquids for removal of the liquid container and management of the liquid in accordance with Section 6.4.

- Containers that contain debris inconsistent with that which is noted in the field file will not be opened unless they exhibit attributes that are indicative of a waste stream mixture. Additional characterization could be required.

- Containers that contain small quantities of soil for the possible addition of waste codes as applicable based on the characterization of soil from that complex in accordance with Section 6.2. A low-range (1-20 ppm) benzene analyzer tube will be used to determine the applicability of the diesel fuel soil streams designation for the container.

On identifying a container that meets any of the above criteria, Tank Farms will administratively 'flag' the container for further activities. For flagged containers that might contain mixtures of waste streams, Tank Farms will consult characterization information to determine the appropriate waste codes (if any). If insufficient documentation exists to accurately determine (1) whether a container contains a mixture or (2) the identity of the streams, the container must undergo visual inspection.

Visual examination of the container will be performed to determine if the container truly has a mixture of waste streams. During visual examination, Tank Farms will inspect the waste to determine if any indications of additional waste streams exist that would require additional waste codes to be placed on the container (such as HEPAs or batteries).

Also during the visual inspection, Tank Farms will note any discrepancies between the waste description that is noted from the RTR and that identified during the inspection. Any container that (1) is noted as possibly containing other contaminants and (2) does not have characterization information for the contaminants will be flagged for chemical analysis. Analysis will be performed in accordance with the chemical analysis protocol for that waste type.

BOXED WASTE (OPTION 2): Because of the possible limitations in RTR equipment, boxes might not be screened by RTR before visual inspection. In this case, all boxes will be visually examined. During visual 
inspection, Tank Farms will sort through the boxes and flag containers under the following conditions and perform the required actions.

- Containers that contain lead or lead substances for addition of the D008 waste code (Lead used as shielding is considered to be part of the container and will not be assigned the D008 code. The lead will be documented as being used as shielding.)

- Containers that contain free liquids for further characterization and management in accordance with Section 6.4.

- Containers containing containerized liquids for removal of the liquids and management of the liquid in accordance with Section 6.4.

- Containers that contain debris inconsistent with that which is noted in the field file will not be opened unless they exhibit attributes that are indicative of a waste stream mixture. Additional characterization might be required.

- Containers that contain small quantities of soil for the possible addition of waste codes as applicable based on the characterization of soil from that complex in accordance with Section 6.2. A lowrange (1-20 ppm) benzene analyzer tube will be used to determine the applicability of the diesel fuel stream designation for the container.

On identifying a container that meets any of the above criteria, Tank Farms will administratively 'flag' the container for further activities. For flagged containers that might contain mixtures of waste streams, Tank Farms will consult characterization information to determine the appropriate waste codes (if any). If insufficient documentation exists to accurately determine (1) whether a container contains a mixture or (2) the identity of the streams, the container must undergo chemical analysis.

\subsubsection{Chemical Analysis Protocol}

OBJECTIVE: The following is a list of objectives:

- Identify containers with a previously unidentified mixture of waste streams.

- Provide characterization information for the confirmation or completion of designation for the containers.

PROTOCOL: The sample set of containers to be chemically sampled will be determined in accordance with Section 5.7.1.

A container that is flagged for chemical analysis will be emptied and segregated into the following groups using a geiger mueller counter and visual examination: 
(1) No detectable radioactivity above background and no observable chemical contamination

(2) Detectable radioactivity, but no observable chemical contamination and having a field $\mathrm{pH} \geq 5$ and $<9$

(3) Detectable radioactivity, but no observable chemical contamination and having a field $\mathrm{pH} \geq 9$ or $<5$

(4) Debris with observable oil contamination

(5) Debris with observable paint contamination

(6) Debris contaminated with other solids or liquids other than specified above.

Each group will be sampled for the analytes listed in Table 6.1.

\subsubsection{Management Protocol}

Once all analyses have been completed for a waste stream, each container will be mana'yec based on the results. Possible waste streams and designations include the following:

(1) No detectable radioactivity above background and no observable chemical contamination - For the purposes of this WAP, this waste will be managed as F-Listed due to the mixture rule and designated in accordance with Section 4.3.2 and Table 4.4.

(2) Detectable radioactivity, but no observable chemical contamination and having a field $\mathrm{pH} \geq 5$ and $<9$ - For the purposes of this WAP, this waste will be managed as F-Listed due to the mixture rule and designated in accordance with Section 4.3.2 and Table 4.4.

(3) Detectable radioactivity, but no observable chemical contamination and having a field $\mathrm{pH} \geq 9$ or $<5$ - For the purposes of this WAP, this waste will be managed as containing $\mathrm{F}$-Listed waste; additional waste codes will be added in accordance with this characterization effort if applicable. If characterization efforts indicate additional waste codes are necessary per WAC 173-303-070, Section 4.3.2 and Table 4.4 will be updated.

(4) Debris with observable oil contamination - In addition to the applicability of the F-Listed designation previously discussed, additional waste codes will be added and Section 4.3.2 and Table 4.4 will be updated based on characterization information obtained during this effort.

(5) Debris with observable paint contamination - In addition to the applicability of the F-Listed designation previously discussed, 
The HEPA filters and combination mask filters will be designated using previously obtained characterization information unless these filters are known to contain additional contaminants.

For any container that has a mixture of waste streams, the designation will be based on the designation of all waste streams. Samples will not necessarily be taken from each waste stream in the container. Analysis results from the same waste stream might be used for other containers in the waste stream.

\subsection{SOILS}

The waste type soil will be processed through the physical/chemical analysis protocols by waste stream. Figure $6-2$ shows the basic process in a flow diagram.

\subsubsection{Physical Analysis Protocol}

OBJECTIVE: The following is a list of objectives:

- Identify containers with a previously unidentified mixture of waste streams.

- Identify containers with free liquids for proper management of the containers.

- Identify containers with containerized liquids for removal and characterization of the internal container.

- Identify containers with lead to document the lead in the field file and to add the D008 waste code.

- Identify containers with undocumented waste for proper management of the container.

PROTOCOL: Soil containers will be processed through one of the two options described in this section. The first option describes an RTR process similar to the process described in the debris section. The second option describes a process using physical characteristics and visual inspection to fulfill the objectives. The rational for having two options is that RTR equipment might 
not be available that can adequately penetrate the entire waste container. The probability of soil containers with mixtures is very low based on the procedures used for contamination control and spill cleanup.

OPTION 1 (RTR): Physical screening of drummed wastes will consist of $50 \%$ of the containers being processed through RTR. During the RTR process, Tank Farms will flag containers under the following conditions and perform the required actions.

- Containers that contain lead or lead substances for addition of the D008 waste code (Lead used as shielding is considered to be part of the container and will not be assigned the D008 code. The lead will be documented as being used as shielding.)

- Containers that contain free liquids for further characterization and management in accordance with Section 6.4.

- Containers containing containerized liquids for removal of the liquids and management of the liquid in accordance with Section 6.4.

- Containers that contain waste inconsistent with that which is noted in the field file will not be opened unless the containers exhibit attributes that are indicative of a waste stream mixture.

Additional characterization might be required.

On identifying a container that meets any of the above criteria, Tank Farms will administratively ' $\mathrm{flag}$ ' the container for further activities. For flagged containers that might contain mixtures of waste streams, Tank Farms will consult characterization information to determine the appropriate waste codes (if any). If insufficient documentation exists to accurately determine (1) whether a container contains a mixture or (2) the identity of the streams, the container must undergo visual inspection.

Visual examination of the container will be performed to determine if the container truly has a mixture of waste streams. During visual examination, Tank Farms will inspect the waste to determine if any indications of additional waste streams exist that would require additional waste codes to be placed on the container (such as HEPAs or batteries).

Also during the visual inspection, Tank Farms will note any discrepancies between the waste description that is noted from the RTR and that identified during the inspection. Any container that (1) is noted as possibly containing other contaminants and (2) does not have characterization information for the contaminants will be flagged for chemical analysis. Analysis will be performed in accordance with the chemical analysis protocol for that waste type.

OPTION 2 (Physical Measurements): Because of the possible limitations in RTR equipment, soil containers might not be able to be adequately 
screened using RTR. In this case, $100 \%$ of the soil containers will be screened using physical characteristics. Each container's dose rate and weight will be measured and compared to information that appears in the field file. Tank Farms will identify the following conditions:

- Containers that do not meet the dose rate comparison criteria specified in Section 5.6.1.1.

- Containers that do not meet the weight comparison criteria specified in Section 5.6.1.1.

On identifying a container that meets any of the above criteria, Tank Farms will administratively 'flag' the container for further activities. For flagged containers that might contain mixtures of waste streams, Tank Farms will consult characterization information to determine the appropriate waste codes (if any). If insufficient documentation exists to accurately determine (1) whether a container contains a mixture or (2) the identity of the streams, the container must undergo chemical analysis.

Ten percent of the soil containers must be opened and visually verified as a quality control check of the physical characteristics. The containers chosen for visual verification will be containers other than those that have been flagged based on weight and dose rate measurements. During visual inspection, Tank Farms will identify the following conditions:

- Containers that contain lead or lead substances for addition of the D008 waste code (Lead used as shielding is considered to be part of the container and will not be assigned the D008 code. The lead will be documented as being used as shielding.)

- Containers that contain free liquids for further characterization and management in accordance with Section 6.4.

- Containers containing containerized liquids for removal of the liquids and management of the liquid in accordance with Section 6.4.

- Containers that contain waste inconsistent with that which is noted in the field file will not be opened unless the containers exhibit attributes indicative of a waste stream mixture. Additional characterization might be required.

If more than $10 \%$ of the containers chosen for quality control are identified as having significant discrepancies, another $10 \%$ of the soil containers from the same waste stream will be inspected visually. This process will be repeated until the number of containers (chosen for quality control that are identified through visual inspection as having significant discrepancies) is less than $10 \%$ of the total containers that have been checked for that waste stream or all containers have been visually inspected. After a minimum of $20 \%$ of the containers has been opened, instead of continuing to open containers, a conservative 
4

designation could be applied to all remaining containers in the waste stream.

\subsubsection{Chemical Analysis Protocol}

OBJECTIVE: The following is a list of objectives:

- Identify containers with a previously unidentified mixture of waste streams

- Provide characterization information for the confirmation or completion of designation for the containers.

PROTOCOL: The sample set of containers to be chemically sampled will be determined in accordance with Section 5.7.1.

Those containers that are flagged for chemical sampling will be visually examined and a determination as to possible contaminants (other than from the mixture rule) will be made based on the following groups:

(1) No observable chemical contamination and having a field $\mathrm{pH} \geq 5$ and $<9$

(2) No observable chemical contamination and having a field $\mathrm{pH} \geq 9$ or $<5$

(3) Soil with observable oil contamination

(4) Soil with observable paint contamination

(5) Soil contaminated with other possible solids or liquids not specified above.

Each group will be sampled for the analytes listed in Table 6.2. Although the analytical requirements will not be different between F-Listed soil and soil containing diesel fuel spills, Tank Farms must document any indications of soils that might contain diesel fuel spills and apply any additional waste codes.

\subsubsection{Management Protocol}

Once all analyses has been completed for a waste stream, each container will be managed based on the results. Possible waste streams and designations include:

(1) No observable chemical contamination and having a field $\mathrm{pH} \geq 5$ and $<9$ - For the purposes of this WAP, this waste will be managed as F-Listed due to the contained in rule and designated in accordance with Section 4.3.2 and Table 4.4. 
(2) No observable chemical contamination and having a field $\mathrm{pH} \geq 9$ or $<5$ - For the purposes of this WAP, this waste will be managed as containing F-Listed waste. Additional waste codes wi11 be added in accordance with this characterization effort if applicable. If characterization efforts indicate additional waste codes, Section 4.3 .2 and Table 4.4 will be updated.

(3) Soil with observable oil contamination - In addition to the applicability of the F-Listed designation already discussed, additional waste codes will be added and Section 4.3.2 and Table 4.4 will be updated based on characterization information obtained during this effort.

(4) Soil with observable paint contamination - In addition to the applicability of the F-Listed designation already discussed, additional waste codes will be added and Section 4.3 .2 and Table 4.4 will be updated based on characterization information obtained during this effort.

(5) Soil contaminated with other possible solids or liquids (this will be addressed in the field). - In addition to the applicability of the F-Listed designation previously discussed, additional waste codes will be added and Section 4.3 .2 and Table 4.4 will be updated based on characterization information obtained during this effort.

For any container that has a mixture of waste streams, the designation will be based on the designation of all waste streams. Samples will not necessarily be taken from each waste stream in the container. Analysis results from the same waste stream could be used for other containers in the waste stream.

\subsection{Low-Level Waste}

The waste type LLW will be processed through the physical/chemical analysis protocols by waste stream. Figure 6-3 shows the basic process in a flow diagram.

\subsubsection{Physical Analysis Protocol}

OBJECTIVE: The following is a list of objectives:

- Identify containers with a previously unidentified mixture of waste streams.

- Identify containers with free liquids for proper management of the containers.

- Identify containers with containerized liquids for removal and characterization of the internal container. 
- Identify containers with lead to document the lead in the field file and to add the D008 waste code.

- Identify containers with undocumented waste for proper management of the container.

PROTOCOL: $100 \%$ of the LLW containers will either go through RTR (drummed wastes) or visual examination (boxes). The rational for performing this activity is that LLW containers have the highest probability of containing waste stream mixtures that could affect the current designation and possible management of the container.

DRUMMED AND BOXED (OPTION 1) WASTE: Physical screening of containerized wastes will consist of RTR. During the RTR process, Tank Farms will flag containers under the following conditions and perform the required actions.

- Containers that contain lead or lead substances for addition of the D008 waste code (Lead used as shielding is considered to be part of the container and will not be assigned the D008 code. The lead will be documented as being used as shielding.)

- Containers that contain free liquids for further characterization and management in accordance with Section 6.4.

- Containers with containerized liquids for removal of the liquids and management of the liquid in accordance with Section 6.4.

- Containers that contain debris inconsistent with that which is noted in the field file will not be opened unless the containers exhibit attributes that are indicative of a waste stream mixture.

Additional characterization might be required.

- Containers that contain small quantities of soil for the possible addition of waste codes as applicable based on the characterization of soil from that complex in accordance with Section 6.2. A lowrange (1-20 ppm) benzene analyzer tube will be used to determine the applicability of the diesel fuel soil stream designation for the container.

On identifying a container that meets any of the above criteria, Tank Farms will administratively 'flag' the containers for further activities. For flagged containers that might contain mixtures of waste streams, Tank Farms will consult characterization information to determine the appropriate waste codes (if any). If insufficient documentation exists to accurately determine (1) whether a container contains a mixture or (2) the identity of the streams, the container must undergo visual inspection.

Visual examination of the container will be performed to determine if the container truly has a mixture of waste streams. During visual 
examination, Tank Farms will inspect the waste to determine if any indications of additional waste streams exist that would require additional waste codes to be placed on the container (such as HEPAs or batteries).

Also during the visual inspection, Tank Farms will note any discrepancies between the waste description that is noted from the RTR and that identified during the inspection. Any container that (1) is noted as possibly containing other contaminants and (2) does not have characterization information for the contaminants will be flagged for chemical analysis. Analysis will be performed in accordance with the chemical analysis protocol for that waste type.

BOXED WASTE (OPTION 2): Because of the possible limitations in RTR equipment, boxes might not be screened by RTR before visual inspection. In this case, all boxes will be visually examined. During visual inspection Tank Farms will sort through the boxes and flag containers under the following conditions and perform the required actions.

- Containers that contain lead or lead substances for addition of the D008 waste code (Lead used as shielding is considered to be part of the container and will not be assigned the D008 code. The lead will be documented as being used as shielding.)

- Containers that contain free liquids for further characterization and management in accordance with Section 6.4 .

- Containers containing containerized liquids for removal of the liquids and management of the liquid in accordance with Section 6.4.

- Containers that contain debris inconsistent with that which is noted in the field file will not be opened unless the containers exhibit attributes that are indicative of a waste stream mixture. Additional characterization might be required.

- Containers that contain small quantities of soil for the possible addition of waste codes as applicable based on the characterization of soil from that complex in accordance with Section 6.2. A lowrange (1-20 ppm) benzene analyzer tube will be used to determine the applicability of the diesel fuel soil stream designation for the container.

On identifying a container that meets any of the above criteria, Tank Farms will administratively 'flag' the container for further activities. For flagged containers that might contain mixtures of waste streams, Tank Farms will consult characterization information to determine the appropriate waste codes (if any). If insufficient documentation exists to accurately determine (1) whether a container contains a mixture or (2) the identity of the streams, the container must undergo chemical analysis. 


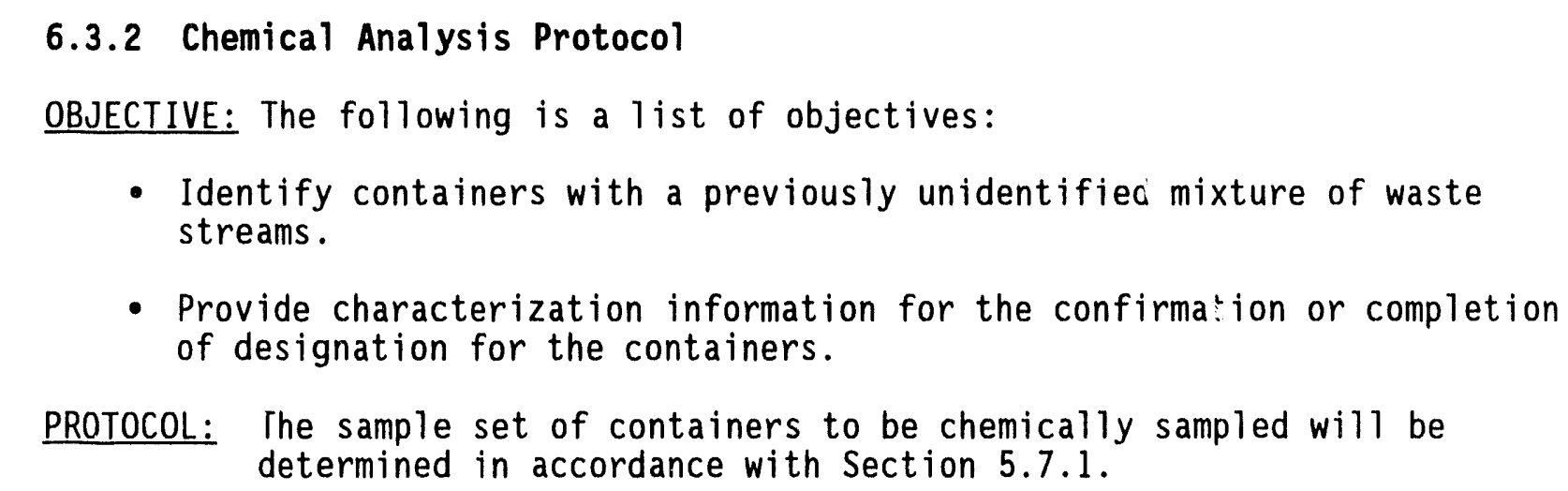

- Identify containers with a previously unidentifiec mixture of waste streams.

- Provide characterization information for the confirmation or completion of designation for the containers.

PROTOCOL: The sample set of containers to be chemically sampled will be determined in accordance with Section 5.7.1.

A container that is flagged for chemical analysis will be emptied and segregated into the following groups using a geiger mueller counter and visual examination:

(1) No detectable radioactivity above background and no observable chemical contamination

(2) Detectable radioactivity, but no observable chemical contamination and having a field $\mathrm{pH} \geq 5$ and $<9$

(3) Detectable radioactivity, but no observable chemical contamination and having a field $\mathrm{pH} \geq 9$ or $<5$

(4) Debris with observable oil contamination

(5) Debris with observable paint contamination

(6) Debris contaminated with other solids or liquids other than specified above.

Each group will be sampled for the analytes listed in Table 6.3.

\subsubsection{Management Protocol}

Once all analyses has been completed for a waste stream, each container will be managed based on the results. Possible waste streams and designations include:

(1) No detectable radioactivity above background and no observable chemical contamination - For the purposes of this WAP, this waste will be managed as F-Listed due to the mixture rule and designated in accordance with Section 4.3.2 and Table 4.4.

(2) Detectable radioactivity, but no observable chemical contamination and having a field $\mathrm{pH} \geq 5$ and $<9$ - For the purposes of this WAP, this waste will be managed as F-Listed due to the mixture rule and designated in accordance with Section 4.3.2 and Table 4.4. 
(3)

Detectable radioactivity, but no observable chemical contamination and having a field $\mathrm{pH} \geq 9$ or $<5$ - For the purposes of this WAP, this waste will be managed as containing F-Listed waste, additional waste codes will be added in accordance with this characterization effort if applicable. If characterization efforts indicate additional waste codes, Section 4.3.2 and Table 4.4 will be updated.

(4) Debris with observable oil contamination - In addition to the applicability of the F-Listed designation previously discussed, additional waste codes will be added and Section 4.3.2 and Table 4.4 will be updated based on characterization information obtained during this effort.

(5) Debris with observable paint contamination - In addition to the applicability of the F-Listed designation previously discussed, additional waste codes will be added and Section 4.3 .2 and Table 4.4 will be updated based on characterization information obtained during this effort.

(6) Debris Contaminated with Other Solids or Liquids - In addition to the applicability of the F-Listed designation previously discussed, additional waste codes will be added and Section 4.3.2 and Table 4.4 will be updated based on characterization information obtained during this effort.

The HEPA filters and combination mask filters will be designated using previously obtained characterization information unless these filters are known to contain additional contaminants.

For any container that has a mixture of waste streams, the designation will be based on the designation of all waste streams. Samples will not necessarily be taken from each waste stream in the container. Analysis results from the same waste stream could be used for other containers in the waste stream.

\subsection{LIQUIDS}

The waste type liquids will be characterized in accordance with the protocol described in this section. Figure 6-4 shows the basic process in a flow diagram.

\subsubsection{Uncontainerized Free Liquids}

The waste type Uncontainerized Free Liquids will be processed in accordance with this section. Uncontainerized free liquids might result from the physical screening processes of LLW, soil, and debris. Uncontainerized free liquids are not expected or allowed in any of the backlog waste except asbestos-containing wastes because of packaging protocols. Containers identified as containing uncontainerized liquids will be managed on a case-bycase basis. 
D0E/RL-93-70, Rev. 1

$10 / 27 / 93$

OBJECTIVE: The following is a list of objectives.

- Identify containers with uncontainerized free liquids that also contain asbestos. Verify that the liquid is water.

- Characterize the liquid from containers with uncontainerized free liquids that do not contain asbestos.

- If possible, determine the type of liquid found in the container using field analysis to minimize laboratory analysis.

PROTOCOL: Uncontainerized liquids will be handled in the following manner:

The first 20 asbestos containers (regardless of waste streams) identified as containing uncontainerized free liquids based on physical protocols and information found in the field files will be opened. The uncontainerized free liquids will be confirmed as water by performing all applicable field testing required by the HAZCAT manual. If field

sampling of all 20 containers reveals no inconsistencies (i.e., all free liquids are water), no further containers that have documented information on the presence of asbestos and the RTR identification of uncontainerized free liquids will be opened for further characterization of the free liquids. All containers that fall into this category will be managed under the appropriate section with the exception that the waste will be overpacked and sufficient absorbent added to absorb twice the amount of free liquids will be placed in the annulus.

Containers that have been identified through RTR to have free 1 iquids and do not have associated documentation that indicates the presence of asbestos in the container must be visually inspected. During visual inspection, Tank Farms will determine if the free liquids are a result of asbestos packaging or due to other factors. Containers identified as containing asbestos will be managed as described in the previous paragraph.

Containers, which are identified as containing uncontainerized free liquids but also do not contain asbestos, will be characterized on a case-by-case basis in accordance with Table 6.4. Tank Farms will attempt to determine the type of liquid based on physical and field sampling to minimize laboratory analytical analysis.

\subsubsection{Containerized Liquids}

The waste type Containerized Liquids will be processed in accordance with this section. Containerized liquids might be detected from the physical screening processes of LLW, soil, and debris. Containers identified as containing containerized liquids will be managed on a case-by-case basis. 
OBJECTIVE: The following is a list of objectives.

- Identify containers with containerized free liquids.

- Gather all applicable information (labeling, process knowledge, MSDS) during and after visual inspection of the container.

- Confirm the applicability of the information collected by performing confirmatory sampling if there is no other mechanism to ensure the container does not contain something other than that labeled.

- Perform chemical confirmation or completion of designation in accordance with Section 5.7.1.

PROTOCOL: All containers identified as containing containerized liquids will be opened, the containerized liquids will be removed, and the original container will be processed through the protocol for the waste type.

The removed container of free liquid will be managed on a case-by-case basis. Tank Farms will gather all applicable information (1abeling, process knowledge, MSDS) during and after visual inspection of the container. Information obtained will be confirmed through field analysis, if there is no other mechanism to ensure the container does not contain something other than that documented. Perform chemical confirmation or completion of designation in accordance with Section 5.7.1 and Table 6.4.

\subsubsection{Management Protocol}

All liquids will be managed on a case-by-case basis in accordance with WAC 173-303 and the current revision of waste acceptance criteria as characterization data requires (WHC 1991).

\subsection{SPECIAL CASE}

The waste type Special Case will be managed on a case-by-case basis and characterized in accordance with WAC 173-303 and waste acceptance criteria (WHC 1991). 


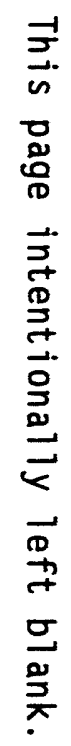

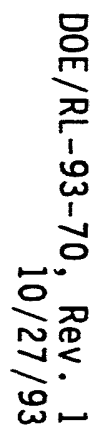

O O 
DOE/RL-93-70, Rev. 1

$10 / 27 / 93$

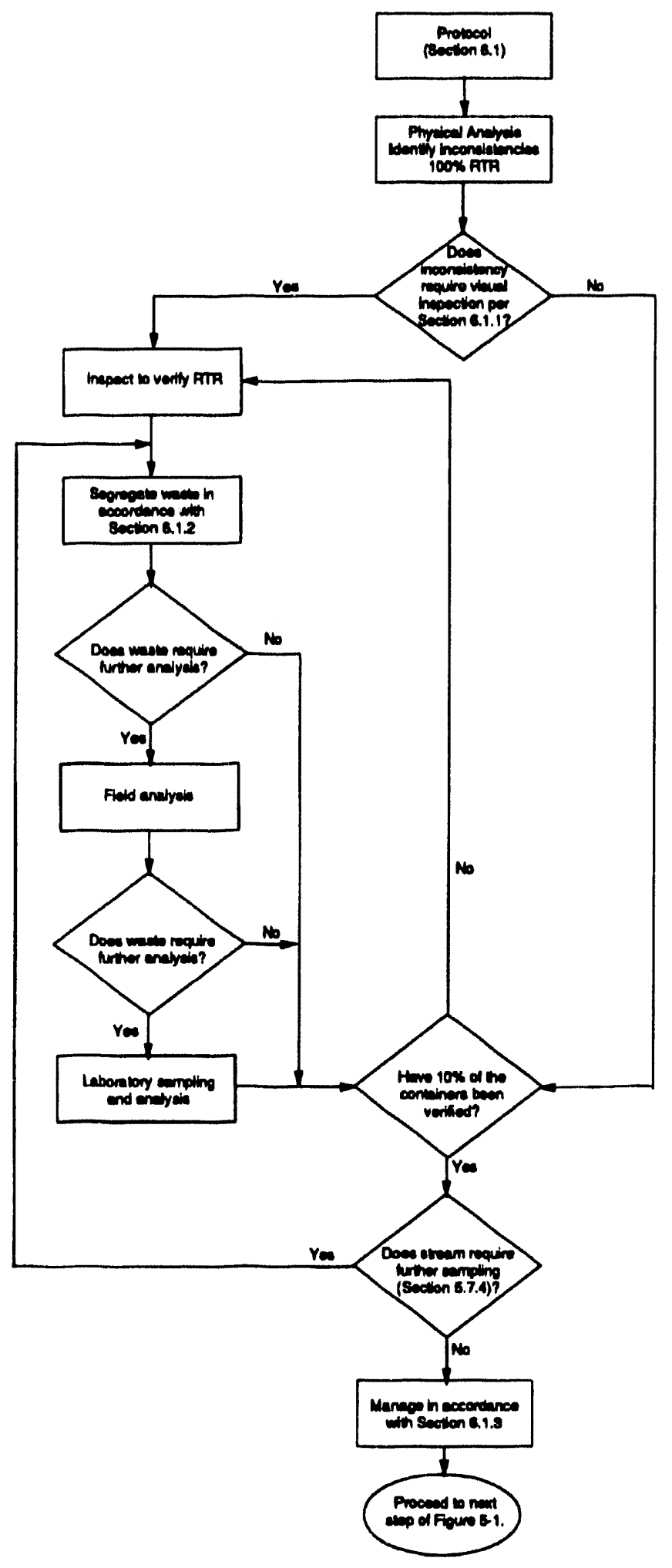

Figure 6-1. Physical and Chemical Analysis Process for Drums and Boxes (Option 1) Containing Debris. (sheet 1 of 2) 


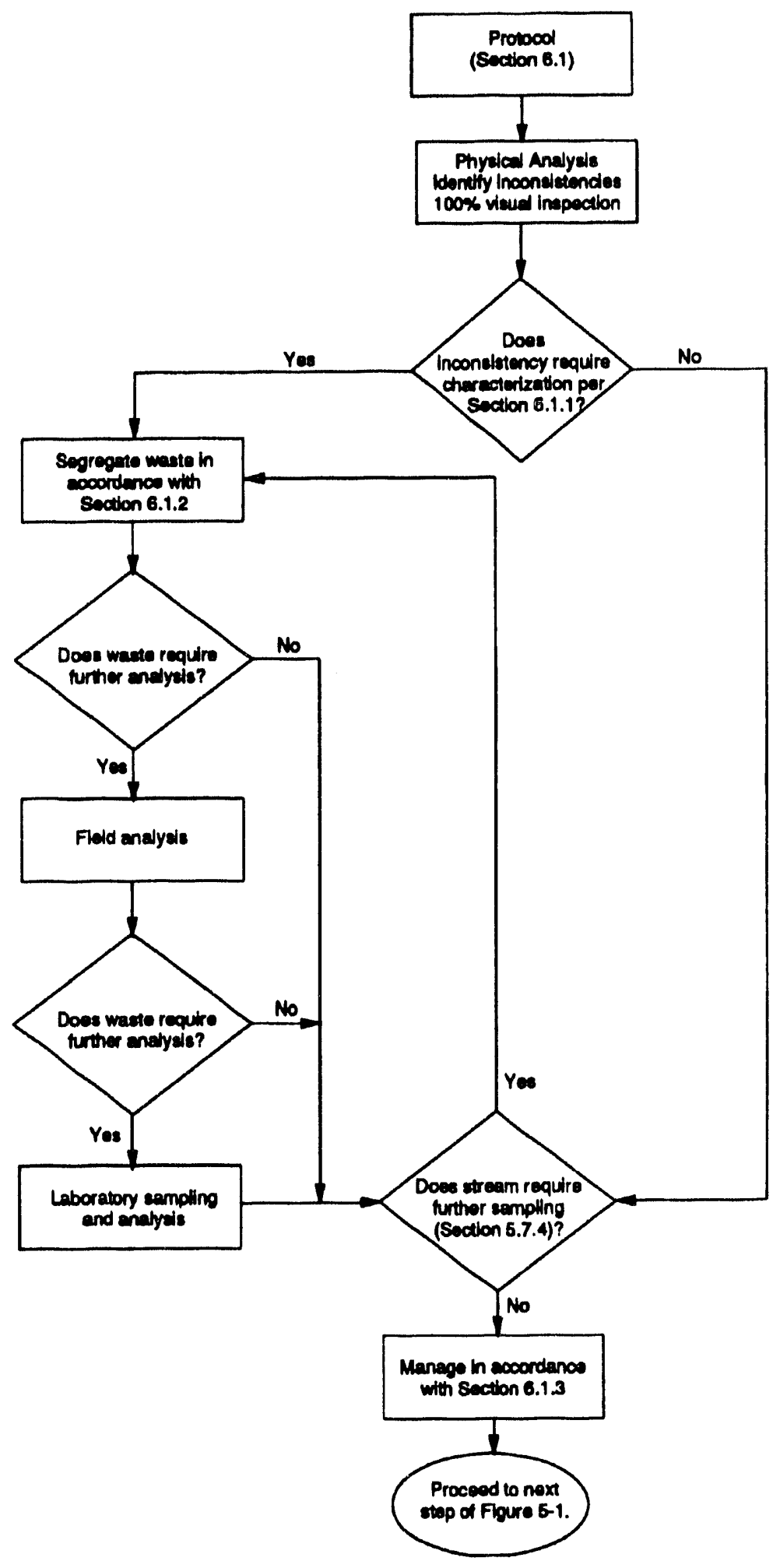

Figure 6-1. Physical and Chemical Analysis Process for Boxes (Option 2) Containing Debris. (sheet 2 of 2) 
DOE/RL-93-70, Rev. 1

$10 / 27 / 93$

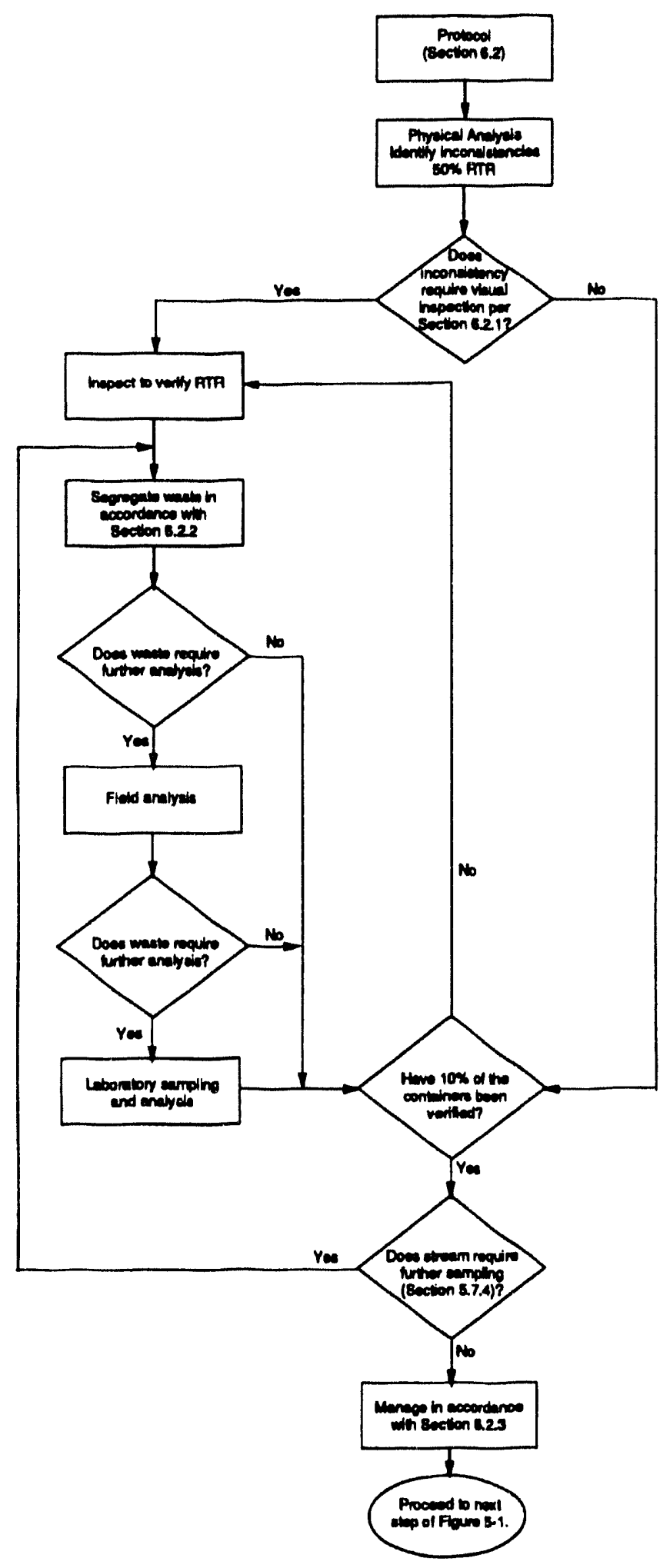

Figure 6-2. Physical and Chemical Analysis Process for Soils Option 1. (sheet 1 of 2) 


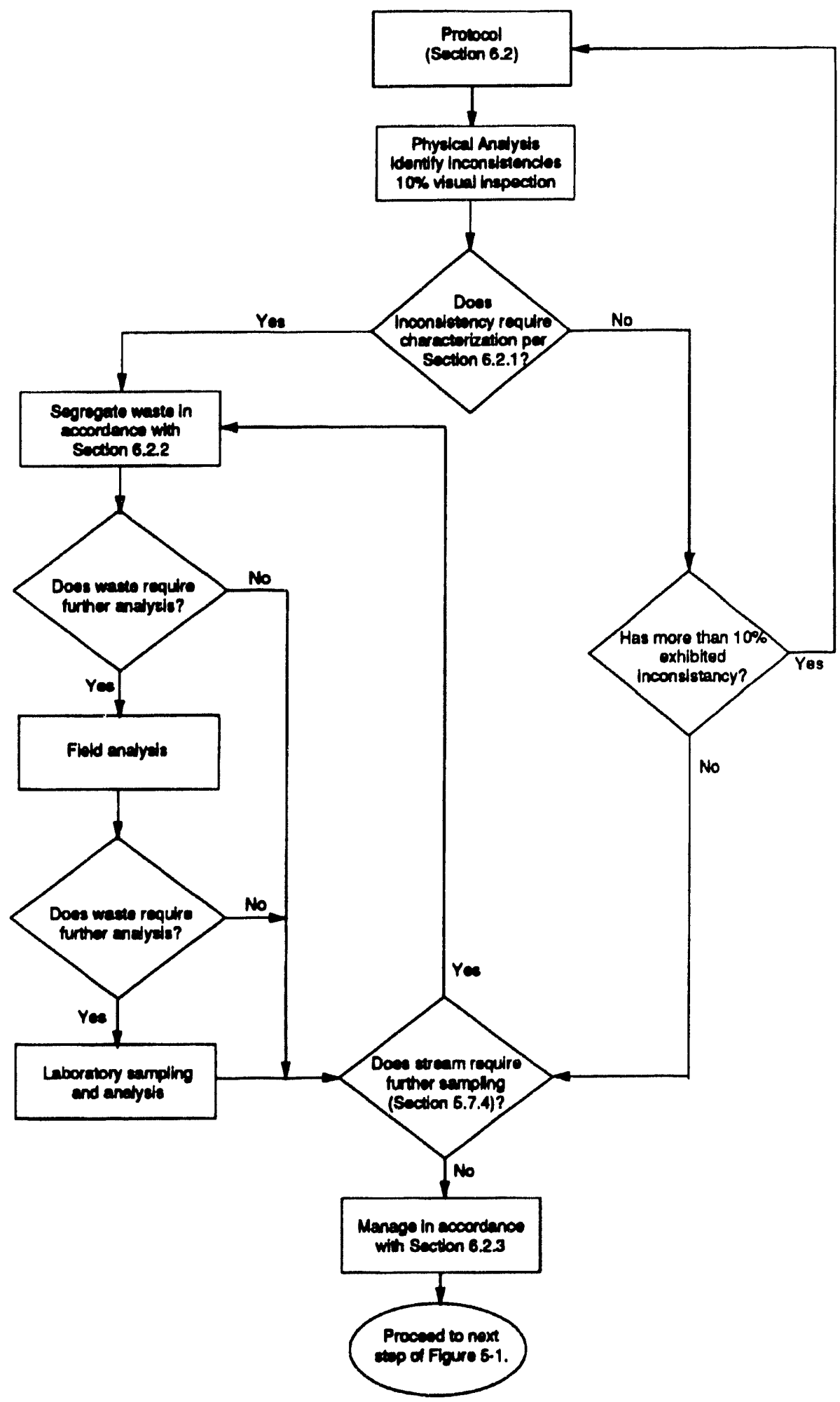

Figure 6-2. Physical and Chemical Analysis Process for Soils Option 2. (sheet 2 of 2 ) 
$\mathrm{DOE} / \mathrm{RL}-93-70$, Rev. 1

$10 / 27 / 93$

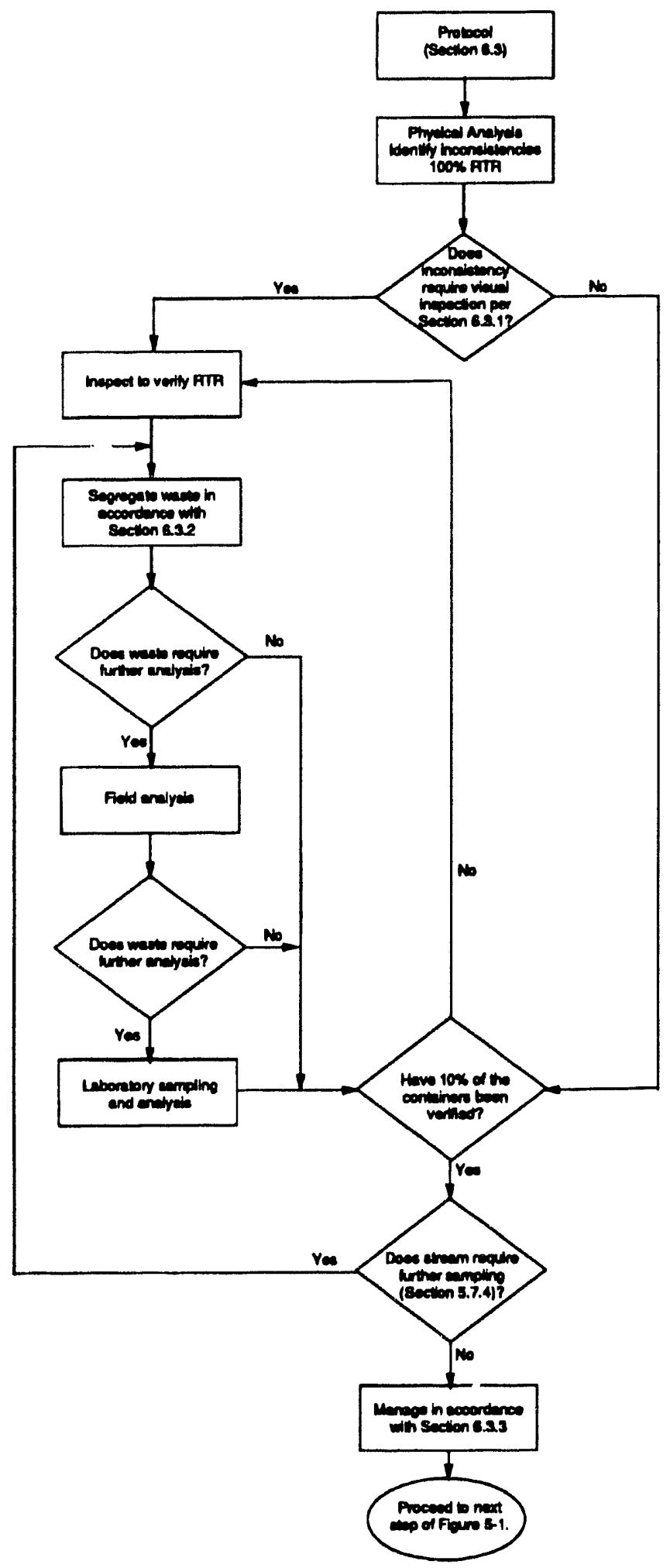

Figure 6-3. Physical and Chemical Analysis Process for Drums and Boxes (Option 1) of Low-Level Waste. (sheet 1 of 2) 
DOE/RL-93-70, Rev. 1

$10 / 27 / 93$

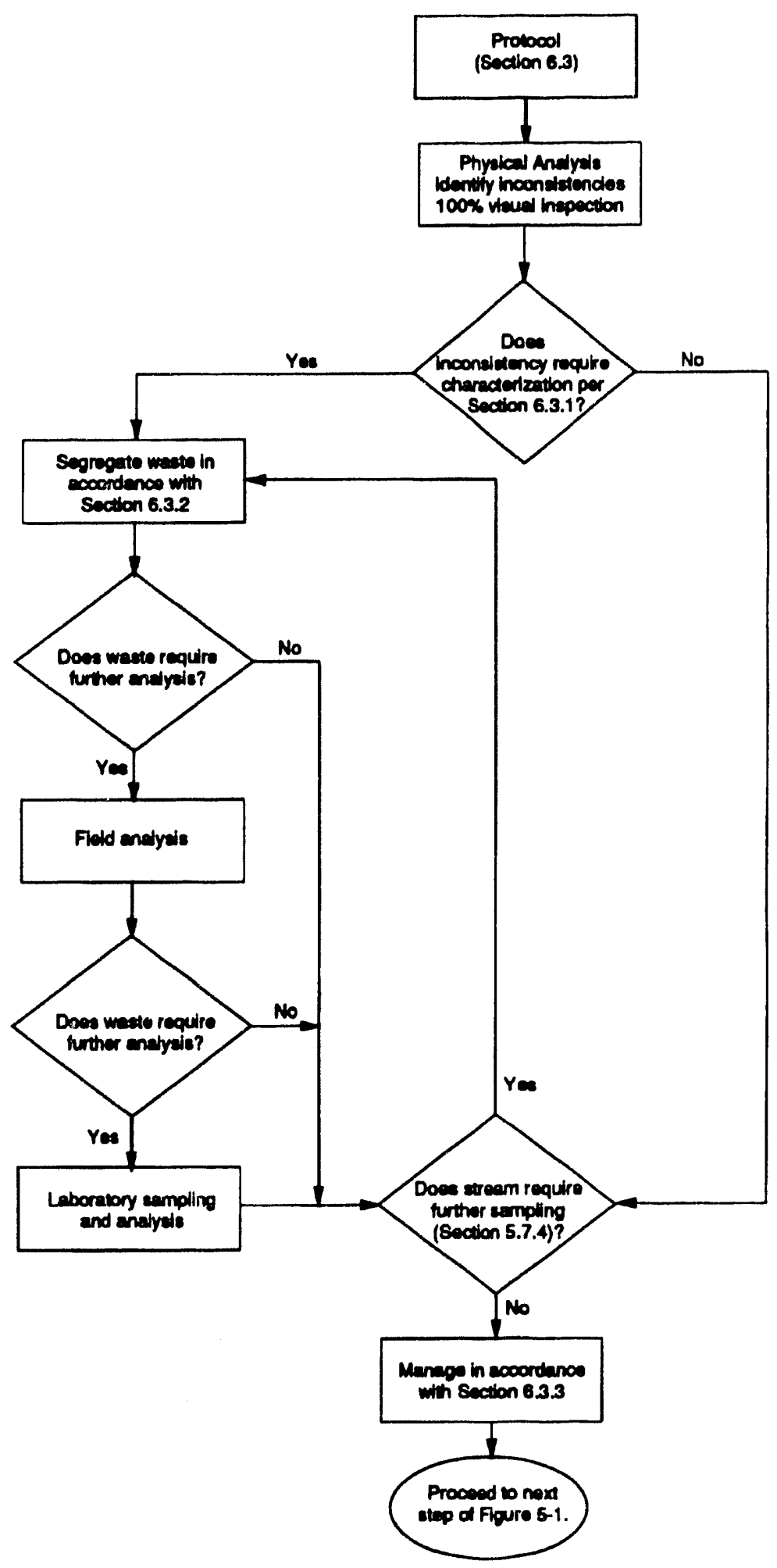

Figure 6-3. Physical and Chemical Analysis Process for Boxes (Option 2) of Low-Level Waste. (sheet 2 of 2) 


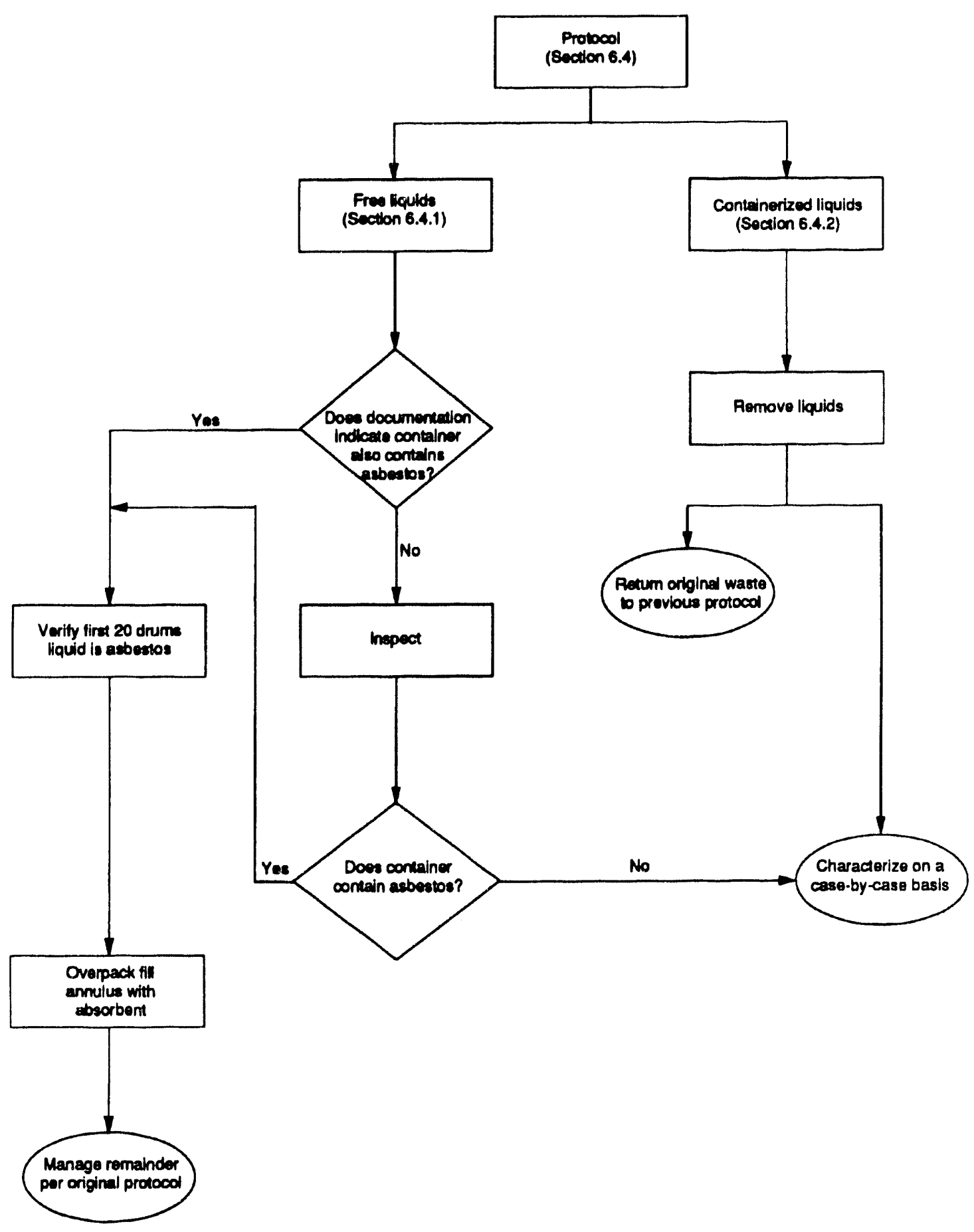

Figure 6-4. Physical and Chemical Analysis Process for Liquids. 
Table 6.1. Analytical Methods for Debris.

\begin{tabular}{|c|c|c|}
\hline CRITERIA & $\begin{array}{l}\text { POSSIBLE } \\
\text { CONTAMINANTS } \\
\end{array}$ & ANALYTICAL METHODS (WAC 173-303-110) \\
\hline $\begin{array}{l}\text { (1) No detectable radioactivity } \\
\text { above background and no } \\
\text { observable chemical contamination }\end{array}$ & $\begin{array}{l}\text { F-Listed solvents; } 1,1,1-\text { trichloroethane } \\
\text { (F001), methylene chiloride (F002), } \\
\text { acetone and methyl isobutyl ketone } \\
\text { (F003), cresols and cresyl ic acid (F004), } \\
\text { methyi ethyl ketone (F005) }\end{array}$ & $\begin{array}{l}\text { No testing is required because concentrations would not require a } \\
\text { change in designation ( } F-L \text { isted waste based on the mixture rule). }\end{array}$ \\
\hline $\begin{array}{l}\text { (2) Detectable radioactivity, but } \\
\text { no observable chemical } \\
\text { contamination and having a field } \\
\text { pH } \geq 5 \text { and }<9\end{array}$ & $\begin{array}{l}\text { - Listed solvents; } 1,1,1-\text { trichloroethane } \\
\text { (F001), methylene chloride (FO02), } \\
\text { acetone and methyl isobutyl ketone } \\
\text { (F003), cresols and cresylic acid (F004), } \\
\text { methyl ethyl ketone (FO05) }\end{array}$ & $\begin{array}{l}\text { No testing is required because concentrations would not require a } \\
\text { change in designation ( } F-\text { Listed waste based on the mixture rule). }\end{array}$ \\
\hline $\begin{array}{l}\text { (3) Radioactively } \\
\text { Contaminated } \\
\text { debris and having a } \\
\text { field } \mathrm{pH} \geq 9 \text { or }<5\end{array}$ & $\begin{array}{l}\text { F-Listed solvents; 1,1,1-trichloroethane } \\
\text { (F001), methylene chioride (F002), } \\
\text { acetone and methyl isobutyl ketone } \\
\text { (F003), cresols and cresylic acid (F004), } \\
\text { methyl ethyl ketone (F005) } \\
\text { Possible sulfide, cyanide contamination } \\
\text { Possible heavy metal contamination }\end{array}$ & $\begin{array}{l}\text { SVOA (Method 8270), VOA (Method 8240) } \\
\text { Cyanide (Method } 9010 \text { or } 9012 \text { )/Sulfide (Method 9030) } \\
\text { React ivity Testing } \\
\text { ICP Metals (Method 6010), Arsenic (Method 7060), Lead (Method 7420) }\end{array}$ \\
\hline $\begin{array}{l}\text { (4) Debris with observable oil } \\
\text { contamination }\end{array}$ & $\begin{array}{l}\text { Possible heavy metal contamination } \\
\text { Possible halogenated hydrocarbon } \\
\text { contamination } \\
\text { Possible PCB contamination }\end{array}$ & $\begin{array}{l}\text { ICP Metals (Method 6010), Arsenic (Method 7060), Lead (Method 7420) } \\
\text { TOX (Method 9020M) } \\
\text { PCB (Method 8080) }\end{array}$ \\
\hline $\begin{array}{l}\text { (5) Debris with observable paint } \\
\text { contamination }\end{array}$ & $\begin{array}{l}\text { Possible solvent contamination } \\
\text { Possible heavy metal contamination; } \\
\text { Lead, Chromium, Mercury }\end{array}$ & $\begin{array}{l}\text { SVOA (Method 8270), VOA (Method 8240) } \\
\text { ICP Metals (Method 6010), Arsenic (Method 7060), Lead (Method } \\
7420 \text { ), Mercury (Method 7471) }\end{array}$ \\
\hline $\begin{array}{l}\text { (6) Debris Contaminated with } \\
\text { Other Sol ids or Liquids, not } \\
\text { otherwise specified. }\end{array}$ & $\begin{array}{l}\text { Possible solvent contamination } \\
\text { Possible sulfide, cyanide contamination } \\
\text { Possible heavy metal contamination } \\
\text { Possible halogenated hydrocarbon } \\
\text { contamination } \\
\text { Possible PCB contamination } \\
\text { Possible acid contamination }\end{array}$ & $\begin{array}{l}\text { SVOA (Method } 8270 \text { ), VOA (Method } 8240 \text { ) } \\
\text { Cyanide (Method } 9010 \text { or 9012)/Sulfide (Method 9030) } \\
\text { React ivity Testing } \\
\text { ICP Metals (Method 6010), Arsenic (Method 7060), Lead } \\
\text { (Method 7420) } \\
\text { TOX (Method 9020M) } \\
\text { PCB (Method 8080) } \\
\text { Anions (including nitrates and nitrites), (Methods EPA-600 } \\
300.0,353.1,353.2 \text {, and 353.3) } \\
\text { Washington State pH }\end{array}$ \\
\hline
\end{tabular}

931027.1618 
Table 6.2. Analytical Methods for Soil.

\begin{tabular}{|c|c|c|}
\hline CRITERIA & $\begin{array}{c}\text { POSSIBLE } \\
\text { CONTAMINANTS }\end{array}$ & ANALYTICAL METHODS (WAC 173-303-110) \\
\hline $\begin{array}{l}\text { (1) No detectable radioactivity } \\
\text { above background and no } \\
\text { observable chemical contamination } \\
\text { and a } \mathrm{pH} \geq 5 \text { and }<9\end{array}$ & $\begin{array}{l}\text { F-Listed solvents; } 1,1,1-\text { trichloroethane } \\
\text { (F001), methylene chloride (F002), } \\
\text { acetone and methyl isobutyl ketone } \\
\text { (F003), cresols and cresylic acid (F004), } \\
\text { methyl ethyl ketone (F005) }\end{array}$ & $\begin{array}{l}\text { No testing is required due to the fact that concentrations would } \\
\text { not be require a change in designation ( } F-L \text { Listed waste based on the } \\
\text { contained in rule). }\end{array}$ \\
\hline $\begin{array}{l}\text { (2) No observable or measured } \\
\text { chemical contamination and having } \\
\text { a field pH } \geq 9 \text { or }<5\end{array}$ & $\begin{array}{l}\text { F-Listed solvents; } 1,1,1 \text {-trichloroethane } \\
\text { (F001), methylene chioride (F002), } \\
\text { acetone and methyl isobutyl ketone } \\
\text { (F003), cresols and cresylic acid (F004), } \\
\text { methyl ethyl ketone (F005) } \\
\text { Possible sulfide, cyanide contamination } \\
\text { Possible heavy metal contamination }\end{array}$ & $\begin{array}{l}\text { SVOA (Method } 8270 \text { ), VOA (Method } 8240 \text { ) } \\
\text { Cyanide (Method } 9010 \text { or } 9012 \text { )/Sulfide (Method 9030) } \\
\text { Reactivity Testing } \\
\text { ICP Metals (Method 6010), Arsenic (Method 7060), Lead (Method } \\
7420 \text { ) }\end{array}$ \\
\hline $\begin{array}{l}\text { (3) Soil with observable oil } \\
\text { contamination }\end{array}$ & $\begin{array}{l}\text { Possible heavy metal contamination } \\
\text { Possible halogenated hydrocarbon } \\
\text { contamination } \\
\text { Possible PCB contamination }\end{array}$ & $\begin{array}{l}\text { ICP Metals (Method 6010), Arsenic (Method 7060), Lead } \\
\text { (Method 7420) } \\
\text { TOX (Method 9020M) } \\
\text { PCB (Method 8080) }\end{array}$ \\
\hline $\begin{array}{l}\text { (4) Soil with observable paint } \\
\text { contamination }\end{array}$ & $\begin{array}{l}\text { Possible solvent contamination } \\
\text { Possible heavy metal contamination; } \\
\text { Lead, Chromium, Mercury }\end{array}$ & $\begin{array}{l}\text { SVOA (Method 8270), VOA (Method 8240) } \\
\text { ICP Metals (Method 6010), Arsenic (Method 7060), Lead } \\
\text { (Method 7420), Mercury (Method 7471) }\end{array}$ \\
\hline $\begin{array}{l}\text { (5) Soil contaminated with } \\
\text { other possible solids or liquids }\end{array}$ & $\begin{array}{l}\text { Possible solvent contamination } \\
\text { Possible sulfide, cyanide contamination } \\
\text { Possible heavy metal contamination } \\
\text { Possible halogenated hydrocarbon } \\
\text { contamination } \\
\text { Possible PCB contamination } \\
\text { Possible acid contamination, based on } \\
\text { field pH }\end{array}$ & $\begin{array}{l}\text { SVOA (Method } 8270 \text { ), VOA (Method } 8240 \text { ) } \\
\text { Cyanide (Method } 9010 \text { or } 9012 \text { )/Sulfide (Method 9030) } \\
\text { React ivity Testing } \\
\text { ICP Metals (Method 6010), Arsenic (Method 7060), Lead } \\
\text { (Method 7420) } \\
\text { TOX (Method 9020M) } \\
\text { PCB (Method 8080) } \\
\text { Anions (including nitrates and nitrites), (Methods EPA-600 } \\
300.0,353.1,353.2 \text {, and 353.3) } \\
\text { Washington State } \mathrm{pH}\end{array}$ \\
\hline
\end{tabular}


Table 6.3. Analytical Methods for Low-Level Waste.

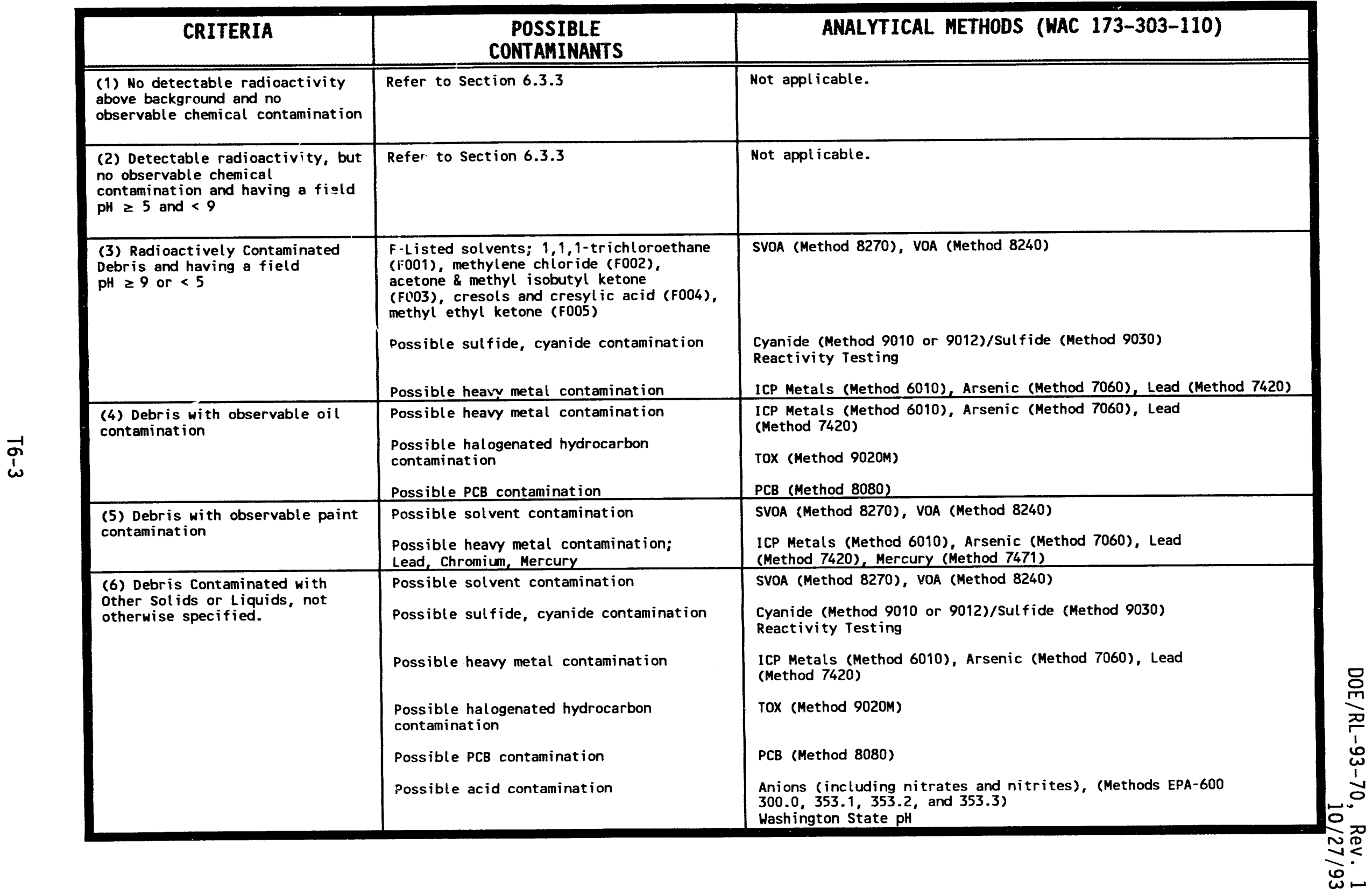


Table 6.4. Analytical Methods for Liquids.

\begin{tabular}{|c|c|c|}
\hline CRITERIA & $\begin{array}{c}\text { POSSIBLE } \\
\text { CONTAMINANTS }\end{array}$ & ANALYTICAL METHODS (WAC 173-303-110) \\
\hline oil & $\begin{array}{l}\text { Possible heavy metal contamination } \\
\text { Possible halogenated hydrocarbon } \\
\text { contamination } \\
\text { Possible PCB contamination } \\
\text { Possibly ignitable }\end{array}$ & $\begin{array}{l}\text { ICP Metals (Method 6010), Arsenic (Method 7060), Lead } \\
\text { (Method 7420) } \\
\text { TOX (Method 9020M) } \\
\text { PCB (Method 8080) } \\
\text { Flashpoint (Method 1010) }\end{array}$ \\
\hline Paint (Oil Based) & $\begin{array}{l}\text { Possible solvent contamination } \\
\text { Possible heavy metal contamination; } \\
\text { Lead, Chromium, Mercury } \\
\text { Possibly ignitable }\end{array}$ & $\begin{array}{l}\text { SVOA (Method 8270), VOA (Method 8240) } \\
\text { ICP Metals (Method 6010), Arsenic (Method 7060), Lead } \\
\text { (Method 7420), Mercury (Method 7471) } \\
\text { Flashpoint (Method 1010) }\end{array}$ \\
\hline Paint (Water Based) & $\begin{array}{l}\text { Possible heavy metal contamination; } \\
\text { Lead. Chromium, Mercury }\end{array}$ & $\begin{array}{l}\text { ICP Metals (Method 6010), Arsenic (Method 7060), Lead } \\
\text { (Method 7420). Mercury (Method 7471) }\end{array}$ \\
\hline $\begin{array}{l}\text { Other Aqueous } \\
\text { Liquids }\end{array}$ & $\begin{array}{l}\text { Possible sulfide, cyanide } \\
\text { contamination } \\
\text { Possible heavy metal contamination } \\
\text { Possibly corrosive }\end{array}$ & $\begin{array}{l}\text { Cyanide (Method } 9010 \text { or } 9012 \text { )/Sulfide (Method 9030) } \\
\text { Reactivity Testing } \\
\text { ICP Metals (Method 6010), Arsenic (Method 7060), Lead } \\
\text { (Method } 7420 \text { ) } \\
\text { Anions (including nitrates and nitrites), (Methods EPA-600 } \\
300.0,353.1,353.2 \text {, and 353.3) } \\
\text { pH (Method } 9045 \text { ) }\end{array}$ \\
\hline $\begin{array}{l}\text { Other Organic } \\
\text { Liquids }\end{array}$ & $\begin{array}{l}\text { Possible solvent contamination } \\
\text { Possible sulfide, cyanide } \\
\text { contamination } \\
\text { Possible heavy metal contamination } \\
\text { Possible halogenated hydrocarbon } \\
\text { contamination } \\
\text { Possible PCB contamination }\end{array}$ & $\begin{array}{l}\text { SVOA (Method } 8270 \text { ), VOA (Method } 8240 \text { ) } \\
\text { Cyanide (Method } 9010 \text { or 9012)/Sulfide (Method 9030) } \\
\text { Reactivity Testing } \\
\text { ICP Metals (Method 6010), Arsenic (Method 7060), Lead } \\
\text { (Method 7420) } \\
\text { TOX (Method 9020M) } \\
\text { PCB (Method 8080) }\end{array}$ \\
\hline
\end{tabular}


DOE/RL-93-70, Rev. 1

$10 / 27 / 93$

\subsection{LABORATORY ANALYSIS METHODS}

This section will be followed whenever laboratory analys is is required as specified in this WAP.

\subsection{DANGEROUS CONSTITUENT SAMPLING}

Sampling of waste streams will be based on a simple random selection method as outlined in SW-846 (EPA 1985). The random selection will be based on a random number generating method. The selection of the sample set for each waste stream is described in Section 5.7.1. Each container in the sample set will be sampled with a bias towards the most contaminated portion of the waste in the container. Specific sampling criteria for each waste type is described in Section 6.0.

Table 7-1 lists the sample and analysis protocol for solids, semi-solids, and liquids. Field analysis and process knowledge will be used to determine the specific analytes to be tested for in a waste. The criteria for each waste type is described in Section 6.0. Note that no analytes are specified for sampling 'hards' (cement, metals, wood, asphalt). A representative sample cannot be taken from this material for chemical testing. Only in cases where there is a 'crust' on the surface of the material that can be scraped off will sampling take place.

\subsection{CRITERIA FOR WASTE TYPE SAMPLING}

Sampling might not included detailed laboratory analysis. Sampling could be specified after visual screening, simple field testing, or analysis for waste type fingerprint parameters as appropriate. The applicability for each waste type is described in Section 6.0.

\subsection{WASTE SAMPLING TECHNIQUES}

This section describes how various waste types are to be sampled, establishes standard procedures for sampling various kinds of waste covered under the Order, and documents how these procedures vary from sampling procedures referenced in Ecology guidance documents, including SW-846, Volume II, Chapter 9.0, "Sampling". Standardized criteria for determining the locations and number of duplicate samples to be collected in various sampling situations are established. These sampling guidelines will be incorporated into work plans.

\subsubsection{Sample Handling}

Waste sample handling will be conducted by S\&ML personnel who have successfully completed training in environmental protocol sampling (Section 3.0). In general, sample handling will follow recommended practices 
1 found in SW-846. Deviations from these practices are described in this

2 section.

\subsubsection{Chain of Custody. All waste samples will have the following chain of} custody.

7.3.1.1.1 Sample Labeling. All waste samples will be labeled before analysis. Where possible, the sample container will be labeled with the following information:

- Sample number or other unique identification

- Requested analysis

- Name or initials of the sampler

- Preservation methods

- Date and time the sample was collected

- Available information on radionuclides and radiation level if applicable

- Location where the sample was collected.

In instances where labeling the sample container is not practical, the sample packaging and/or overpack will be clearly labeled with this information.

7.3.1.1.2 Sample Evidence Tape. Sample evidence tape will be used to ensure sample integrity if practical. If sample evidence tape is required, the tape will be affixed to the sample container where possible, and will include the same information as the waste label (Section 7.3.1.1.1). In instances where sample evidence tape cannot be applied to the sample container, the tape will be applied to the sample overpack. Such instances might occur when application of a sample evidence tape to the container in the field could result in radiological doses that are not consistent with ALARA. Sample evidence tape should be affixed in a manner that will reveal tampering.

7.3.1.1.3 Sample Logbooks. The S\&ML organization will maintain a controlled field logbook. As a minimum, the following entries will be made for each sample:

- Names of personnel involved in the field activity

- Titles and responsibilities of personnel involved in the field activity (if applicable)

- Signature of person making an entry (the printed name of the person is to occur at least once per logbook by their signature)

- Type and purpose of field activity 
- Date of field activity

- Site map, sketch, or other definitive site description

- Field observations

- Brief description of the job

- Sampling methods used

- Instrument calibration information

- Equipment identification numbers (if applicable)

- Condition of equipment

- Field decontamination of equipment and personnel

- Decontamination of equipment before arrival onsite

- Field problems, solutions, corrective actions

- Attachments (e.g., photographs)

- Audits or surveillances conducted during the sampling event

- Sample identification table with identification numbers, date, time, preservative, and analysis

- Field measurement data

- Lot numbers of the sample collection containers used

- The condition of each sampled container (e.g., leaking, bulged, corrosion, etc.)

- Status of the inside liner (e.g., horsetailed, taped, open, if a liner is present or not, etc.)

- PIN of the container sampled

- Any declared waste components and concentrations.

7.3.1.1.4 Chain-of-Custody Record/Sample Analys is Request. A COC/SAR will be completed for each sample shipment and will accompany the shipment to a laboratory. Guidance on documenting and maintaining chain of custody is described in Appendix D. A sample COC/SAR also is included. The COC/SAR will include, at a minimum, the following information for each sample:

- Sample number or other unique identifier (matching that in the sample logbook) 
- Date and time of sample collection

- Description of sampling location

- Number of sample containers associated with each sample

- Analyses requested

- Inclusive times and dates of sample possession, and signatures for each person handling the sample shipment.

Where possible, the COC/SAR will be packaged with the samples in the shipping container (e.g., sealed in a plastic bag). In instances where it is not practical to package the COC/SAR with the sample, the COC/SAR will accompany the sample during transport.

The following steps will ensure the integrity of the samples.

Step 1: The S\&ML sampling technician will initiate and maintain custody.

- The S\&ML sampling technician will maintain custody of sample(s) from collection until appropriate transfer of custody.

- The S\&ML sampling technician will record the following in the field logbook:

- Sample identification numbers

- Witness name.

Step 2: To document transfer of samples, the person relinquishing custody and the next person accepting custody will sign, date, and record the time of transfer on the COC form. The COC form initiator and the first person to sign the "Relinquished by" block on the COC form will be the same person.

Step 3: The original COC form will accompany the sample(s), and a copy of the COC form will be given to the S\&ML sampling technician for information.

Step 4: A copy of the COC/SAR, shipping documentation, and radiation documentation will be forwarded to HASM for tracking purposes by the close of business the working day following sample shipment.

Step 5: The 1aboratory sample custodian will inspect transferred samples to ensure the following:

- Seals are intact

- Labels are affixed and legible

- A SAR accompanies each sample or discrete set of samples

- The physical condition of samples is acceptable

- Samples being transferred are those on the COC form. 
2

3

Once the inspection is completed, the laboratory sample custodian will sign the COC documentation.

7.3.1.2 Sample Containers. Where possible, sample containers indicated on Table 7-1 will be used for sample collection and transport. All sample containers will have the proper Teflon ${ }^{*}-1$ ined 1 id as described in Table 7.1. In some instances, sample containers required by SW-846 cannot be used. In these instances, samples will be shipped to the laboratory as soon as practical, and transferred to an approved container.

Sample containers will be vendor certified, precleaned, with Teflon-lined closures, and bar coded from the manufacturer with lot number and identification number. The number and sizes of the required containers will depend on the analysis requested and the specific laboratory requirements. The HASM will provide a list of the container volumes required by the specific analytical laboratory before sampling.

7.3.1.3 Reagents. Reagents used during sampling will include the following:

- ASTM Type II water

- Pre-certified silica sand.

- $\mathrm{HNO}_{3}$

- $\mathrm{S}_{2} \mathrm{O}_{4}$

- $\mathrm{ZnAC}+\mathrm{NaOH}$

All chemical reagents will be analytical grade or better.

7.3.1.4 Equipment. The following is a typical list of equipment that could be used in the collection of samples (additional items could be required, depending on the individual sampling task):

- Sample containers

- Sample labels, pre-printed and blank

- Sampling scoops and trowels

- Sampling bowls

- Composite liquid waste sampler (COLIWASA)

- Thief sampler (open tube sampler)

- Grain sampler

- Sampling trier

- Hand-auger

- Dip sampler

- Surgeons gloves

- Safety glasses

- Scissors

- Ice chest

- Peristaltic pump

- Evidence tape

- Bung wrench

- Absorbent pads

"Teflon is a trademark of E. I. du Pont de Nemours and Company. 


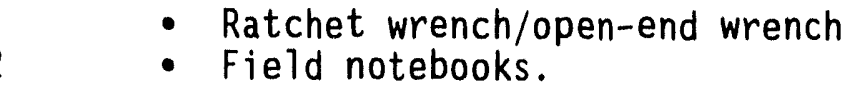

\subsubsection{Sample Collection}

Standard sampling protocol used for confirmation and characterization of waste covered under the Order is summarized in the following sections. Most of these methods are based on or are correlated to suggested sampling methods in SW-846 or ASTM Methods referenced in WAC 173-303.

\subsubsection{Sample Disposition}

Waste generated during sampling and samples returned from the laboratory will be disposed of with the same or a compatible waste stream. Wastes generated from field analysis will be disposed of with a compatible waste stream.

Chemical constituents of concern will be noted on the contents inventory of the container where the waste is placed.

\subsubsection{Container Sampling Procedures}

The container sampling procedures will be as follows:

- Verify the PIN on the container to be sampled

- Photograph the container to be sampled and date and label the photograph. (If possible, the side of the container that the PIN number is on should be photographed.)

NOTE: If any hazards are discovered that could jeopardize personnel safety, discontinue sampling of the container(s) and notify the backlog engineer and/or the S\&ML cognizant scientist. Any anomalies will be noted in the field logbook.

- Inspect the outside of the container for any previously unidentified leaks, bulging, or other hazards

- Observe the environment for any possible contamination problems (dust, odors, liquid, breezes, etc.):

- Document existence of possible contamination problems

- Evaluate potential effects on the samples.

- Open the container. For a container ring, use either a bung wrench or open-end wrench, depending on the type of container

- Sample collection will be performed in accordance with Drum Sampling Procedure (WHC 1993b). 


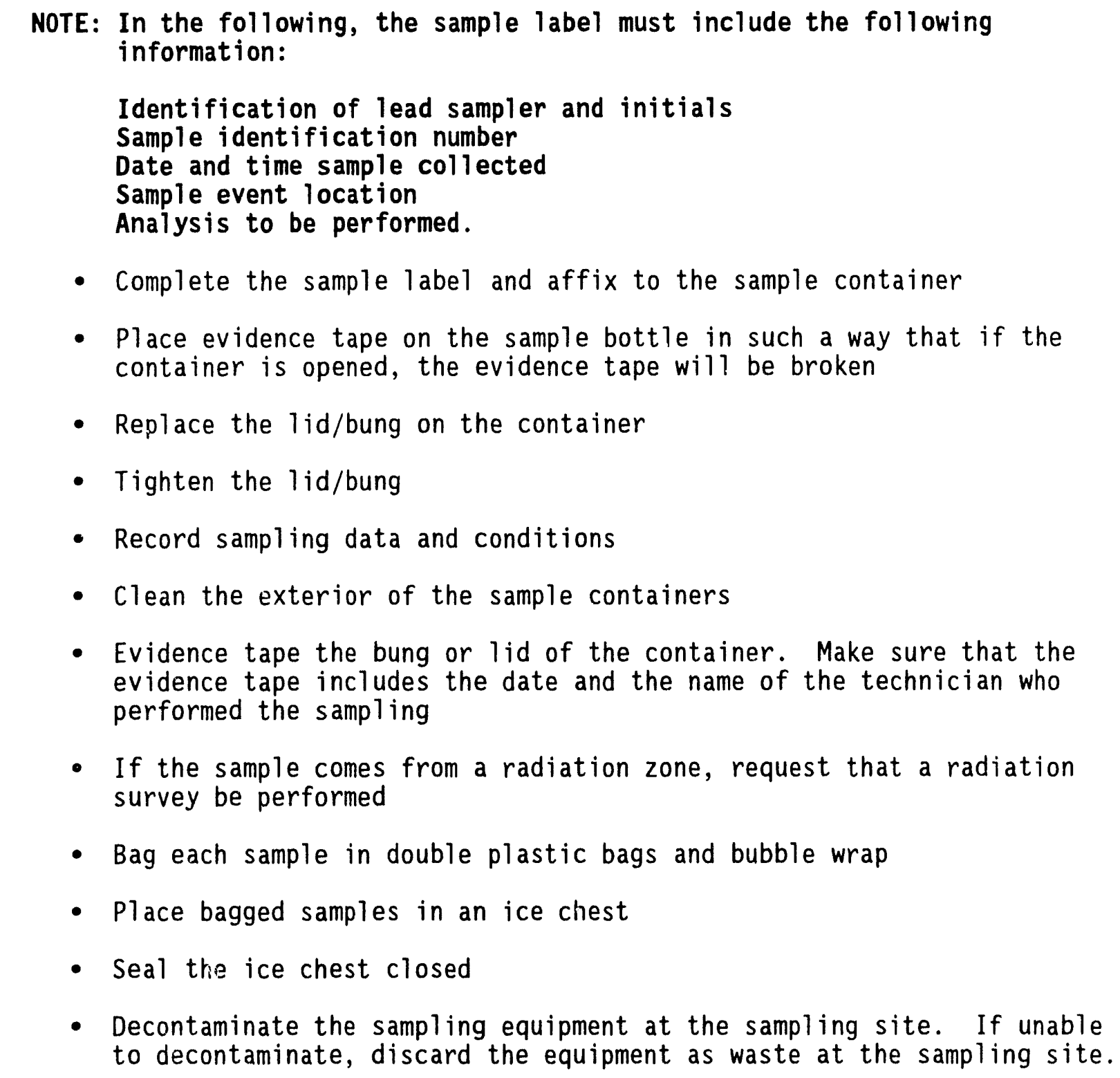

- Complete the sample label and affix to the sample container

- Place evidence tape on the sample bottle in such a way that if the container is opened, the evidence tape will be broken

- Replace the $1 \mathrm{id} /$ bung on the container

- Tighten the lid/bung

- Record sampling data and conditions

- Clean the exterior of the sample containers

- Evidence tape the bung or lid of the container. Make sure that the evidence tape includes the date and the name of the technician who performed the sampling

- If the sample comes from a radiation zone, request that a radiation survey be performed

- Bag each sample in double plastic bags and bubble wrap

- Prace bagged samples in an ice chest

- Seal the ice chest closed

- Decontaminate the sampling equipment at the sampling site. If unable to decontaminate, discard the equipment as waste at the sampling site.

\subsection{QUALITY ASSURANCE AND QUALITY CONTROL PROTOCOL}

In general, $Q A$ and $Q C$ will follow recommended practices found in SW-846.

Deviations from these practices are described in this section. Spikes, duplicates, and blanks will be run per batch of samples, with 20 samples as a maximum per batch or one for each waste stream sampled, whichever is less, as described in the latest revision of SW-846. 


\subsubsection{Blank Samples}

Blank samples will be transported with the collected samples to a laboratory for analysis. The samples will be used to determine the following:

- Cleanliness of sampling equipment

- Contamination or cross-contamination that might occur during sample handling and transportation

- Document the precision of sampling and analytical techniques.

Depending on the sample matrix (soil or water), pre-certified silica sand or reverse osmosis/deionized ASTM Type II water will be used for equipment and trip blanks.

\subsubsection{Equipment Blanks}

Equipment blanks will be collected using the exact sampling equipment that is to be used in subsequent sample collection and will imitate the sampling event. Equipment blanks will be representative of all equipment used in sample collection. Equipment blanks will be analyzed for the same constituents as an actual sample collected during the sampling event.

\subsubsection{Trip Blanks}

Trip blanks will be collected in a controlled environment. A container from the same lot number that will be used in the sampling event will be used to contain the trip blank. Trip blank(s) will be collected only if VOA is to be performed on an actual sample. As a recommendation, one trip blank will be prepared for every ice chest that contains a VOA sample and all VOA samples per shipment will be sent in one ice chest to minimize the number of trip blanks.

\subsubsection{Duplicate Samples}

A duplicate sample will be two samples that are collected from the same container or composite material. The basis of collecting a duplicate sample will be to evaluate the replicability of sampling and analysis. A duplicate sample will be analyzed for the same constituents as the sample it duplicates.

\subsection{ANALYTICAL TECHNIQUE REQUIREMENTS}

The standard methods to be used to analyze waste parameters associated with the waste covered under the Order are described in the following sections. In general, these methods are based on SW-846 and will be consistent with SW-846 requirements. These requirements include, but are not limited to, (where appropriate) duplicates, matrix spikes, matrix spike duplicates, laboratory 


\begin{abstract}
blanks, and surrogate spikes. However, mixed waste analysis protocol varies slightly from those described in SW-846; a general summary of those areas of variance are provided in Section 7.3. Online instrumentation (e.g., continuous air monitors, radiation monitors, etc.) will be discussed in the work plans.
\end{abstract}

\title{
7.5.1 Liquid Matrix Analytical Methods
}

The methods used for liquid mixed waste samples will be based on SW-846 methods. In some instances, three different methods are provided for mixed waste samples. The actual laboratory and analytical method used for a given waste sample depend on sample characteristics and the specific laboratory where the analysis is performed.

\subsubsection{Solid Waste Matrix Analytical Methods}

Analysis of mixed waste solid samples will be based on SW-846. As described in Section 7.3.1, up to three different methods will be provided for some mixed waste constituents.

\subsubsection{Deviations from SW-846 Protocol}

This section provides a general discussion of the currently documented deviations from SW-846 protocol that will occur during the analysis of mixed waste samples. Many of the deviations from SW-846 protocol arise from the radioactive nature of the samples handled. In addition to the specific deviations mentioned, recommended sample holding times are probably going to be exceeded for the waste samples that must be handled in laboratory hot cells. Preparation of these samples is complicated by the remote nature of the hot cell operations. Additionally, redundant laboratory instruments currently are not available for many hot cell operations. Maintenance and repair activities also are complicated by the remote hot cell environment. Instrument failures also have caused holding times to be exceeded.

The samples will be sent to Thermal Analytical, Incorporated, (TMA), unless the total radioactivity (total alpha, total beta, aild total gamma) of the sample is $\geq 100$ nanocuries per gram. If the radioactivity is above this limit, the samples will be sent onsite to either Pacific Northwest Laboratory (PNL) or the 222-S Laboratory Complex. In general, when samples cannot be sent to offsite laboratories because of radioactive content, PNL and the 222-S Laboratory Complex will deviate from SW-846 protocol. Analytical methods used by PNL are described in "Analytical Chemistry Laboratory (ACL) Procedure Compendium", PNL-MA-599 (PNL 1993). Procedures used by the 222-S Laboratory Complex are: ICP metals including arsenic, lead, and selenium - LA-505-151; mercury - LA-325-104; cyanide - LA-695-102; nitrite, nitrate, fluorine, chlorine, sulfate, and phosphate - LA-533-105; and $\mathrm{pH}-$ LA-212-102. Sample preparation procedures include -LA-504-101; -LA-505-158, AND - LA-505-159 (WHC 1993a). 
1 7.5.3.1 Inorganic Analysis. Analytical procedures used to characterize 2 inorganic species deviate from SW-846 protocols in the general areas of sample 3 preparation, sample size, and analytical techniques. These deviations are 4 discussed in the following sections.

7.5.3.1.1 Sample Size and Preparation. In general, smaller sub-sample sizes ( 0.25 grams to 0.5 grams versus 1 to 2 grams) are to be used when sampling mixed waste samples to reduce radiation exposure to laboratory personnel. Many sample preparation steps will be performed in disposable Teflon beakers.

All samples that are sent to TMA will have the minimum volume requirement as described in SW-846, unless the amount of waste is less than the amount required for the sample. If the volume is less than required, it will be noted in the logbook and the volume will be noted on the chain-of-custody form.

7.5.3.1.2 Analytical Techniques. Fluoride, nitrate, sulfate, and phosphate analyses will be performed using an ion chromatographic method. This method is based on EPA methods for waste water analyses (EPA 1982).

7.5.3.2 Volatile and Semivolatile organics. Because of radiological controls and exposure constraints, it will not be possible to refrigerate mixed waste samples during laboratory storage. This complicates the ability to comply with required storage temperature constraints.

7.5.3.3 Toxicity Characteristics Leaching Procedure. Onsite laboratories can perform the TCLP [Method 1311 (WAC 173-303)] on a very limited basis. As the ability to ship and process samples is limited by radiological constraints, total analyses are going to be used in place of TCLP extractions. Solid samples containing a total concentration of a toxic characteristic (TC) regulated compound, which is less than 20 times the regulatory limit on the Toxicity Characteristics List (WAC 173-303-090(8)(c)), are not considered TC wastes. 
Table 7.1 Sample and Analysis Protocol. (sheet 1 of 2)

\begin{tabular}{|c|c|c|c|c|c|c|}
\hline $\begin{array}{l}\text { ANALYTE } \\
\text { PROCEDURE }\end{array}$ & $\begin{array}{l}\text { SAMPLING } \\
\text { METHOD }\end{array}$ & $\begin{array}{l}\text { SAMPLING } \\
\text { CONTAINER }\end{array}$ & $\begin{array}{l}\text { HOLDING } \\
\text { TIMES }\end{array}$ & $\begin{array}{c}\text { SAMPLE } \\
\text { PRESERVATION } \\
\text { METHOD } \\
\end{array}$ & $\begin{array}{c}\text { SAMPLE } \\
\text { PREPARATION } \\
\text { METHOD } \\
\end{array}$ & $\begin{array}{l}\text { ASSOCIATED } \\
\text { QA/QC } \\
\text { PROCEDURES }\end{array}$ \\
\hline \multicolumn{7}{|c|}{ SOLIDS } \\
\hline $\begin{array}{l}\text { METALS } \\
\text { ICP }: 6010 \\
\text { As: } 7060 \\
\text { Pb: } 7420 \\
\text { Se: } 7740\end{array}$ & \multirow[t]{10}{*}{$\begin{array}{c}\text { REFER TO } \\
\text { SECTION } 7.3 .4\end{array}$} & $P$ & 6 Months & \multirow[t]{10}{*}{$4^{\circ} \pm 2^{\circ} \mathrm{C}$} & 3050 & \multirow{10}{*}{ REF $\mathrm{CH} .1 \mathrm{SH}-846$} \\
\hline $\mathrm{Hg}: 7471$ & & & 28 Days & & & \\
\hline $\begin{array}{l}\text { VOA } \\
8240\end{array}$ & & Gs & 14 Days & & $N / A$ & \\
\hline $\begin{array}{l}\text { SVOA } \\
8270 \\
\end{array}$ & & aG & 14 Days & & 3500 & \\
\hline $\begin{array}{c}\text { TOX } \\
9020 \mathrm{M} \\
\text { Ref EPA Docuement } \\
\text { No. } 600 / 4 / 84-008 \\
\text { APp. d } \\
\end{array}$ & & aGs & 28 Days & & N/A & \\
\hline $\begin{array}{c}\text { REACIIVITY } \\
9030 \text { (SULFIDE) } \\
\end{array}$ & & \multirow{2}{*}{$\begin{array}{l}P \\
P\end{array}$} & 7 Days & & \multirow[t]{2}{*}{ N/A } & \\
\hline $\begin{array}{l}\text { REACTIVITY } \\
9010 \text { or } 9012 \\
\text { (CYANIDE) } \\
\end{array}$ & & & 28 Days & & & \\
\hline $\begin{array}{c}\text { ANIONS } \\
300.0 \\
353.1, .2, .3 \\
\end{array}$ & & $\begin{array}{l}G \\
P \\
\end{array}$ & 28 Days & & EPA 2.3 & \\
\hline $\begin{array}{c}\text { pH } \\
\text { WA State Method" }\end{array}$ & & N/A & $N / A$ & & N/A & \\
\hline $\begin{array}{l}\text { PCB } \\
8080\end{array}$ & & aG & 7 Days & & 3580 & \\
\hline
\end{tabular}

\footnotetext{
1 Sample container: P (plastic), aGs (amber glass septa (id), $g$ (glass), aG (amber glass). Container volumes will be as specified by the
} laboratory. For offsite laboratories, sampling container volumes will be no smaller than those specified in SW-846.

2 Laboratories do not perform Hashington State $\mathrm{pH}$. 
Tabie 7.1 Sampling and Analysis Protocol. (sheet 2 of 2)

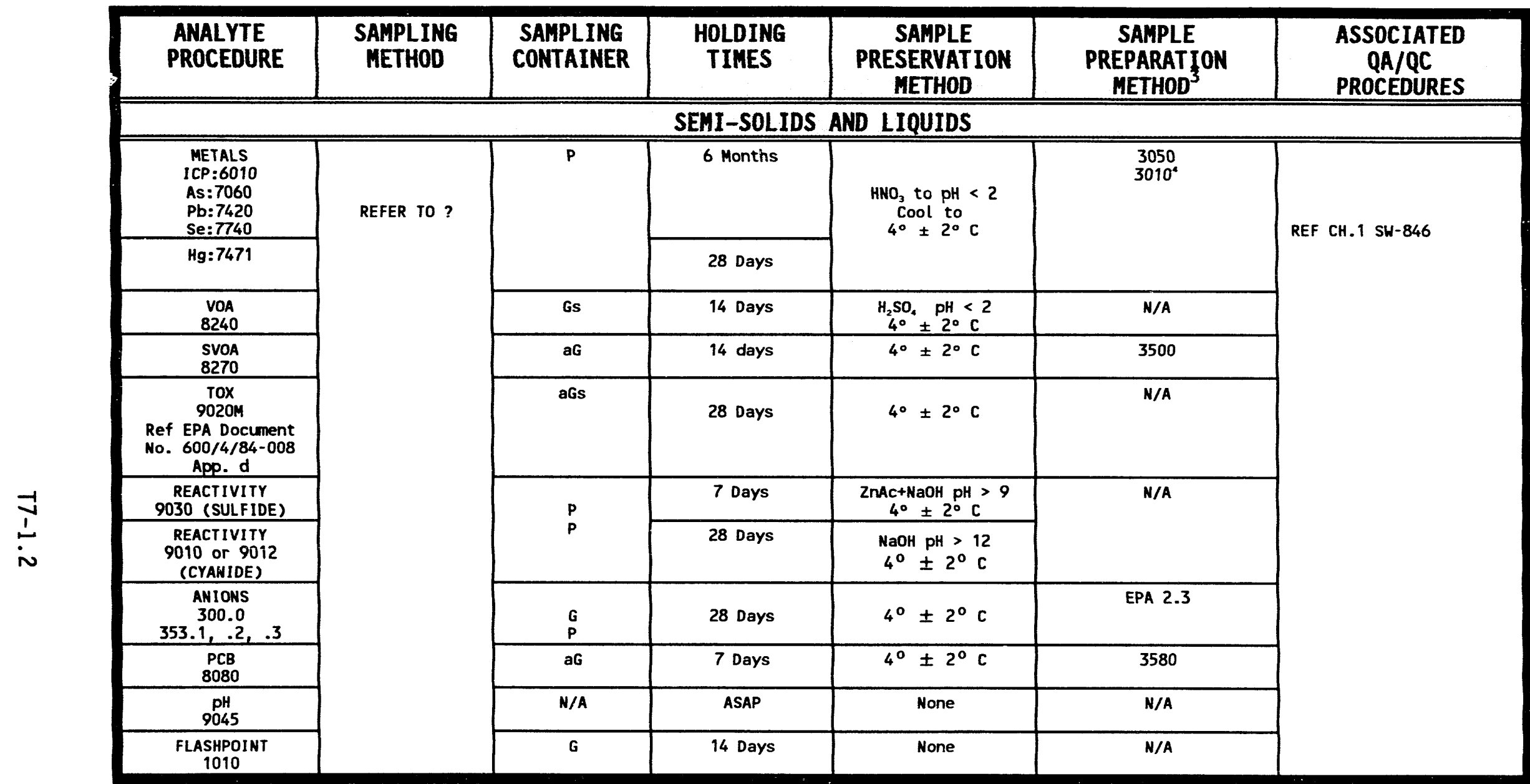

3 All chemicals used for preservation will be for aqueous phase only.

4 Method 3010 will be used for aqueous samples only. 


\subsection{RECORDKEEPING}

2

3

4

5

6

7

8

9 10

A11 container files and documentation generated during the confirmation or completion of designation process defined in this WAP will be maintained by Generator and Acceptance Services at M0279, in the 200 West Area. Once the process is completed, the container files will be turned over to the custody of Tank Farms. If staging of the files at a different location is necessary, Ecology will be informed in writing of the new location.

Records generated during the implementation of the WAP will be maintained until closure of the Hanford Facility pursuant to WAC 173-303-380 or as required during any postclosure period. 
DOE/RL-93-70, Rev. 1 $10 / 27 / 93$

$$
\begin{aligned}
& 1 \\
& 2 \\
& 3 \\
& 4 \\
& 5
\end{aligned}
$$

This page intentionally left blank. 


\subsection{REFERENCES}

DOE-RL, 1988, Hanford Facility Dangerous Waste Part A Permit Application, DOE/RL-88-21, revised periodically, U.S. Department of Energy, Richland Operations Office, Richland, Washington.

DOE-RL, 1992, "Unusual Occurrence Report", RL-I'HC-TANKFARM-1992-0007, U.S. Department of Energy, Richland Operations Office, Richland, Washington.

Ecology, 1993, "Notice of Penalty, Order No. 93NM-201", issued to U.S. Department of Energy, Richland Operations Office and Westinghouse Hanford Company, March 10, 1993, Washington State Department of Ecology.

EPA, 1982, Sampling and Sample Preservation of Water and Waste Water, EPA/4-82-029, U.S. Environmenta1 Protection Agency, Washington, D.C.

EPA, 1984, Waste Analysis Plans, A Guidance Manua7, EPA/530-SW-84-001, U.S. Environmental Protection Agency, Washington, D.C.

EPA, 1986, Test Methods for Evaluating Solid Waste: Physical/Chemical Methods, SW-846, U.S. Environmental Protection Agency, Washington, D.C. Note: The most recent promulgated version of $\mathrm{SW}-846$ is required.

EPA, 1987, Data Quality Objectives for Remedial Response Activities, Development Processes, EPA/540-87-003, U.S. Environmental Protection Agency, Washington, D.C.

NIOSH, 1993, Registry of Toxic Effects of Chemical Substances, National Institute for Occupational Safety and Health, updated quarterly.

PCHR, 1993, Stipulation to Revise Settlement Agreement and Order Thereon, PCHB 93-64, September 15, 1993, among Washington State Department of Ecology, U.S. Department of Energy, Richland Operations Office, and Westinghouse Hanford Company, Pollution Control Hearing Board, Lacey, Washington.

PNL, 1993, Analytical Chemistry Laboratory (ACL) Procedure Compendium, PNL-MA-599, 7 Vols., Pacific Northwest Laboratory, Richland, Washington.

WHC, 1991, Hanford Site Solid Waste Acceptance Criteria, WHC-EP-0063, as revised, Westinghouse Hanford Company, Richland, Washington.

WHC, 1992, Central Waste Complex Final Safety Analysis Report, FSAD Upgrade, WHC-SD-WM-SAR-049, as revised, Westinghouse Hanford Company, Rich1and, Washington.

WHC, 1993a, 222-S Laboratory Procedures for the Confirmation or Completion of Tank Farms Backlog Waste Designation, WHC-SD-WM-PROC-011, as revised, Westinghouse Hanford Company, Richland, Washington. 
WHC, 1993b, Drum Sampling Procedure, L0-080-441, Rev. A-0, Westinghouse Hanford Company, Richland, Washington.

Resource Conservation and Recovery Act of 1976, as amended, 42 USC 6901 et seq.

Toxic Substances Control Act of 1976, 90 Stat. 2003, 15 USC 2601 et seq.

WAC 173-303, Dãngerous Waste Regulations.

10 CFR 61, Licensing Requirements for Land Disposal of Radioactive Waste.

40 CFR 265, Interim Status Standards for Owners and Operators of Hazardous Waste Treatment, Storage, and Disposal Facilities.

40 CFR 268, Land Disposal Restrictions.

40 CFR 302, Designation, Reportable Quantities, and Notification.

49 CFR 172, Hazardous Material Tables and Hazardous Materials Communications.

49 CFR 173, Shipper--General Requirements for Shipments and Packagings.

DOE Order 5400.5, Radiation Protection of the Public and the Environment. 
DOE/RL-93-70, Rev. 1

$10 / 27 / 93$

\section{APPENDICES}

A BACKLOG WASTE DESIGNATION GUIDANCE

B DOCUMENTATION ASSESSMENT

C BACKLOG WASTE REAL-TIME RADIOGRAPHY GUIDANCE

D CHAIN OF CUSTODY/SAMPLE ANALYSIS REQUEST GUIDANCE

11 
DOE/RL-93-70, Rev. 1

This page intentionally left blank. 
DOE/RL-93-70, ReV. 1

$10 / 27 / 93$

APPENDIX A

BACKLOG WASTE DESIGNATION GUIDANCE 


(1)

\author{
APPENDIX A
}

CONTENTS

1.0 DESCRIPTION $\ldots \ldots \ldots \ldots$ APP A-1

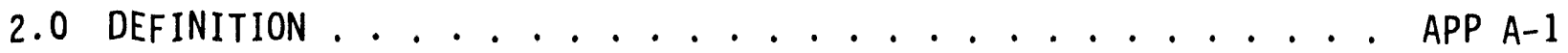

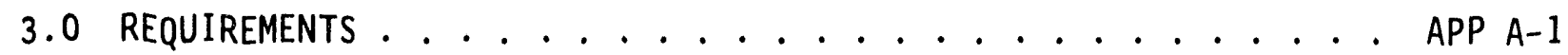

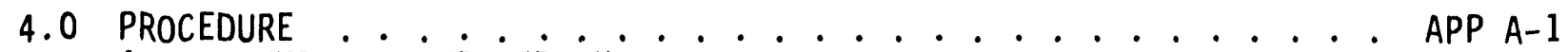

4.1 CHEMICAL COMPOSITION ......................... APP A-1

4.2 DISCARDED CHEMICAL PRODUCTS . . . . . . . APP A-2

4.3 DANGEROUS WASTE SOURCES ......................... APP A-3

4.4 INFECTIOUS DANGEROUS WASTES ............. APP A-3

4.5 DANGEROUS WASTE MIXTURES $\ldots \ldots \ldots$. . . . . . . . APP A-3

4.5 .1 Toxicity ................. APP A-4

4.5.2 Persistence ............... APP A-4

4.5 .3 Carcinogens .................... APP A-5

4.6 DANGEROUS WASTE CHARACTERISTICS ........... APP A-6

4.6 .1 Ignitability . . . . . . . . . . . APP A-6

4.6 .2 Corrosivity . . . . . . . . . . . . APP A-7

4.6 .3 Reactivity. . . . . . . . APP A-7

4.6.4 Toxicity Characteristic ........... APP A-8

4.7 POLYCHLORINATED BIPHENYLS ............... APP A-9

4.8 SUMMARY OF WASTE DESIGNATION PROCEDURE $\ldots \ldots$ APP A-9

4.9 SPECIAL CASE WASTES ........................ APP A-9

4.9 .1 Alkali Metals . . . . . . . . . . . . APP A-10

4.9 .2 Aerosol Cans ................. APP A-10

4.9.3 Fluorescent Light Ballasts ............ APP A-10

4.9.4 Nonregulated Empty Containers . . . . . . . APP A-10

5.0 GLOSSARY . . . . . . . . . . . . . APP A-11

\title{
TABLE
}

A1. Toxicity Characteristic List for Liquids and

Soluble Solids ................................ APP T-1.1 


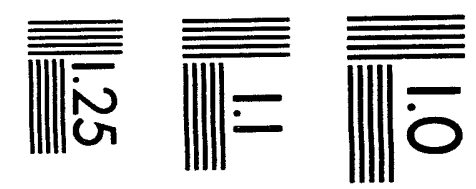

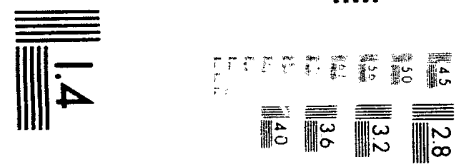

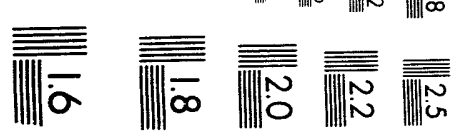



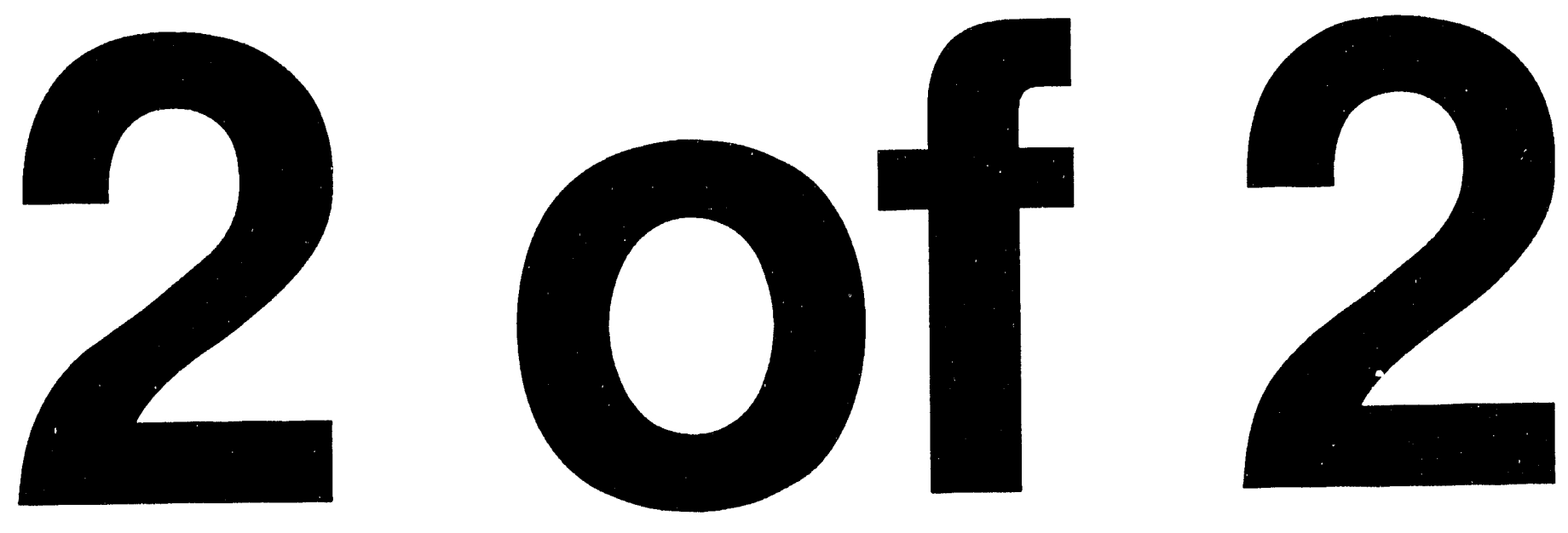


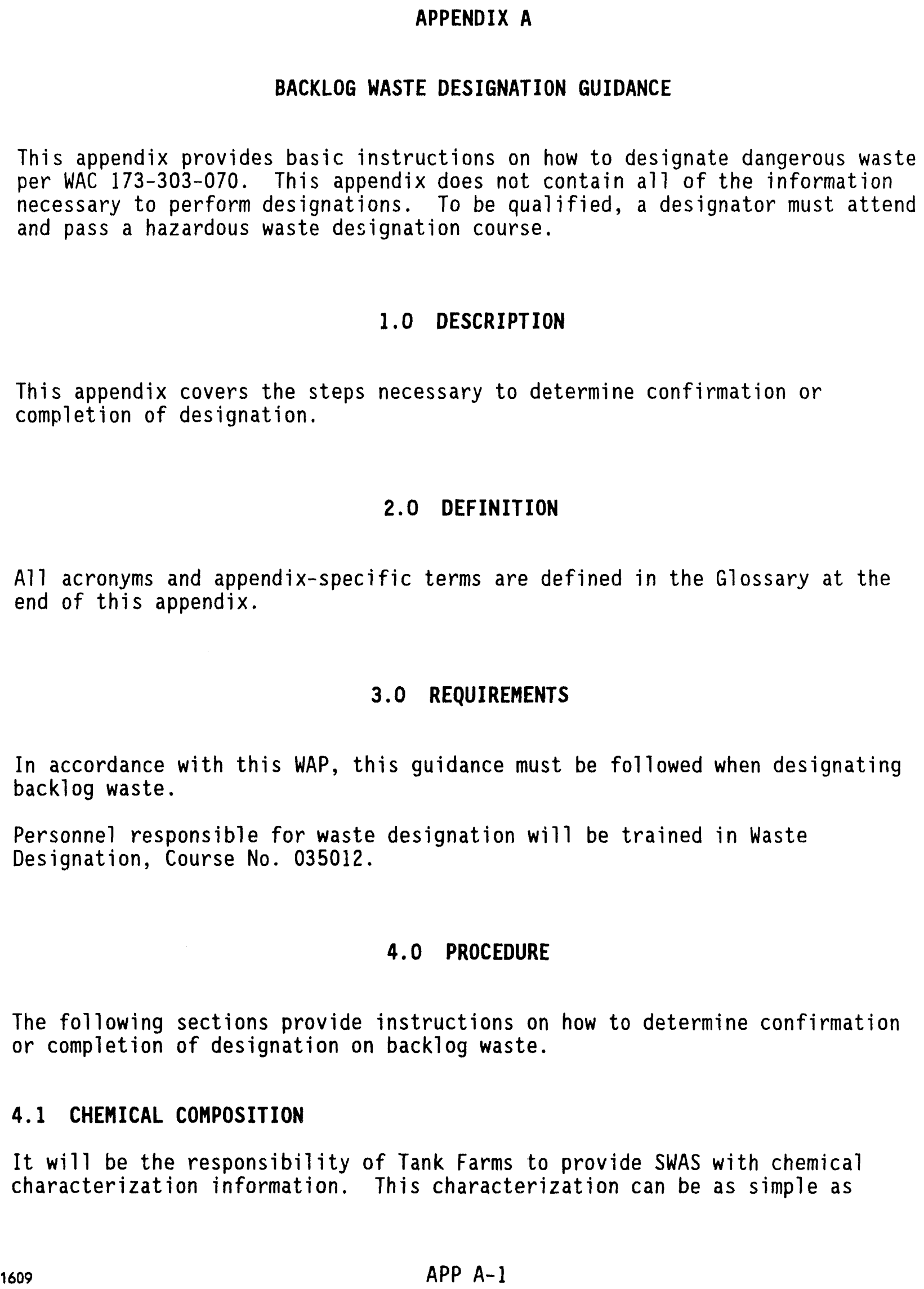

1.0 DESCRIPTION

This appendix covers the steps necessary to determine confirmation or completion of designation.

\subsection{DEFINITION}

A11 acronyms and appendix-specific terms are defined in the Glossary at the end of this appendix.

\subsection{REQUIREMENTS}

In accordance with this WAP, this guidance must be followed when designating backlog waste.

Personnel responsible for waste designation will be trained in Waste Designation, Course No. 035012.

\subsection{PROCEDURE}

The following sections provide instructions on how to determine confirmation or completion of designation on backlog waste.

\subsection{CHEMICAL COMPOSITION}

It will be the responsibility of Tank Farms to provide SWAS with chemical characterization information. This characterization can be as simple as 


\section{including the MSDS(s) for the chemical(s) that make up the waste matrix or as} complicated as performing laboratory analysis on the waste matrix.

The MSDS does not always give adequate information on the chemical composition of the waste. In these cases, the manufacturer of the product should be contacted for more information. The designator should make a reasonable attempt to get a ful1 chemical characterization from the manufacturer or at least obtain the assurance that the product contains no halogenated hydrocarbons and polycyclic aromatic hydrocarbons, carcinogens, or constituents listed on Table Al.

\subsection{DISCARDED CHEMICAL PRODUCTS}

A Discarded Chemical Product is an unused chemical product that is 1 isted in the Discarded Chemical Product List (WAC 173-303-9903) and must be a commercial product or a manufacturing chemical intermediate. The Discarded Chemical Product List is separated into two sections: Moderately Dangerous and Acutely Dangerous Chemical Products. Both sections must be consulted when determining whether or not the chemical is a Discarded Chemical Product.

Each of the listed chemicals has a dangerous waste number in accordance with WAC 173-303-070. These numbers are located on the Discarded Chemical Products List. Designate 'Acutely Hazardous Waste' as AHW. Designate 'Acutely Dangerous Chemical Products' as EHW. Designate 'Moderately Dangerous Chemical Products' as DW.

NOTE: Refer to Glossary. The terms 'Acutely Dangerous' and 'Acutely Hazardous' do not share the same definition.

Discarded Chemical Products include the following.

- Original 'unused' products as received from the manufacturer that contain a listed product as the sole active ingredient. (Trace additives, inert constituents, and water are not considered active ingredients.)

- Any of these products that are of off-specification composition.

- Any container or inner liner that has been used to hold any of these praducts or off-specification products. If the chemical is an AHW, the container or inner liner will receive a waste number from the list. If the container has been triple-rinsed with an appropriate cleaner or solvent per WAC 173-303-160(2), this designation does not apply.

- Any residue, contaminated soil, water, or other debris resulting from the cleanup of a spill of any off-specification product or listed product will receive a waste number from the list.

The designator must consider all mentioned criteria and assign the applicable waste codes to the waste. 
DOE/RL-93-70, Rev. 1

$10 / 27 / 93$

\subsection{DANGEROUS WASTE SOURCES}

Dangerous Waste Sources are designated based on the list provided in WAC 173-303-9904. These 'Non-Specific Sources' and 'Specific Sources' describe waste with certain chemical components and/or waste from specific operations.

Dangerous Waste Sources include:

- Wastes 1isted in the WAC 173-303-9904 tables

- Any mixture of a 'Dangerous Waste Source' with another waste

- Only wastes that are designated as 'Used' by Tank Farms.

If a waste contains one or more of the chemical components in a given source entry, or is produced by a listed process ${ }^{1}$, the waste will be designated a Dangerous Waste Source. Dangerous waste numbers provided in WAC 173-303-9904 will be assigned. In general, Dangerous Waste Sources are designated DW. In some cases, however, footnotes on the tables in WAC 173-303-9904 describe special circumstances where these wastes are designated EHW.

The designator must examine the waste components and determine if the waste meets the above criteria.

\subsection{INFECTIOUS DANGEROUS WASTES}

There are no infectious dangerous waste regulations at this time (WAC 173-303-083).

\subsection{DANGEROUS WASTE MIXTURES}

To designate Dangerous Waste Mixtures, the designator will determine if the waste is toxic, persistent, and/or carcinogenic as defined by WAC 173-303-084. This designation applies to pure chemicals as well as to waste mixtures. Note that additional codes are not required if a designation has been made under Discarded Chemical Products Lists (WAC 173-303-9903) as stated in WAC 173-303-070(6).

NOTE: The designator must designate the waste for any further special knowledge that is known concerning the waste and provide CWC with the appropriate information to allow for the proper storage of the waste (i.e., flammable, corrosive, reactive). The designator al so must ensure that the waste has been appropriately designated DW or EHW. 
DOE/RL-93-70, Rev. 1

$10 / 27 / 93$

\subsubsection{Toxicity}

To designate for Toxicity, the designator will assign 'Toxic Categories' to the constituents and will calculate the 'Equivalent Concentration' (EC) per WAC 173-303-084(5). The designator will compare the EC to the ranges given.

The designator will determine Toxic Categories of $X, A, B, C$, or $D$ (1 isted in their order of severity) directly from the 'Registry of Toxic Effects of Chemical Substances' (RTFCS), published by the National Institute for Occupational Safety and Health referenced in WAC 173-303-084. To determine the Toxic Category from data, the designator will check each constituent against the Toxic Category Table.

Four toxicity criteria are given in WAC 173-303-084: oral (Rat) $L_{50}(\mathrm{mg} / \mathrm{kg})$, aquatic ( $\mathrm{Fish}) \mathrm{LC}_{50}$ or $\mathrm{TLm}_{96}$ ( $\left.\mathrm{Fish}\right)(\mathrm{ppm})$, inhalation (Rat) $\mathrm{LC}_{50}$ (mg/L), and dermal (Rabbit) $L_{50}(\mathrm{mg} / \mathrm{kg})$. The designator should be aware that these four criteria are not the only published toxicity parameters. However, these are the only criteria that Ecology uses for book designation of toxicity.

If data are available from more than one source, use only RTECS to determine the Toxicity Category. If toxicity data are not found in the RTECS, do not assign a Toxic Category to that constituent. If the MSDS gives the toxicity for the product, which is a mixture of several chemicals, use the toxicity noted on the MSDS.

Once the designator establishes toxic categories for all constituents, the designator will calculate the EC using the formula in WAC 173-303-084(5)(b).

For example, a waste of $10 \%$ Category A material, $5 \%$ Category B material, $15 \%$ Category $D$ material, and $70 \%$ waste (non-toxic) will have the following EC:

$$
E C=10 \% / 10+5 \% / 100+15 \% / 10,000=1.0515
$$

The designator will assign the DW or EHW classifications based only on the EC, as follows:

- If a waste is DW, assign the waste code WT02

- If a waste is EHW assign the waste code WTO1

- If the $\mathrm{EC} \%$ is below $.001 \%$, the waste is not regulated for toxicity.

\begin{tabular}{cl} 
Equivalent Concentration & Designation \\
\hline$<0.001$ & Not regulated \\
0.001 to 0.01 & DW \\
$>0.01$ & EHW
\end{tabular}

\subsubsection{Persistence}

If the waste contains halogenated hydrocarbons, or polycyclic aromatic hydrocarbons, the designator will evaluate for persistence per WAC $173-303-084(6)$. 
1 Halogenated hydrocarbons are organic compounds composed of carbon, hydrogen, 2 and any one or more of the halogens: fluorine, chlorine, astatine, bromine, 3 or iodine. Halogenated hydrocarbons may also contain other elements. Other 4 criteria also apply per WAC 173-303-084(6).

The designator will evaluate the designation of halogenated hydrocarbons by adding the weight percents of all halogenated hydrocarbons in the waste mixture. The sum will be the 'Total Halogenated Hydrocarbons Concentration'.

The designator will assign the waste category using the following:

\begin{tabular}{ll} 
Wt $\%$ halogenated hydrocarbons & Designation \\
\hline 0.01 & Not Regulated \\
0.01 to 1.0 & DW \\
$>1.0$ & EHW
\end{tabular}

The designator will assign EHW halogenated hydrocarbons waste mixtures the dangerous waste number WPO1.

The designator will assign DW halogenated hydrocarbons waste mixtures the dangerous waste number WP02.

Polycyclic aromatic hydrocarbons are hydrocarbon molecules composed of two or more fused benzene ring structures. Conjugated ('daisy-chain') ring structures are not regulated structures. Only molecules containing four, five, and six fused rings are regulated (WAC 173 303-084).

To evaluate polycyclic aromatic hydrocarbons, the designator will add the weight percents of all of the four-, five-, and six-ring polycyclic aromatic hydrocarbons in the waste mixture. The sum is the 'Total Polycyclic Aromatic Hydrocarbons Concentration' [WAC 173-303-084(4)(b)].

If the waste has a polycyclic aromatic hydrocarbons concentration greater than $1.0 \mathrm{wt} \%$, the designator will designate the waste as EHW and use the waste code WP03. For example, a mixture of 5 wt\% pyrene and $95 \%$ acetone is EHW, WP03. Wastes with less than $1 \%$ polycyclic aromatic hydrocarbons are not regulated for polycyclic aromatic hydrocarbons.

\subsubsection{Carcinogens}

The third element of the Dangerous Waste Mixtures evaluation will involve checking the waste for carcinogens [WAC 173-303-084(7)].

The designator will check each constituent of the waste mixture to determine whether the waste is a human or animal, sufficient or limited carcinogen. This information is published by the International Agency for Research on Cancer and is available in the RTECS. 
The designator will designate waste mixtures as carcinogens as follows.

- When the concentration of any one International Agency for Research on Cancer sufficient carcinogen (human or animal) exceeds $1.0 \mathrm{wt} \%$ of the waste mixture, the mixture will be designated as EHW and assign the dangerous waste code WCO1.

- When the concentration of any one International Agency for Research on Cancer sufficient carcinogen (human or anima 1 ) is $>.01 \mathrm{wt} \%$ of the waste mixture, but $<1.0 \mathrm{wt} \%$, the mixture will be designated as DW and assigned the dangerous waste code WCO2.

- When the total concentration summed for all International Agency for Research on Cancer sufficient and limited carcinogens (human or animal) exceeds $1.0 \mathrm{wt} \%$ of the waste mixture, the mixture wi1l be designated as DW and assigned the dangerous waste code WCO2.

The International Agency for Research on Cancer carcinogenic wastes, labeled carcinogenic solely because of tests involving implantation into test animals, are not regulated as carcinogens. This information can be found in the International Agency for Research on Cancer Monographs on the Evaluation of the Carcinogenic Risk of Chemicals to Humans [WAC 173-303-084(7)(c)]. Some respiratory carcinogens, such as asbestos, are exempt from the dangerous waste regulations as long as these are managed in compliance with the requirements of 10 CFR 61 .

\subsection{DANGEROUS WASTE CHARACTERISTICS}

If the waste has not been designated previously as DW or EHW, analysis may be required to determine characteristics. The approved sampling methods are given in WAC 173-303-110. Instructions for checking wastes for the dangerous waste characteristics are provided in the following sections.

\subsubsection{Ignitability}

A waste is ignitable [WAC 173-303-090(5)] if the waste has any of the following properties:

- Liquid (other than an aqueous solution containing less than $24 \%$ alcohol by volume) with a flash point less than $60^{\circ} \mathrm{C}$ according to published or experimental closed cup test data.

- Solid or sludge, under standard conditions of temperature and pressure, capable of causing fire through friction, absorption of moisture or spontaneous chemical changes, and when ignited, burns so vigorously and persistently that it creates a hazard.

NOTE: WAC 173-303-110 specifies the 'Chemical Testing Methods for Complying with the Dangerous Waste Regulations' as the appropriate 


A

procedure for ignitability determinations. This document states that the test for ignitable solids is a 'prose test'.

- Ignitable compressed gas as defined in 49 CFR 173.300.

- Oxidizer as defined in 49 CFR 173.151. Oxidizers include nitrates and nitrites in solid form or in solutions of $40 \%$ or greater.

The designator will designate wastes determined to be ignitable as DW and will assign the dangerous waste code D001. Aerosol cans, which have a MSDS that states that the aerosol product is not flammable, will not be designated as a D001. A MSDS that states that the product is flammable or combustible will be regulated as a D001 with a flash point $<100^{\circ} \mathrm{F}$ for flammable or flash point of $100^{\circ} \mathrm{F}-140^{\circ} \mathrm{F}$ for combustible.

\subsubsection{Corrosivity}

A waste is corrosive [WAC 173-303-090(6)] if the waste has any of the following properties.

- Aqueous with a pH less than or equal to $2(\leq 2)$, or a $\mathrm{pH}$ greater than or equal to $12.5(\geq 12.5)$ according to accepted Ecology test methods.

- Liquid that corrodes Society of Automotive Engineers (SAE) 1020 steel faster than 0.250 inch per year at a temperature of $130^{\circ} \mathrm{F}$. Rate is determined by an Ecology-approved method.

- Solid or Semi-Solid that has an aqueous phase $\mathrm{pH}$ of $\leq 2$, or a $\mathrm{pH} \geq 12.5$ when it is made into a 50 wt\% mixture with water. Ecology will provide approved test methods.

The designator will designate wastes determined to be Corrosive as DW and will assign the dangerous waste code D002.

\subsubsection{Reactivity}

A waste is Reactive [WAC 173-303-090(7)] if the waste has any of the following properties:

- Is normally unstable and readily undergoes violent change without detonating

- Reacts violently with water or forms potentially explosive mixtures with water

- When mixed with water, generates toxic gasses, vapors or fumes in quantities that present a danger to human health or the environment 
- It is a cyanide $(-C N)$ or sulfide $(-S)$ bearing waste that, when exposed to $\mathrm{pH}$ conditions between 2 and 12.5 , can generate toxic gasses, vapors or fumes in amounts sufficient to present a danger to human health or the environment. Numbers provided in SW- 846 for evaluating reactivity are 250 milligrams hydrogen cyanide per kilogram of waste and 500 milligrams hydrogen sulfide per kilogram of waste

- Is capable of detonation or explosive reaction if subjected to a strong initiating source or heated under confinement

- Is readily capable of detonation or explosive decomposition, or reaction at standard temperature and pressure.

- It is a U.S. Department of Transportation Forbidden Explosive, a Class A or Class B Explosive as defined in 49 CFR 173.51, .53 and .88. Examples are as follows:

Nitroglycerin, liquid: Forbidden Explosive (not desensitized)

Black powder (gunpowder): Class A Explosive

Exhibition display fireworks: Class B Explosive

The designator will designate the waste as DW and assign the dangerous waste code D003.

\subsubsection{Toxicity Characteristic}

The $T C$ relates to the concentration of 40 specific chemicals [WAC 173-303-090(8)] that could leach from a solid or liquid waste matrix. These chemicals include heavy metals (lead, chromium, etc.), and certain pesticides and herbicides. Wastes may be DW or EHW depending on the concentration of these chemicals in the leachate.

The TCLP is used to test the solubility and mobility of hazardous components in a buffered aqueous solution. In a 'worst-case' calculation, a solid waste could be assumed to dissolve completely in the buffered extractant, which is always 20 times the mass of the waste sample. For liquids, concentration limits are imposed directly on the waste. Table Al specifies limiting concentrations that could cause the extract to be designated TC.

The designator will designate the waste and will assign the dangerous waste codes (Table Al). Select dangerous waste numbers from the table, select the waste class (EHW or DW). 


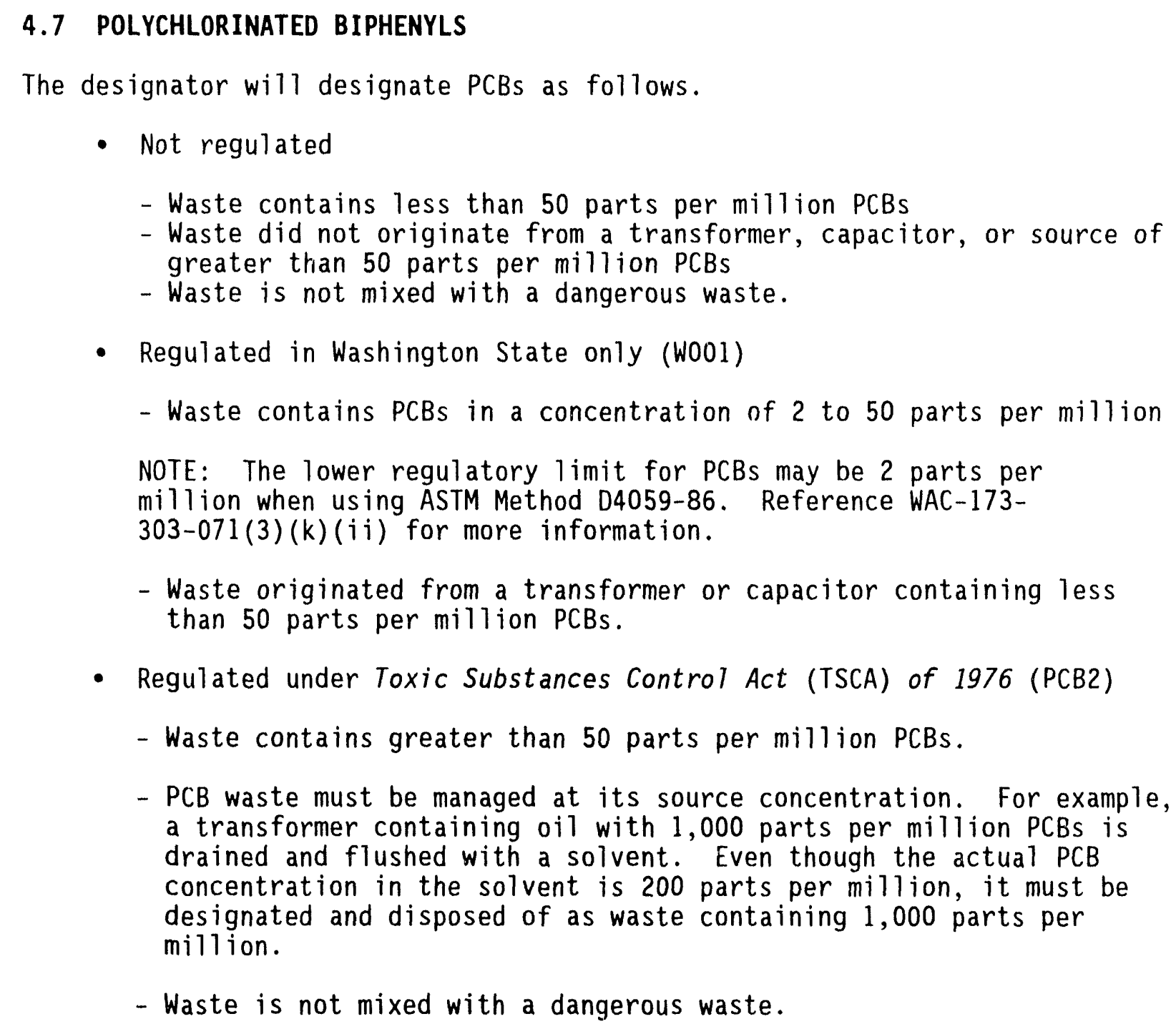

- Regulated in Washington State only (W001)

- Waste contains PCBs in a concentration of 2 to 50 parts per million

NOTE: The lower regulatory limit for PCBs may be 2 parts per million when using ASTM Method D4059-86. Reference WAC-173303-071(3)(k)(ii) for more information.

- Waste originated from a transformer or capacitor containing less than 50 parts per million PCBs.

- Regulated under Toxic Substances Control Act (TSCA) of 1976 (PCB2)

- Waste contains greater than 50 parts per million PCBs.

- PCB waste must be managed at its source concentration. For example, a transformer containing oil with 1,000 parts per million PCBs is drained and flushed with a solvent. Even though the actual PCB concentration in the solvent is 200 parts per million, it must be designated and disposed of as waste containing 1,000 parts per million.

- Waste is not mixed with a dangerous waste.

\subsection{SUMMARY OF WASTE DESIGNATION PROCEDURE}

After the waste designation has been completed, the designator will determine the Waste Class of the waste by reviewing all categories (WAC 173-303). If any of the categories have been designated an AHW, the waste is classed as an AHW. If any of the categories have been designated EHW, the waste is classed EHW. Otherwise, the waste is classed as a DW or not regulated.

\subsection{SPECIAL CASE WASTES}

Some wastes require special management. The following directions will aid in disposing of these wastes. Not all special cases are covered in this section. Whenever there are questions concerning management of an unusual waste, the designator will consult SWAS. The following special case wastes are not discussed in this appendix. 
Animal carcasses

Brass, bronze

Copper wire

Fluorescent 1 ight tubes

Neutralization

Stainless steel

Paints
Bat.eries (other than lead)

Construction debris Lead used as shielding

Mercury

Office waste

Welding rods

The following sections discuss sampling the most common special case wastes.

\subsubsection{Alkali Metals}

Solid and semi-solid wastes that contain alkali metals will be designated as D001, D002, and D003 (WAC 173-303-090). Under no circumstances should alkali metals be mixed with water.

\subsubsection{Aerosol Cans}

Empty aerosol cans normally not regulated could be discarded to trash. Any empty aerosol can that held an AHW as the sole ingredient is regulated as if the container were full unless the container was triple-rinsed. Trace ingredients, water, and inert materials will be considered as ingredients.

Aerosol cans that have lost propellent but still contain material (shake the can) will be designated as if the product is there, but the designator will subtract the propellant and adjust the concentrations of remaining constituents. Aerosol cans that are punctured before disposal will be treated in the same manner.

\subsubsection{Fluorescent Light Ballasts}

This section applies to fluorescent light ballasts (or small capacitors) taken out-of-service. Items for collection are ballasts containing PCBs. All unmarked ballasts must be assumed to contain PCBs.

NOTE: PCB ballasts are regulated by TSCA 30-day storage requirements. The disposal of $\mathrm{PCB}$-free ballasts will be determined by WAC 173-303 regulations.

\subsubsection{Nonregulated Empty Containers}

For designation, empty containers fall into two categories: Ecology regulated and nonregulated. Certain empty containers that previously held dangerous waste are not regulated by Ecology. These containers contained wastes that are not acutely hazardous, and that are not pesticide containers bearing a danger or warning label. 'Acutely Hazardous' wastes are defined in WAC 173-303-040 and in the Glossary. The following describes the designation of empty containers. 
DOE/RL-93-70, Rev. 1

$10 / 27 / 93$

4.3.4.1 Ecology Regulated Containers. Ecology-regulated empty containers are those that contained an 'acutely hazardous' substance when full, and/or pesticide containers that bear a danger or warning label. The containers must have been designated and waste codes assigned, must have an EPA Hazardous Waste sticker, have a unique number when manifested, and be shipped exactly as if the containers were full.

4.9.4.2 Nonregulated Empty Containers. An empty container will not be regulated as follows:

- It contained a U.S. Department of Transportation-regulated material and has been rinsed and cleaned. These containers must be marked 'Non-regulated, MT, cleaned'. A11 hazard or warning labels must be removed or obliterated.

- It contained an AHW and has been triple-rinsed per WAC 173-303-160. These containers must not have an EPA Hazardous Waste sticker and must be marked 'Non-regulated, MT, triple rinsed'. Hazard and warning labels must be removed or obliterated.

- It contained materials that were not regulated by U.S. Department of Transportation or Ecology when full. These containers must be labeled 'Non-regulated, MT.'

- Containers of 5 gallons or less, are empty (MT), did not contain an AHW, are not regulated, and can be disposed of in a landfill.

\subsection{GLOSSARY}

Acutely dangerous waste--Any dangerous waste specifically identified on the WAC 173-303-9903 Discarded Chemical Products List as EHW by the Ecology.

Acutely hazardous waste (AHW)--Some items identified on the Discarded Chemical Products List and some pesticide containers and pesticide waste. Acutely Hazardous Wastes are those with dangerous waste numbers beginning with a ' $P$ ' or those that show an ' $X$ ' or an ' $A$ ' in the Reason for Designation column. Also pesticide containers that bear a 'Danger' or 'Warning' label.

Combustible liquid--Term used in 49 CFR 173.115 for liquids with closed cup flash points at or above $100^{\circ} \mathrm{F}$ and below $200^{\circ} \mathrm{F}$. In WAC 173-303, this term includes material with a flash point $\geq 100^{\circ} \mathrm{F}$ and below $140^{\circ} \mathrm{F}$.

Container--Any portable device in which a material is stored, transported, treated, disposed of, or otherwise handled. 
Dangerous waste--The words 'dangerous waste' refer to the full universe of regulated solid wastes designated as either dangerous or extremely hazardous in WAC 173-303-070 through WAC 173-303-103. (Refer to 'DW' and 'EHW. ')

DW (dangerous waste)--The abbreviation 'DW' refers to that part of the solid waste universe that is dangerous waste only, and not EHW.

EHW (extremely hazardous waste)--The abbreviation 'EHW' refers to those dangerous wastes that are extremely hazardous.

Empty (MT)--Containers that contain no more than $1 \%$ of its capacity if the container can hold under 110 gallons or no more than $0.3 \%$ of its capacity if the container can hold more than 110 gallons. A compressed gas container (aerosol can) is 'empty' when the pressure inside the container equals, or nearly equals, atmospheric pressure.

Equivalent concentration (EC)--Equivalent concentration is a value determined by dividing the concentration of a constituent by its toxicity value. This value is used to determine the relative toxicity of a waste matrix.

Flammable liquid--Term used in 49 CFR 173.115 for liquids having closed cup flash points below $100^{\circ} \mathrm{F}$.

Generator--Any person, by site, whose act or process produces dangerous waste or whose act first causes a dangerous waste to become subject to regulation. For the purposes of this waste analysis plan, the generator is DOE-RL.

Halogenated hydrocarbon (HH)--An organic chemical compound composed of carbon, hydrogen, and any one or more of the halogens: fluorine, chlorine, bromine, or iodine. Halogenated hydrocarbons also might contain other elements. Other criteria are defined in WAC 173-303-084(6). The compound also might be referred to as halogenated organic compounds (HOC).

Halogenated organic compound (HOC)--Refer to halogenated hydrocarbon.

Hazardous substance--A chemical substance that is listed in the hazardous materials table in 49 CFR 172.101 and exceeds its reportable quantity when packaged in a single container (refer to Reportable Quantity).

Ignitable--Term used in WAC 173-303-090 for a waste that can cause a fire through friction, absorption of moisture, or spontaneous chemical reaction, etc. This term generally applies to oxidizers as defined in 49 CFR 173.151. It also applies to liquids with flash points below $140^{\circ} \mathrm{F}$. 
DOE/RL-93-70, Rev. 1

Incompatible waste--A dangerous waste that is unsuitable for placement in a particular device or structure because the waste might corrode or decay the containment materials, or is unsuitable for mixing with another waste or material because the mixture might produce heat or pressure, fire or explosion, violent reaction, toxic dusts, fumes, mists or gases, or flammable fumes or gasses.

Listed product--A chemical product that meets the definition of a Discarded Chemical Product and appears in the Discarded Chemical Product List (WAC 173-303-9903).

Listed source--A waste source that has resulted from a process listed in the Dangerous Waste Source List (WAC 173-303-9904).

Material safety data sheet (MSDS)--A document that conveys product safety information from the manufacturer to the user.

Persistence--The quality of a material that retains more than half of its initial activity after 1 year (365 days) in either a dark anaerobic or dark aerobic environment of ambient conditions.

Polycyclic aromatic hydrocarbon (PAH)--Hydrocarbon molecules composed of two or more fused benzene ring structures.

Registry of Toxic Effects of Chemical Substances (RTECS)--This document is published by the National Institute for Occupational Safety and Health and provides the toxicity and International Agency for Research on Cancer data used during the designation process.

Reportable quantity (RQ)--This is the quantity of material or waste that if released into the environment must be reported immediately to the National Response Center. Reportable quantities are listed in the hazardous materials table in 49 CFR 172.101 and in 40 CFR 302.4 (refer to Hazardous substance).

Solid waste--Any solid, semi-solid, liquid or contained gaseous material, garbage, refuse, sludge or discarded commodity resulting from industrial, commercial, mining, agricultural, or community operations or activities that is not a primary product of such operations or activities.

Some solid wastes, which are dangerous wastes, are identified in WAC 173-303-016. The reuse, use for energy recovery, reclamation, and speculative accumulation, as well as disposal of some of these wastes, are regulated by Ecology as described in WAC 173-303-016.

Waste generator--Any person, by site, whose act or process produces dangerous waste and whose act first causes a dangerous waste to become subject to regulation (WAC 173-303-040). For purposes of RCRA and WAC 173-303, the Hanford Site is considered to be a single generator comprised of a number of generating units. 
DOE/RL-93-70, Rev. 1

$10 / 27 / 93$

1 Washington Administrative Code (WAC)--Specifically, WAC 173-303 contains

2 all the solid waste regulations for the state of Washington. 
4

6

7

8

9

10

11

12

13

14

15

16

17

18

19

20

21

22

23

24

25

26

27

28

29

30

31

32

33

34

35

Table Al. Toxicity Characteristic List for Liquids and Soluble Solids.

(sheet 1 of 2)

\begin{tabular}{|c|c|c|c|c|c|c|}
\hline \multirow[t]{2}{*}{$\begin{array}{l}\text { Waste } \\
\text { code }\end{array}$} & \multirow[t]{2}{*}{ Constituent } & \multirow[t]{2}{*}{$\begin{array}{l}\text { CAS } \\
\text { no. }\end{array}$} & \multicolumn{2}{|c|}{$\begin{array}{c}\text { Liquid waste } \\
\text { concentration } \\
(\mathrm{mg} / 1)\end{array}$} & \multicolumn{2}{|c|}{$\begin{array}{c}\text { Solid waste } \\
\text { concentration (wt } \%)\end{array}$} \\
\hline & & & DW & EHW & DW & EHW \\
\hline D004 & Arsenic & $7440-38-2$ & $5-500$ & $>500$ & $0.01-1$ & $>1$ \\
\hline D005 & Barium & $7440-39-3$ & $100-10,000$ & $>10,000$ & $0.2-20$ & $>20$ \\
\hline 0006 & Cadmium & $7440-43-9$ & $1 \cdot 100$ & $>100$ & $0.002 \cdot 0.2$ & $>0.2$ \\
\hline 0007 & Chromium & $7440-47-3$ & $5-500$ & $>500$ & $0.01-1$ & $>1$ \\
\hline D008 & Lead & $7439-92-1$ & $5-500$ & $>500$ & $0.01-1$ & $>1$ \\
\hline D009 & Mercury & $7439-97-6$ & $0.2-20$ & $>20$ & $0.0004-0.04$ & $>0.04$ \\
\hline D010 & Selenium & $7782-49-2$ & $1 \cdot 100$ & $>100$ & $0.002-0.2$ & $>0.2$ \\
\hline Do11 & silver & $7440-22-4$ & $5-500$ & $>500$ & $0.01-1$ & $>1$ \\
\hline D012 & Endr in & $72-20-8$ & $0.02-2$ & $>2$ & $0.00004-0.004$ & $>0.004$ \\
\hline 0013 & Lindane & $58-89-9$ & $0.4-40$ & $>40$ & $0.0008-0.08$ & $>0.08$ \\
\hline D014 & Methoxychlor & $72-43-5$ & $10-1,000$ & $>1,000$ & $0.02-2$ & $>2$ \\
\hline D015 & Toxaphene & $8001-35-2$ & $0.5-50$ & $>50$ & $0.001-1$ & $>1$ \\
\hline D016 & $2,4-D$ & $94-75-7$ & $10-1,000$ & $>1,000$ & $0.02-2$ & $>2$ \\
\hline D017 & $2,4,5$-TP silvex & $93-72-1$ & $1-100$ & $>100$ & $0.002 \cdot 0.2$ & $>0.2$ \\
\hline D018 & Benzene & $71-43-2$ & $0.5-50$ & $>50$ & $0.001-0.1$ & $>0.1$ \\
\hline D019 & Carbon Tetrachloride & $56-23-5$ & $0.5-50$ & $>50$ & $0.001-0.1$ & $>0.1$ \\
\hline D020 & Chlordane & $57-74-9$ & $0.03-3$ & $>3$ & $0.00006-0.006$ & $>0.006$ \\
\hline D021 & Chlorobenzene & $108-90-7$ & $100-10,000$ & $>10,000$ & $0.2 \cdot 20$ & $>20$ \\
\hline D022 & Chloroform & $67-66-3$ & $6.0-600$ & $>600$ & $0.012-1.2$ & $>1.2$ \\
\hline D023 & 0 -Cresol* & $95-48-7$ & $200-20,000$ & $>20,000$ & $0.4 \cdot 40$ & $>40$ \\
\hline D024 & m-Cresol* & $108-39-4$ & $200-20,000$ & $>20,000$ & $0.4-40$ & $>40$ \\
\hline$D 025$ & p-Cresol* & $106-44-5$ & $200-20,000$ & $>20,000$ & $0.4-40$ & $>40$ \\
\hline D026 & Cresol & ......... & $200-20,000$ & $>20,000$ & $0.4-40$ & $>40$ \\
\hline 0027 & 1,4-Dichlorobenzene & $106-46-7$ & $7.5-750$ & $>750$ & $0.015-1.5$ & $>1.5$ \\
\hline D028 & 1,2-Dichlorobenzene & $107-06-2$ & $0.5-50$ & $>50$ & $0.001-0.1$ & $>0.1$ \\
\hline
\end{tabular}

* If $0-, m-$, and $p$-cresol concentrations cannot be differentiated, the total cresol (D026) is used. 
Table Al. Toxicity Characteristic List for Liquids and Soluble Solids. (sheet 2 of 2)

3

\begin{tabular}{|c|c|c|c|c|c|c|}
\hline \multirow[t]{2}{*}{$\begin{array}{l}\text { Waste } \\
\text { code }\end{array}$} & \multirow[t]{2}{*}{ Constituent } & \multirow[t]{2}{*}{ CAS no. } & \multicolumn{2}{|c|}{$\begin{array}{c}\text { Liquid waste } \\
\text { concentration } \\
(\mathrm{mg} / 1)\end{array}$} & \multicolumn{2}{|c|}{$\begin{array}{c}\text { Solid waste } \\
\text { concentration (wt\%) }\end{array}$} \\
\hline & & & DW & EHW & DW & EHW \\
\hline D029 & $\begin{array}{l}1,1- \\
\text { Dichloroethylene }\end{array}$ & $75-35-4$ & $0.7-70$ & $>70$ & $0.0014-0.14$ & $>0.14$ \\
\hline D030 & 2,4-0 initrotoluene & $121-14-2$ & $0.13-13$ & $>13$ & $0.00026-0.026$ & $>0.026$ \\
\hline D031 & $\begin{array}{l}\text { Heptachlor (\& its } \\
\text { OH) }\end{array}$ & $76-44-8$ & $0.008-0.8$ & $>0.8$ & $0.000016-0.0016$ & $>0.0016$ \\
\hline 0032 & Hexachlor obenzene & $118-74-1$ & $0.13 \cdot 13$ & $>13$ & $0.00026-0.026$ & $>0.026$ \\
\hline D033 & Hexachlor obutadiene & $87-68-3$ & $0.5-50$ & $>50$ & $0.001-0.1$ & $>0.1$ \\
\hline D034 & Hexachlor oethane & $67-72-1$ & $3-300$ & $>300$ & $0.006-0.6$ & $>0.6$ \\
\hline 0035 & Methyl ethyl Ketone & $78-93-3$ & $200-20,000$ & $>20,000$ & $0.4-40$ & $>40$ \\
\hline D036 & Nitrobenzene & $98-95-3$ & $2-200$ & $>200$ & $0.004-0.4$ & $>0.4$ \\
\hline D037 & Pentachlorophenol & $87-86-5$ & $100-10,000$ & $>10,000$ & $0.2-20$ & $>20$ \\
\hline D038 & Pyridine & $110-86-1$ & $50-500$ & $>500$ & $0.01-1$ & $>1$ \\
\hline D039 & Tetrachloroethylene & $127-18-4$ & $0.7-70$ & $>70$ & $0.0014 \cdot 0.14$ & $>0.14$ \\
\hline D040 & Irichloroethylene & $79-01-6$ & $0.5-50$ & $>50$ & $0.001-0.1$ & $>0.1$ \\
\hline D041 & \begin{tabular}{|l}
$2,4,5-$ \\
rifichlorophenol \\
\end{tabular} & $95-95-4$ & $400-40,000$ & $>40,000$ & $0.8-80$ & $>80$ \\
\hline D042 & $\begin{array}{l}2,4,6- \\
\text { Trichlorophenol }\end{array}$ & $88-06-2$ & $2-200$ & $>200$ & $0.004-0.4$ & $>0.4$ \\
\hline 0043 & Vinyl Chloride & 75 & 0.2 & 20 & $0.0004-0$. & $>0.04$ \\
\hline
\end{tabular}

Conversion:

$1 \mathrm{ppm}=0.0001 \%$

$10 \mathrm{ppm}=0.001 \%$

$1,000 \mathrm{ppm}=0.1 \%$

$100 \mathrm{ppm}=0.01 \%$

CAS no. = Chemical Abstract Service number.

$\mathrm{mg} / 1=$ milligrams per liter .

$w t \%=$ weight percent.

$\mathrm{DW}=$ dangerous waste.

$\mathrm{EHW}=$ extremely hazardous waste.

ppm = parts per million. 
DOE/RL-93-70, Rev. 1

$10 / 27 / 93$

\section{APPENDIX B}

DOCUMENTATION ASSESSMENT 


(1)

\section{APPENDIX B}

CONTENTS

1.0 PURPOSE .................................... APP B-1

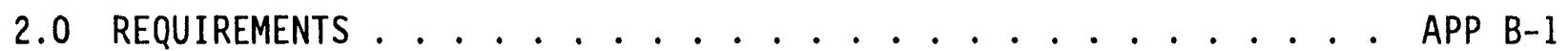

3.0 DOCUMENTATION ASSESSMENT . . . . . . . . . . . . . . . APP B-1

3.1 TRACKING INFORMATION . . . . . . . . . . . . . . APP B-1

3.2 VERIFICATION OF BACKLOG WASTE INFORMATION SHEET

INFORMATION .................. APP B-2

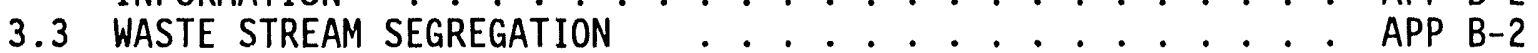

3.4 CHARACTERIZATION INFORMATION ............ APP B-2

3.5 FLAGGING FOR SPECIAL HANDLING . . . . . . . . . . APP B-2

\section{FIGURES}

B1. Waste Documentation Checklist ............ APP B F-1 
$\mathrm{DOE} / \mathrm{RL}-93-70, \mathrm{Rev} .1$

$10 / 27 / 93$

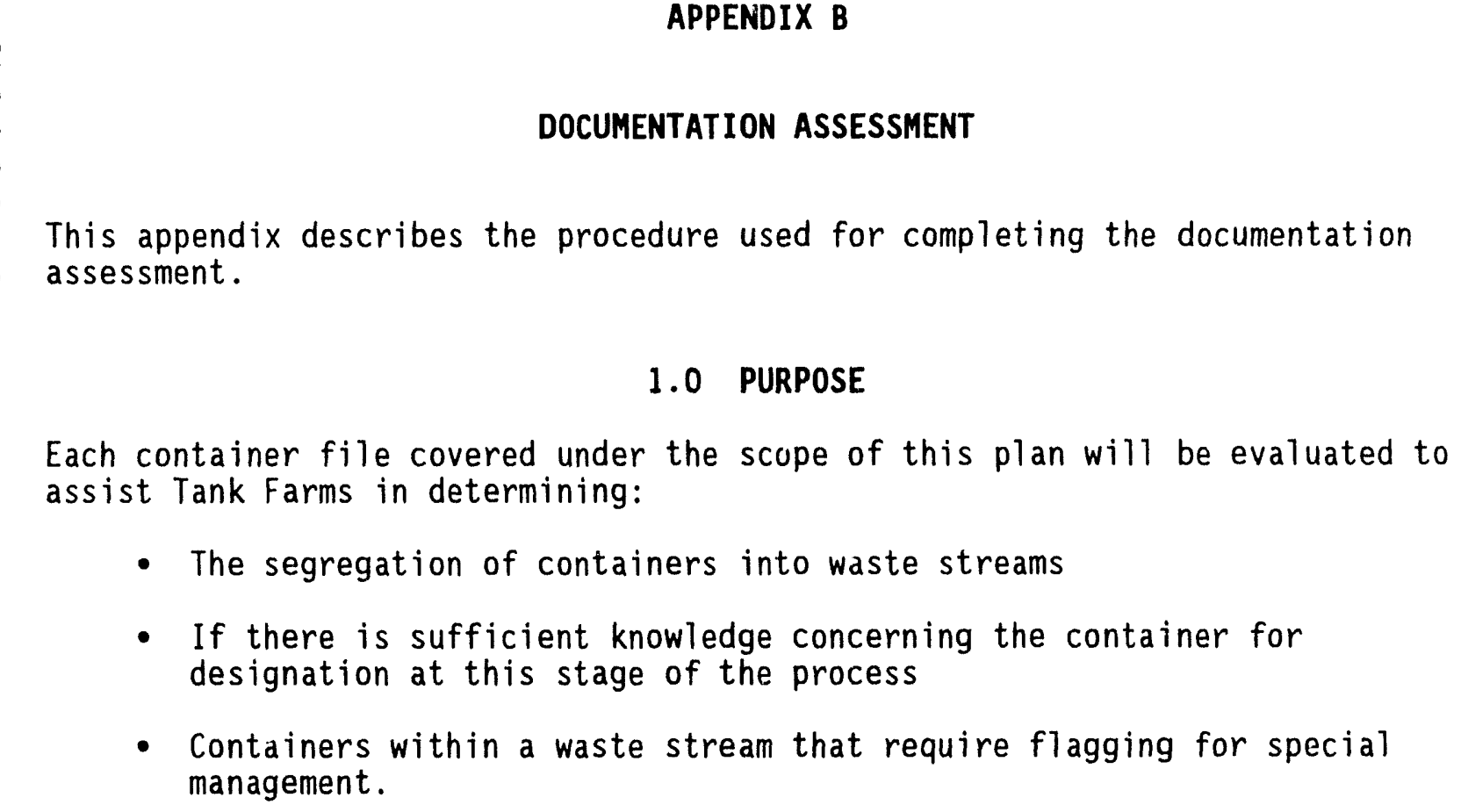

\section{DOCUMENTATION ASSESSMENT}

This appendix describes the procedure used for completing the documentation assessment.

\subsection{PURPOSE}

Each container file covered under the scupe of this plan will be evaluated to assist Tank Farms in determining:

- The segregation of containers into waste streams

- If there is sufficient knowledge concerning the container for designation at this stage of the process

- Containers within a waste stream that require flagging for special management.

\section{APPENDIX B}

\subsection{REQUIREMENTS}

This appendix must be followed when completing the documentation assessment of the backlog waste in accordance with this WAP.

\subsection{DOCUMENTATION ASSESSMENT}

Each container of waste covered under the scope of this WAP will be evaluated in accordance with the 'Container Waste Documentation Checklist' (Figure B1). The BWISs for each container will be reviewed and compared to information gathered from the Tank Farms container files. The checklist will be completed at the time of the review. The checklist will be maintained as part of the operating record for the container.

All questions on the checklist must be answered. Specific comments should be noted in the 'COMMENTS' section as appropriate so that information can be obtained from the checklist as needed in further steps of the confirmation or completion of designation process.

\subsection{TRACKING INFORMATION}

The signature of the evaluator and the date of the evaluation will be completed. Both the Backlog PIN and the Generating Unit PIN will be given. 


$$
\begin{aligned}
& \text { The purpose of this section of the checklist is to verify that the waste type } \\
& \text { and inventory listed on the BWIS is accurate. All inconsistencies should be }
\end{aligned}
$$$$
\text { noted for correction in SWITS. }
$$

\subsection{WASTE STREAM SEGREGATION}

The purpose of this section of the checklist is to gather information to segregate the waste into waste streams and to flag any container that has a mixture of waste types to ensure that the container is designated appropriately. All waste types should be clearly noted whenever a container is found that contains a mixture of waste types.

\subsection{CHARACTERIZATION INFORMATION}

The purpose of this section is to determine the type of documentation available for a container and to determine if the documentation is sufficient to designate the waste for storage.

All references to characterization information must be clearly described so that the information can be easily retrieved.

The determination of whether sufficient information exists for designation for storage is made by the evaluator. For any container with a mixture of waste streams, sufficient information must be available on all waste streams. If the evaluator believes enough information exists, an SDAR can be requested from SWAS in accordance with Section 5.3 of the WAP.

\subsection{FLAGGING FOR SPECIAL HANDLING}

The purpose of this section is to flag containers that might need special handiing during the remaining analysis for confirmation or completion of designation.

Containers that require physical analysis and cannot undergo NDE must be opened for visual inspection. Examples include boxes (unless RTR capability for boxes is obtained) and drums with lead shielding.

Any item on the inventory that raises a question about the designation should undergo further analysis. Examples could include HEPA filters or cases where the inventory is in question because of 1ack of detail. These containers should be flagged; the exact reason for the flag must be noted on the checklist. 


\section{CONTAINER WASTE DOCUMENTATION CHECKLIST}

ACKLOG PIN:

GENERATING UNIT PIN:

BL- - OO-MAP EVALUATOR SIGNATURE/DATE:

\section{VERIFICATION OF BWIS}

1. Is the waste type correct? (If no, give correct

waste type.)

2. Does the file documentation (i.e. inventory sheet) agree with the BWIS?

\section{WASTE STREAM SEGREGATION}

3. List the waste type for the container.

4. List the Tarik Farm Complex.

5 . Is the waste a single waste type? (If no, list ail types in the mixture.)

\section{CHARACTERIZATION INFORMATION}

6. Does an inventory sheet exist?

7. Is the inventory sheet certified with a signature and date?

8. Is specific information related to the waste generating process contained/referenced in the le?

Are analytical results available for the container?

10. Are specific dangerous constituents and percents listed or MSDSs provided in the field file?

11. Is documented process knowledge available from other containers from the same waste stream?

12. Are analytical results available from other containers from the same activity?

13. Is other characterization information available for the waste stream?

DOES ADEQUATE DOCUMENTATION FOR DESIGNATION FOR STORAGE EXIST?

\section{FLAGGING FOR SPECIAL HANDLING}

14. Can the container have NDE performed on it?

(if no, state reason.)

15. Does the documentation in the container

indicate any waste which needs further analysis?

16. Is any of the documentation questionable such

that the container needs further analysis?

Figure $\mathrm{Bl}$. Waste Documentation Checklist. 
DOE/RL-93-70, Rev. 1

$10 / 27 / 93$

\section{APPENDIX C}

BACKLOG WASTE REAL-TIME RADIOGRAPHY GUIDANCE 
DOE/RL-93-70, Rev. 1

$10 / 27 / 93$

1
2
3
4
5

\section{APPENDIX C}

This appendix provides a NDE Checklist to be used in RTR of the backlog waste. 
NDE CHECKLIST

\begin{tabular}{|l|l|}
\hline \hline Backlog PIN: BL- -00-MAP & Generating Unit PIN: \\
\hline Date: & Container Weight: \\
\hline RTR Log Number: & Batch ID \#: \\
\hline
\end{tabular}

WASTE CONTENTS EVALUATION

1. Is a liner present in the container? O horsetailed

2. Are any free liquids observed? 0 containerized Liquid amount:

O $1 \%$ or more of contianer

3. Are any powdered materials observed? o kitty liter/amount -

4. Are any dense objects observed? O batteries o lead

5. Are any compressed gases or pressurized-type containers observed?

6. Are any sharp, pointed objects observed? O padded

7. Are any HEPAs potentially present in the waste? O mask cartridges 0 woodframed

8. Is there general agreement between the observed container contents and the inventory sheet?

GYALUAT ION (TO BE COMPLGTED AFTER RTR OF IHE CONTATIERI

DOES THE CONTAINER NEED OVERPACKING BEFORE BEING RETURNED TO CWC? $\square$ YES $\square$ NO

ANY WASTE THAT IS DETERMINED TO CONTAIN AEROSOL CONTAINERS THAT CONTAIN LIQUIDS WILL BE MANAGED AS FLAMMABLE LIQUIDS UNTIL SUCH TIME THAT FURTHER CONFIRMATION/COMPLETION OF DESIGNATION CAN BE PERFORMED. THE FOLLOWING LABELS/MARKINGS

SHOULD BE APPLIED TO THE CONTAINER: "Flash point < 100 "F" Marking, DOT Flammable Liquid, "This End Up" Marking, "Liquid Organic Waste" Marking. A D001 WASTE CODE WILL BE ADDED TO THE EPA HAZARDOUS WASTE LABEL.

NEW STORAGE LOCATION CWC/FIammable Staging

DOES THE CONTAINER NEED FURTHER ANALYSIS? $\quad \square$ YES $\square$ NO TANK FARM REPRESENTATIVE

(If yes, label the container with a white sticker marked "TO T-PLANT".) (Signature/Date)

DESCRIPTION OF DISCREPANCIES: 
ADOITIONAL CONMENTS (TNCLUDE ANY ABDTTIONAL TTEHS THAT COULB BE IDENTIFIED, ETC. .): 
DOE/RL-93-70, Rev. 1

$10 / 27 / 93$

\section{APPENDIX D}

CHAIN OF CUSTODY/SAMPLE ANALYSIS REQUEST GUIDANCE 


\author{
APPENDTX D
}

CONTENTS

1.0 SCOPE .................................. APP D-1

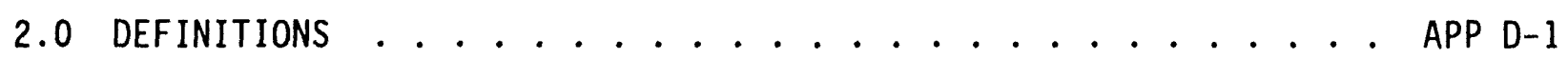

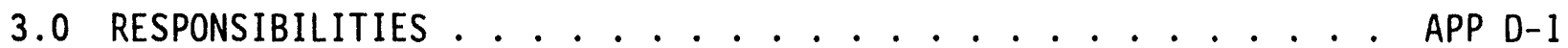

3.1 FIELD TEAM LEADER/COGNIZANT ENGINEER . . . . . . . . . . . APP D-2

3.2 WITNESS . . . . . . . . . . . . . . . . . . . APP D-2

3.3 TRANSPORTER . . . . . . . . . . . . . . . . . APP D-2

3.4 LABORATORY SAMPLE CUSTODIAN ......................... APP D-2

3.5 HANFORD ANALYTICAL SERVICES MANAGEMENT . . . . . . . . . APP D-2

4.0 GENERAL REQUIREMENTS . . . . . . . . . . . . . . . . . . APP D-2

5.0 DESCRIPTION OF PROCEDURE ................. . APP D-3

5.1 CUSTODY INITIATION ................... APP D-3

5.2 CHAIN-OF-CUSTODY FORM INITIATION ........... . APP D-3

5.3 TRANSFER OF CUSTODY ................. . APP D-3

5.4 RECEIPT AT DESTINATION . . . . . . . . . . . APP D-3

5.5 SAMPLE DISPOSAL . . . . . . . . . . . . . . . APP D-3

5.6 RECORDS ...................... . . . . . . . . . . . .

\title{
FIGURE
}

D1. Typical Chain-of-Custody Form ............. APP D F1 
DOE/RL-93-70, Rev. 1 $10 / 27 / 93$

\section{APPENDIX D}

\section{CHAIN OF CUSTODY/SAMPLE ANALYSIS REQUEST GUIDANCE}

This procedure guidance (guidance) summarizes the general requirements for documenting and maintaining chain of custody for backlog waste environmental samples from point of origin to receipt at the analytical laboratory.

\subsection{SCOPE}

This guidance applies to backlog waste environmental samples collected in accordance with contracting documents. This guidance is applicable from time of sample acquisition until custody of the sample is transferred to a laboratory.

\subsection{DEFINITIONS}

Chain of Custody. Chain-of-custody documentation is required as evidence of sample integrity for transfer of samples from time of sample acquisition to receipt by the laboratory.

Custody. The physical responsibility for sample integrity, handling, and/or transportation custody responsibilities are effectively met if samples are in the individual's physical possession or direct observation after possession is taken, secured by the individual so that no tampering can occur, or secured or locked by the individual in an area in which access is restricted to authorized personnel only.

Custody Seals and Evidence Tape. Security tape or other similar material affixed such that any tampering with samples during transfer will be apparent.

Witness. A sampling team member who participates in the actual sampling, or who is an observer to the sampling, and is responsible for initial custody of samples.

\subsection{RESPONSIBILITIES}

The field team leader/cognizant engineer, witness, transporter, laboratory sample custodian, and HASM will all be involved in the chain-of-custody 
1 process. Descriptions of these positions and their responsibilities are

2 provided in the following sections.

3

4

\subsection{FIELD TEAM LEADER/COGNIZANT ENGINEER}

The field team leader/cognizant engineer is responsible for chain-of-custody documentation to ensure sample transfer documentation is complete.

\subsection{WITNESS}

The witness is responsible for maintaining custody of samples from sample collection until proper transfer of custody.

\subsection{TRANSPORTER}

The transporter is responsible for transporting samples and corresponding chain-of-custody documentation to the next custodian. If the transporter is a private carrier, bonding will be required.

\subsection{LABORATORY SAMPLE CUSTODIAN}

The laboratory sample custodian is responsible for accepting custody of samples, and inspecting transferred samples to ensure that seals are intact and labels are affixed and sample condition is acceptable.

\subsection{HANFORD ANALYTICAL SERVICES MANAGEMENT}

The HASM is responsible for ensuring that a copy of the completed chain-ofcustody documentation is received with the laboratory sample data package and for transmitting the laboratory sample data package, including original chainof-custody documentation, to the environmental data management organization.

\subsection{GENERAL REQUIREMENTS}

Chain of custody must be documented on the established chain-of-custody form or on chain-of-custody forms that are laboratory specific. The chain of custody/sample analys is request form is shown in Figure Dl. 
DOE/RL-93-70, Rev. 1

$10 / 27 / 93$

2

3

4

5

6

7

8

9

10

11

12

13

14

15

16

17

18

19

20

21

\section{2}

23

24

25

26

27

28

29

30

31

32

33

34

35

36

\subsection{DESCRIPTION OF PROCEDURE}

Samples are to be prepared, packaged, and transported to the laboratory in accordance with developed sample packaging and shipping descriptions.

\subsection{CUSTODY INITIATION}

The witness will take custody of samples in accordance with the definition of "custody" (Section 3.0 of this guidance) as soon as samples are collected. This custody is maintained until the appropriate time of transfer of custody.

\subsection{CHAIN-OF-CUSTODY FORM INITIATION}

The field team leader or the witness as determined by the field team leader initiates the chain-of-custody form. The chain-of-custody forms will be completed in accordance with established procedures.

\subsection{TRANSFER OF CUSTODY}

To document transfer of samples, the person relinquishing custody and the next person accepting custody signs, dates, and records time of transfer on the chain-of-custody form. The original chain-of-custody form will accompany samples, and a copy will be given to the field team leader for information. A copy of the chain-of-custody form is forwarded to the HASM organization for sample tracking purposes.

\subsection{RECEIPT AT DESTINATION}

The laboratory sample custodian inspects transferred samples to ensure that seals are intact, labels are affixed and legible, a sample analysis request accompanies each sample or discrete set of samples, the physical condition of samples is acceptable, and samples being transferred are those identified on the chain-of-custody form. Any problems encountered as a result of the inspection of samples must be handled in accordance with the statement of work with the laboratory. A laboratory sample custodian must sign, date, and record time of transfer of custody of samples on the chain-of-custody form. The laboratory sample custodian retains the original chain-of-custody form until project documentation is dispositioned. Laboratory custody descriptions are implemented on completion of transfer of custody.

\subsection{SAMPLE DISPOSAL}

Sample disposal is handled by the HASM and the "Final Disposition" block on the chain-of-custody form will be completed on sample disposal. 


\subsection{RECORDS}

2

3 The HASM organization ensures that a copy of the completed chain-of-custody

4 form accompanies the sample data package received from the laboratory. The

5 HASM organization receives the completed, original chain-of-custody form(s)

6 (as part of the sample data package) from the laboratory after project

7 completion, and forwards the forms to environmental data management for

8 processing into the environmental information management system and subsequent

9 transmittal to information resource management for permanent retention.

10 Chain-of-custody form(s) documenting receipt are transmitted to information

11 resource management for permanent retention by the field file custodian in

12 accordance with descriptions established by information resources management. 


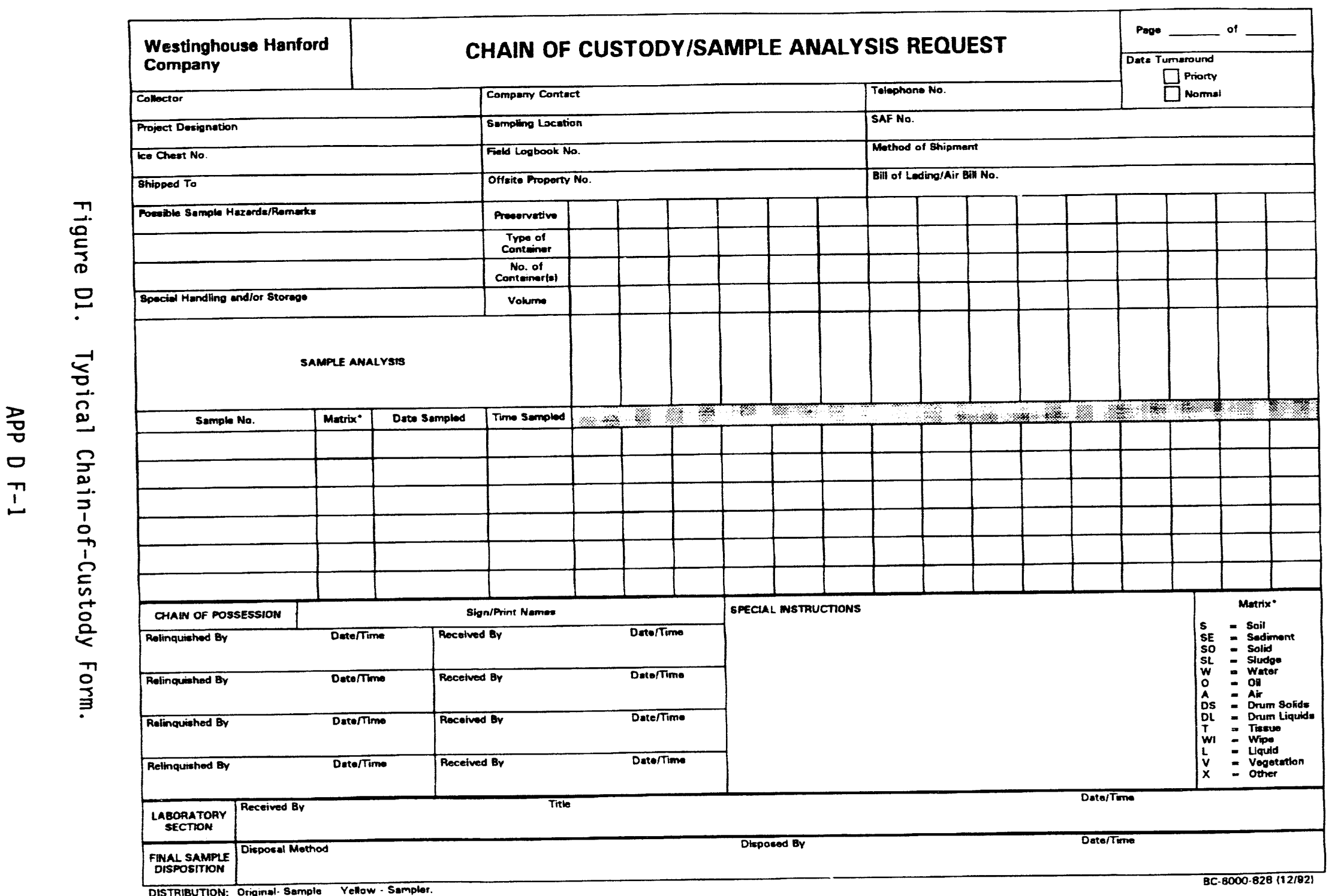




\section{DISTRIBUTION}

Number of Copies

OFFSITE

5 Washington State Department of Ecology

M. Lerchen - 01 ympia

Enforcement Officer - 01ympia

T. Tebb - Kennewick

L. Russel1 - Kennewick

R. Stanley - 0lympia

$3 \quad$ U.S. Environmental Protection Agency

D. Duncan - Seattle

G. C. Hofer - Olympia

D. R. Sherwood - Richland

ONSITE

18 U.S. Department of Energy, Richland Operations office

MISN

R. P. Carter

R3-80

C. E. Clark

D. W. Claussen (4)

A5- 15

R. E. Gerton

R3-80

R. R. Guercia

R3 -72

J. M. Hennig

P. J. Krupin (2)

R3-80

R. P. Saget

R3-80

E. J. Senat

A5- 15

A5-52

R3-72

G. C. Uetrect

R3-77

P. W. Willison

S. H. Wisness

Reading Room (2)

A4-52

A5- 15

H2-53

1 Pacific Northwest Laboratory

Hanford Technical Library

$K 1-11$

51 Westinghouse Hanford Company
M. D. Aichele
D. L. Allen
W. T. Alumkal
B. M. Barnes 


\section{DISTRIBUTION}

S6-30

J. C. Biagini

R. J. Bottenus

R. C. Bowman

G. A. Brannon

D. J. Campeau

M. W. Cline

P. L. Crane

L. K. Dickinson

R. R. Durfee

D. L. Edwards

G. Egert

B. G. Erlandson

G. W. Faulk

C. J. Geier

C. K. Girres (2)

E. M. Greager

W. H. Hamilton, Jr.

P. L. Hapke

D. A. Harrow

K. Hathaway

P. L. Hemsworth

L. J. Hogue

G. W. Jackson

J. R. Kasper

M. J. La Barge

J. L. Lee

P. J. Mackey

R. L. Martin

H. E. McGuire

D. E. McKenney

R. A. Meznarich

R. D. Pierce

S. M. Price

K. Schlick

D. R. Shreve

J. H. Tillman

G. C. Triner (2)

G. A. Whitney

L. D. Zuck

EPIC (2)

ER

Information Release Administration (3)
T3-28

H6-24

S6-30

S6-30

H6-24

T3-28

T3-04

T3-04

S3-90

T3-04

H6-20

T3-28

R2-50

T3-04

$\mathrm{H} 6-30$

N3-10

T4-05

S6-30

T3-04

T4-06

T4-06

H6-21

R2-50

$\mathrm{H} 6-30$

R2-36

B3-15

T3-03

B3-63

T3-28

S3-90

T3-04

H6-23

T3-28

T3-04

T3-04

H5-33

$\mathrm{H} 4-23$

H6-08

H6-07

H4- 17
H4-23 

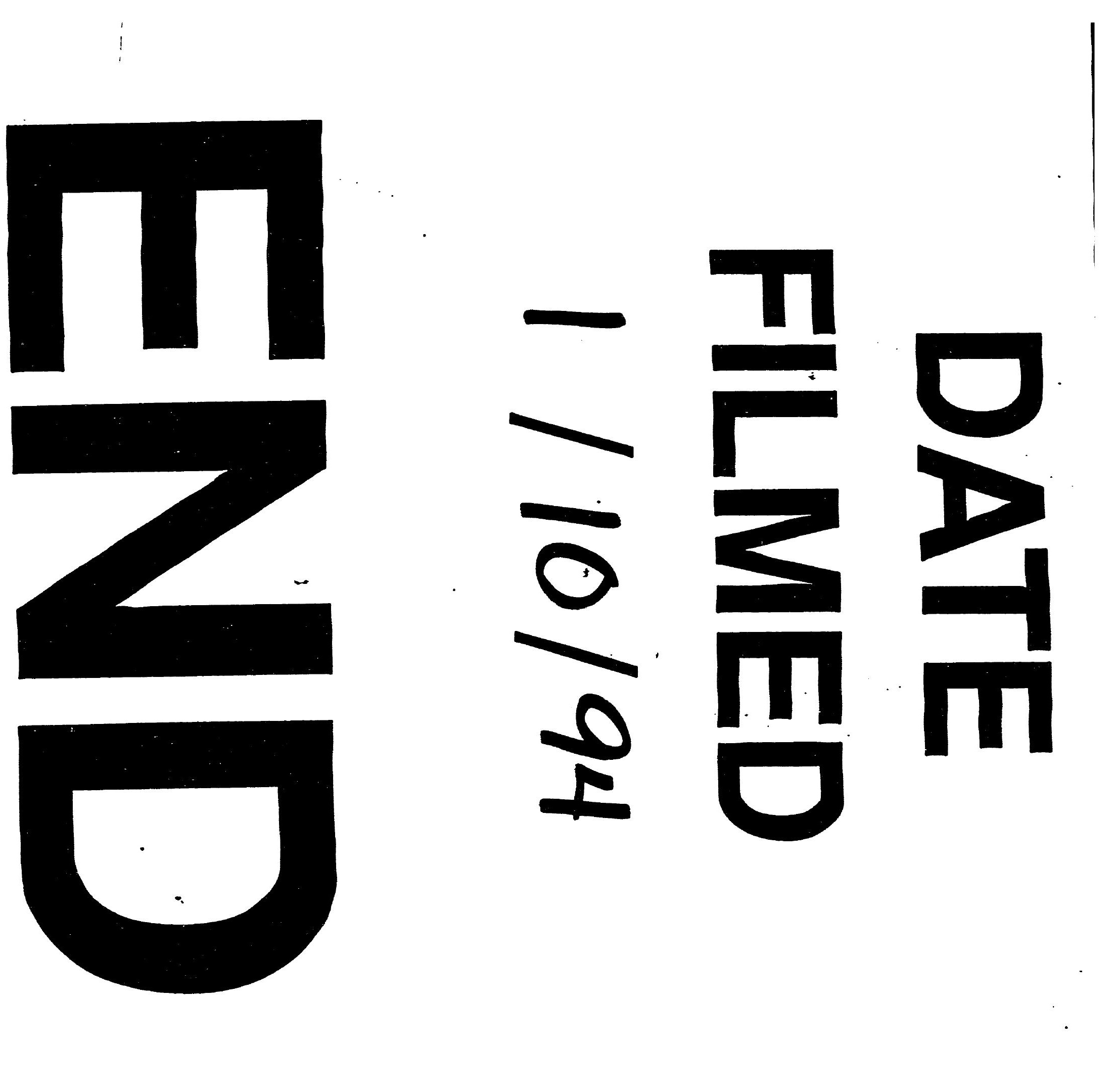
